University of Louisville

ThinkIR: The University of Louisville's Institutional Repository

Electronic Theses and Dissertations

8-2010

\title{
Simulation and fabrication of microhotplates for metal oxide gas sensors.
}

Kane Jonathan Miller 1987-

University of Louisville

Follow this and additional works at: https://ir.library.louisville.edu/etd

\section{Recommended Citation}

Miller, Kane Jonathan 1987-, "Simulation and fabrication of microhotplates for metal oxide gas sensors." (2010). Electronic Theses and Dissertations. Paper 980.

https://doi.org/10.18297/etd/980

This Master's Thesis is brought to you for free and open access by ThinkIR: The University of Louisville's Institutional Repository. It has been accepted for inclusion in Electronic Theses and Dissertations by an authorized administrator of ThinkIR: The University of Louisville's Institutional Repository. This title appears here courtesy of the author, who has retained all other copyrights. For more information, please contact thinkir@louisville.edu. 
SIMULATION AND FABRICATION OF MICROHOTPLATES FOR METAL OXIDE GAS SENSORS

\author{
By \\ Kane Jonathan Miller \\ B.S., University of Louisville, 2009
}

\begin{abstract}
A Thesis
Submitted to the Faculty of the

University of Louisville

J. B. Speed School of Engineering

in Partial Fulfillment of the Requirements

for the Professional Degree
\end{abstract}

MASTER OF ENGINEERING

Department of Chemical Engineering

August 2010 



\section{SIMULATION AND FABRICATION OF MICROHOTPLATES FOR METAL OXIDE}

GAS SENSORS

Submitted by:

Kane Jonathan Miller

A Thesis Approved On

(Date)

by the Following Reading and Examination Committee:

\begin{tabular}{c}
\hline Xiao-An Fu, Thesis Director \\
\hline James C. Watters \\
\hline Kevin M. Walsh
\end{tabular}

Kevin M. Walsh 


\section{ACKNOWLEDGEMENTS}

My thanks to Dr. Xiao-An Fu, my advisor, who gave me the opportunity to enter a new and interesting research area for the Department of Chemical Engineering at the University of Louisville.

I would also like to thank Dr. Julia Aebersold for training and assistance with infrared imaging, Mr. Tommy Roussel for assistance and support in design and analysis using computer software, along with Mr. Steve Williamson for general computer support.

I thank the University of Louisville cleanroom staff and users, especially Mr. Mark Crain, Mr. Joseph Lake, Mr. Don Yeager, Ms. Caitlin Grothaus, Ms. Vanessa Velasco, and Mr. Hiren Trada, for equipment training and support and for their time. In addition, I thank Mr. Curt McKenna, who prepared the photomasks used in this research.

Special thanks to Dr. James Watters, Dr. Kevin Walsh, and Mr. Michael Martin for suggestions and improvements. 


\begin{abstract}
Microhotplates for metal oxide gas sensors are fabricated using platinum microheaters and tested. Power consumption is monitored and temperature distributions are observed using infrared microscopy. Temperature line traces are extracted from the resulting thermal images and compared with simulations of the microhotplates in CoventorWare 2008. Methodology for creating simulations in this software is presented. Both unreleased and thermally isolated microhotplates are fabricated and simulated. It is shown that unreleased microhotplates are ineffective in heating the microhotplate membrane, while thermally isolated microhotplates require an order of magnitude less power than unreleased devices to bring to operating temperature $\left(300^{\circ} \mathrm{C}\right)$ for a gas sensor.

Further, CoventorWare is used to simulate microhotplates using nitrogen-doped silicon carbide microheaters, which require smaller volumes than platinum microheaters due to having higher electrical resistivity than platinum. The effects of microheater resistance and microhotplate geometry are discussed, and "coplanar" and "stacked" configurations of microhotplates resulting in uniform temperature distributions are simulated and presented. For microhotplates using a constant sensor area of $100 \mu \mathrm{m}$ by $100 \mu \mathrm{m}$, the "stacked" configuration is found to be desirable because of the ability to thermally isolate a microhotplate with a smaller area, increasing the temperature attained.
\end{abstract}




\section{TABLE OF CONTENTS}

APPROVAL PAGE ii

ACKNOWLEDGEMENTS

ABSTRACT iv

NOMENCLATURE $\quad$ vi

LIST OF TABLES vii

LIST OF FIGURES $\quad$ ix

$\begin{array}{ll}\text { I. INTRODUCTION } & 1\end{array}$

II. FABRICATION AND TESTING OF 6 MICROHOTPLATES USING PLATINUM MICROHEATERS

III. SIMULATION OF MICROHOTPLATES USING 21 PLATINUM MICROHEATERS

IV. $\quad$ SIMULATION AND OPTIMIZATION OF 45 MICROHOTPLATES USING SILICON CARBIDE MICROHEATERS

V. CONCLUSIONS 56

VI. RECOMMENDATIONS 57

$\begin{array}{ll}\text { APPENDIX } & 58\end{array}$

$\begin{array}{ll}\text { REFERENCES } & 76\end{array}$

$\begin{array}{lr}\text { VITA } & 80\end{array}$ 


\section{NOMENCLATURE}

\begin{tabular}{|c|c|c|}
\hline A & Cross-sectional area & $\mathrm{m}^{2}$ \\
\hline $\mathrm{I}$ & Current & A \\
\hline $\mathrm{k}$ & Thermal conductivity & $\mathrm{W} / \mathrm{m} / \mathrm{K}$ \\
\hline $\mathrm{L}$ & Length & $\mathrm{m}$ \\
\hline $\mathrm{P}$ & Power & $\mathrm{W}$ \\
\hline $\mathrm{Q}$ & Volumetric heat generation & $\mathrm{W} / \mathrm{m}^{3}$ \\
\hline $\mathrm{R}$ & Resistance & $\Omega$ \\
\hline $\mathrm{T}$ & Temperature & $\mathrm{K}$ \\
\hline $\mathrm{T}_{\text {experimental }}$ & Temperature of point read from fabricated device & $\mathrm{K}$ \\
\hline $\mathrm{T}_{\text {simulation }}$ & Temperature of point obtained from simulation & $\mathrm{K}$ \\
\hline $\mathrm{t}$ & Thickness & $\mathrm{m}$ \\
\hline $\mathrm{V}$ & Voltage & $\mathrm{V}$ \\
\hline Vol & Volume & $\mathrm{m}^{3}$ \\
\hline $\mathrm{w}$ & Width & $\mathrm{m}$ \\
\hline $\mathrm{x}$ & Distance along microheater length & $\mathrm{m}$ \\
\hline$\rho$ & Electrical resistivity & $\Omega \cdot \mathrm{m}$ \\
\hline$\nabla$ & Gradient operator & $\mathrm{m}^{-1}$ \\
\hline$\% \mathrm{E}$ & Percent error & $\%$ \\
\hline
\end{tabular}




\section{LIST OF TABLES}

1.1 PUBLISHED OPERATING TEMPERATURES OF SELECTED

METAL OXIDES COMMONLY USED IN GAS SENSORS

2.1 CURRENT-VOLTAGE MEASUREMENTS AND

RESISTANCE AND POWER CALCULATIONS FOR

FABRICATED PLATINUM MICROHEATERS TESTED

3.1 SIMULATION PROCESS DEFINITION FOR A

MICROHOTPLATE WITH PLATINUM TRACES

RESISTIVITY AND THERMAL CONDUCTIVITY OF

DOPED SIC TO PLATINUM

4.2 ANALYTICAL AND SIMULATED ONE-DIMENSIONAL TEMPERATURE PROFILES OF PLATINUM AND SILICON CARBIDE RESISTORS

4.3 SIMULATION PROCESS DEFINITION FOR A COPLANARCONFIGURED MICROHOTPLATE USING SILICON CARBIDE TRACES

A.1 OBSERVED TEMPERATURE DATA FROM FABRICATED 308- $\Omega$ MICROHEATER ON $100 \mu \mathrm{m}$ UNRELEASED MICROHOTPLATE

A.2 OBSERVED TEMPERATURE DATA FROM FABRICATED 411- $\Omega$ MICROHEATER ON $200 \mu \mathrm{m}$ UNRELEASED MICROHOTPLATE

A.3 OBSERVED TEMPERATURE DATA FROM FABRICATED $100 \mu \mathrm{m}$ THERMALLY ISOLATED MICROHOTPLATE 
A.4 TEMPERATURE DATA FROM $100 \mu \mathrm{m}$ UNRELEASED 63 MICROHOTPLATE SIMULATION

A.5 TEMPERATURE DATA FROM $200 \mu \mathrm{m}$ UNRELEASED 64 MICROHOTPLATE SIMULATION

A.6 TEMPERATURE DATA FROM $100 \mu$ m THERMALLY 66 ISOLATED MICROHOTPLATE SIMULATION

A.7 TEMPERATURE DATA FROM $100 \mu$ m THERMALLY 68 ISOLATED MICROHOTPLATE SIMULATION WITH CONVECTION

A.8 TEMPERATURE DATA FROM FINELY MESHED $100 \mu \mathrm{m}$ UNRELEASED MICROHOTPLATE SIMULATION

A.9 TEMPERATURE DATA FROM FINELY MESHED $200 \mu \mathrm{m}$ UNRELEASED MICROHOTPLATE SIMULATION

A.10 TEMPERATURE DATA FROM FINELY MESHED $100 \mu \mathrm{m}$ THERMALLY ISOLATED MICROHOTPLATE SIMULATION WITH CONVECTION

A.11 CURRENT MAGNITUDE QUERIES AT SIMULATION 74 INLET AND OUTLET BOUNDARIES 


\section{LIST OF FIGURES}

1.1 Sensor response for detection of $200 \mathrm{ppm} \mathrm{CO}$ at a constant temperature of $350^{\circ} \mathrm{C}$ [3]

1.2 Layers of a Microhotplate Fabricated by Semancik

[1] et al.

2.1 Process Flow Diagram For Fabricating a Coplanarconfigured Microhotplate with Platinum Microheaters

2.2 Optical Micrograph of $200 \mu \mathrm{m}$ Microhotplate After Liftoff In NMP, 50x Magnification

2.3 Optical Micrograph of $200 \mu \mathrm{m}$ Microhotplate After 20 30-second Cycles of $\mathrm{XeF}_{2}$ Etching at 1.5 Torr, 50x Magnification

2.4 MWIR Micrograph of $200 \mu \mathrm{m}$ Unreleased

Microhotplate with Probes Attached, 4x Magnification

2.5 MWIR Thermal Micrograph of Unreleased $200 \mu \mathrm{m}$ Microhotplate with $60 \mathrm{~mA}$ of Current through One Microheater, 12x Magnification

2.6 MWIR Thermal Micrograph of Thermally Isolated $100 \mu \mathrm{m}$ Microhotplate with $5 \mathrm{~mA}$ of Current through One Microheater, 12x Magnification

2.7 Temperature Line Traces Extracted from an Unreleased $100 \mu \mathrm{m}$ Microhotplate Microheater under Constant Current Conditions from $20 \mathrm{~mA}$ to $100 \mathrm{~mA}$ 
2.8 Temperature Line Traces Extracted from an

Unreleased $200 \mu \mathrm{m}$ Microhotplate Microheater under Constant Current Conditions from $20 \mathrm{~mA}$ to $100 \mathrm{~mA}$

2.9 Temperature Line Traces Extracted from a

Thermally Isolated $100 \mu \mathrm{m}$ Microhotplate Membrane under Constant Current Conditions from $2 \mathrm{~mA}$ to $10 \mathrm{~mA}$

3.1 General Process Flow Diagram for Creating

Simulations in CoventorWare

3.2 CoventorWare Function Manager (Designer)

3.3 Material Properties Database

3.4 CoventorWare Process Editor

3.5 Partial Layout of a $100 \mu \mathrm{m}$ Isolated Microhotplate with Platinum Traces

3.6 Three-dimensional Model of a $100 \mu \mathrm{m}$ Isolated Microhotplate

3.7 Meshed Model of a $100 \mu \mathrm{m}$ Isolated Microhotplate

3.8 CoventorWare Surface Boundary Conditions

3.9 Temperature Line Traces Extracted from an Unreleased $100 \mu \mathrm{m}$ Microhotplate Simulation under Constant Current Conditions from $20 \mathrm{~mA}$ to 100 $\mathrm{mA}$

3.10 Temperature Line Traces Extracted from an Unreleased $200 \mu \mathrm{m}$ Microhotplate Simulation under Constant Current Conditions from $20 \mathrm{~mA}$ to 100 $\mathrm{mA}$

3.11 Temperature Plot of a Simulated Unreleased $200 \mu \mathrm{m}$ Microhotplate with $60 \mathrm{~mA}$ of Current through One Microheater 
3.12 Current Density Plot of a Simulated Unreleased 100

$\mu \mathrm{m}$ Microhotplate with $70 \mathrm{~mA}$ of Current through

One Microheater

3.13 Temperature Line Traces Extracted from a

Thermally Isolated $100 \mu \mathrm{m}$ Microhotplate

Simulation under Constant Current Conditions from $2 \mathrm{~mA}$ to $10 \mathrm{~mA}$

3.14 Temperature Plot of a Simulated Thermally Isolated

$100 \mu \mathrm{m}$ Microhotplate with $9 \mathrm{~mA}$ of Current

through One Microheater

3.15 Temperature Line Traces Extracted from a

Thermally Isolated $100 \mu \mathrm{m}$ Microhotplate

Simulation with Heat Loss by Convection

3.16 Temperature Plot of a Simulated Thermally Isolated $100 \mu \mathrm{m}$ Microhotplate with $9 \mathrm{~mA}$ of Current through One Microheater and Convection Effects

3.17 Temperature Line Traces Extracted from an

Unreleased $100 \mu \mathrm{m}$ Microhotplate Simulation using a Fine Mesh

3.18 Temperature Line Traces Extracted from an

Unreleased $200 \mu \mathrm{m}$ Microhotplate Simulation using

a Fine Mesh

3.19 Temperature Plot of a Finely Meshed Simulated

Unreleased $100 \mu \mathrm{m}$ Microhotplate with $70 \mathrm{~mA}$ of

Current through One Microheater

3.20 Temperature Line Traces Extracted from a Finely

Meshed Thermally Isolated $100 \mu \mathrm{m}$ Microhotplate

Simulation with Heat Loss by Convection

3.21 Temperature Plot of a Finely Meshed Simulated

Thermally Isolated $100 \mu \mathrm{m}$ Microhotplate with 9 $\mathrm{mA}$ of Current through One Microheater and Convection Effects

4.1 One-dimensional Analytical Solution of Heat Equation for Identical $2000 \mu \mathrm{m}^{3}$ Rectangular Resistors with $100 \mu \mathrm{A}$ Applied 
4.2 Simulated Temperature Profiles of Simple Platinum and Silicon Carbide $2000 \mu \mathrm{m}^{3}$ Resistors with 100 $\mu$ A Applied

4.3 Layout of a $100 \mu \mathrm{m}$ Isolated Microhotplate with 4.5$\mathrm{k} \Omega$ Silicon Carbide Microheaters

4.4 Dimensions of Coplanar-configured $100 \mu \mathrm{m}$ Isolated Microhotplate Model with Silicon Carbide Microheaters

4.5 Dimensions of Stacked-configured $100 \mu \mathrm{m}$ Isolated Microhotplate Model with Silicon Carbide Microheaters

4.6 Temperature Plot of a Simulated Coplanar Microhotplate with SiC Microheaters Using $60 \mathrm{~mW}$ of Power

4.7 Temperature Profile across Coplanar Microhotplate with SiC Microheaters Using $60 \mathrm{~mW}$ of Power

4.8 Temperature Plot of a Simulated Stacked Microhotplate with SiC Microheaters Using $60 \mathrm{~mW}$ of Power

4.9 Temperature Profile across Stacked Microhotplate with SiC Microheaters Using $60 \mathrm{~mW}$ of Power 


\section{INTRODUCTION}

Gas sensors see use in many applications and in varying environments. From detecting traces of volatile, explosive chemicals to monitoring emissions of toxic substances and air pollutants, gas sensors play a large role in the development and enforcement of standards and regulations.

Microfabricated gas sensors have become an active research interest in recent years. Along with the advantage of small physical size, these devices require low power consumption to operate and maintain [1], and can easily be incorporated into sensor arrays for detecting concentrations of multiple gases [2].

The type of microfabricated gas sensor of interest in this work is the metal oxide chemiresistor gas sensor. Gas sensors of this type commonly rely on the ability to detect a change in electrical properties of a metal oxide sensing material when exposed to a gas mixture. The adsorption or reaction of a gas on a sensing film of a particular metal oxide introduces a measurable change in the resistance of the film [3]. The change in resistance can be correlated to the concentration of the gas, allowing the film to be calibrated as a

gas sensor. A dramatic resistance change when one particular sensor, fabricated by Triantafyllopoulou and Tsamis [3], is exposed to carbon monoxide is shown in Figure 1.1. 


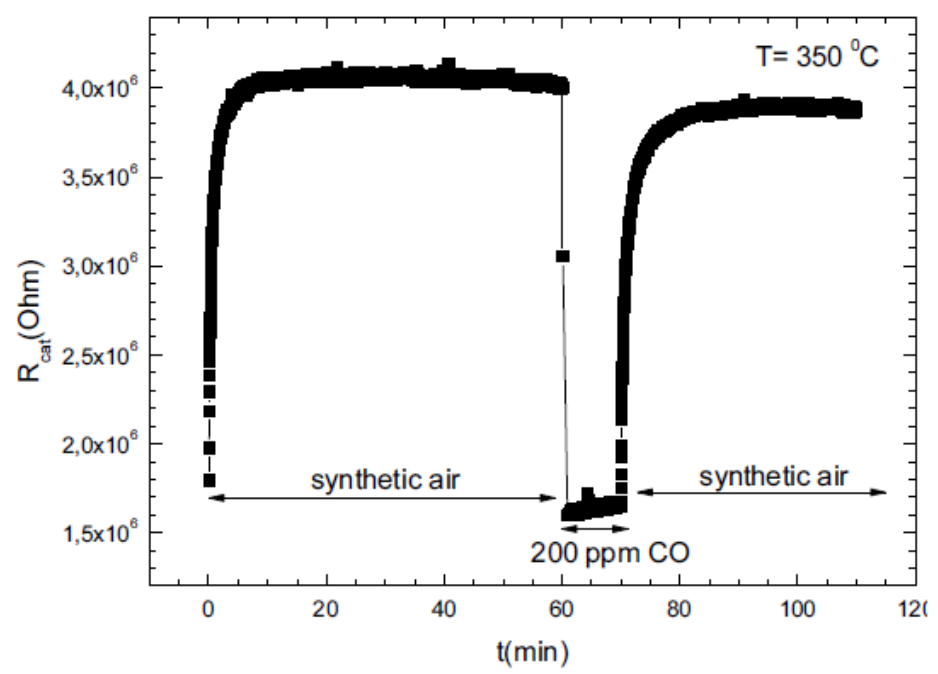

FIGURE 1.1 - Sensor response for detection of 200 ppm CO at a constant temperature of $350^{\circ} \mathrm{C}$ [3]

Several metal oxides with varying nanostructures and fabrication methods, and the resulting sensitivities to target gases, are reported in literature. Tin oxide is commonly used in the form of nanowires or nanorods [4-8], and sensitivities to various gases are reported using tin oxide alone or doped with other materials, including copper [9] and antimony [10].

Zinc oxide is another common metal oxide in use, whether alone [11-14], combined with tin oxide as a backbone-coating composite structure [15-18], or doped with silver $[19,20]$. Work is also reported using oxides of other metals, including copper oxide [2123] and tungsten oxide [24-26]. Many references and gas sensor papers have been compiled and reviewed by Fine [27] et al.

Metal oxide chemiresistor sensors are capable of detecting wide ranges of multiple gases. Carbon monoxide detection is a common goal for personal safety and pollution monitoring, and can be accomplished with tin oxide $[3,6]$, though some research has investigated the use of titanium oxide and cerium oxide [27]. Nitrogen oxides can be 
detected using tungsten oxide [25, 26] or indium oxide [27] films. Other target gases include ammonia [28] and hydrogen sulfide [9] for personal safety, hydrogen [23, 29] and ethanol [18] for fuel sensing applications, and acetone [24] in human breath as a means to monitor the onset of diabetes.

In most of these sensors, the sensing material requires heating to an operating temperature. Typical operating temperatures for tin oxide-based chemiresistors reach or exceed $300^{\circ} \mathrm{C}[3,8]$. Zinc oxide chemiresistors are maintained at $300^{\circ} \mathrm{C}$ as well [16], while tungsten oxide chemiresistors operate at temperatures up to $500^{\circ} \mathrm{C}$ [24]. See Table 1.1.

TABLE 1.1

\section{PUBLISHED OPERATING TEMPERATURES OF SELECTED METAL OXIDES COMMONLY USED IN GAS SENSORS}

\begin{tabular}{|l|l|}
\hline Common Metal Oxides & \multicolumn{1}{c|}{ Operating Temperatures } \\
\hline Tin oxide $\left(\mathrm{SnO}_{2}\right)$ & $300^{\circ} \mathrm{C}$ or above \\
\hline Zinc oxide $(\mathrm{ZnO})$ & $300^{\circ} \mathrm{C}$ \\
\hline Tungsten oxide $\left(\mathrm{WO}_{3}\right)$ & $\mathrm{Up}$ to $500^{\circ} \mathrm{C}$ \\
\hline Indium tin oxide $\left(\mathrm{ITO}^{\circ}\right)$ & $300^{\circ} \mathrm{C}$ \\
\hline Titanium oxide $\left(\mathrm{TiO}_{2}\right)$ & $250^{\circ} \mathrm{C}$ \\
\hline Cerium oxide $\left(\mathrm{CeO}_{2}\right)$ & $400^{\circ} \mathrm{C}$ \\
\hline
\end{tabular}

This operating temperature requirement exists because temperature affects the base properties of the sensing film, as well as the reaction rates of adsorption and desorption of target gases. Thus, it is desirable to control and evenly distribute the temperature throughout the sensors. Microhotplate platforms supporting the sensing films provide one method of bringing these devices to operating temperature [1].

Microhotplate platforms normally incorporate at least three layers: a suspended membrane of an electrically insulating material, a resistor that acts as a heating element, 
and a set of electrode structures that make electrical contact when the sensing film is placed over them $[1,30]$ as shown in Figure 1.2. This figure also shows a "thermometer plate,” or temperature distributor layer intended to help evenly heat the metal oxide.

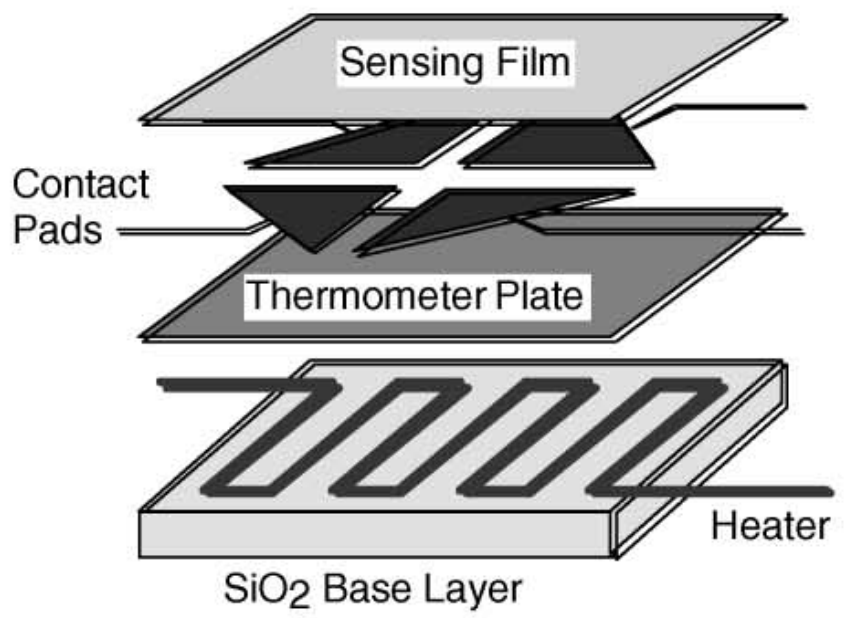

FIGURE 1.2 - Layers of a Microhotplate Fabricated by Semancik [1] et al.

Initially, microhotplates were based on doped polysilicon or metal resistors [31]. However, these devices cannot operate at temperatures much higher than the $300^{\circ} \mathrm{C}$ necessary for tin oxide gas sensors, nor can metal and silicon-based devices withstand harsh environments such as those encountered in aerospace applications [32].

Silicon carbide $(\mathrm{SiC})$ has been studied as a replacement material for both the heating elements and the suspended membrane platform [30,33] as well as in pressure sensors and infrared emitters [34]. Interest in this material is a result of a number of desirable properties, including chemical inertness, resistance to mechanical wear, and high thermal conductivity [30, 35].

The process of fabricating and testing multiple iterations of these devices is timeconsuming and expensive. Finite element analysis software packages, such as COMSOL, 
CoventorWare, and ANSYS, have been used to optimize the design of microhotplates for low power consumption and even temperature distribution prior to fabrication [36-38].

In this work, results of CoventorWare simulations of microhotplates using two sizes of platinum microheaters are compared to experimentally-determined results using microhotplates of the same design. The purpose of this is to test the accuracy and legitimacy of the simulations. Subsequently, simulations are used to design and optimize a microhotplate using silicon carbide microheaters in place of the platinum microheaters. 


\section{FABRICATION AND TESTING OF MICROHOTPLATES USING PLATINUM MICROHEATERS}

The design of simple “coplanar-configured” platinum-based microhotplates for the purpose of comparison to simulation results involves a two-photomask process and basic microfabrication techniques. Coplanar-configured microhotplates, such as the one fabricated by Wiche [30] et al., in which the microhotplate microheaters and gas sensor are deposited on the same plane, are much easier and less time-consuming to fabricate compared with “stacked” microhotplate gas sensors, as reported in reference [1].

The fabrication includes the following steps. First, material intended to form the suspended membrane is deposited or formed on the substrate. A layer of photoresist is patterned to form electrodes and microheater structures. Then, metal is deposited and a liftoff process utilized to remove unwanted material, leaving the sensing electrodes and microheaters. Finally, the membrane is patterned and the substrate is undercut to suspend and thermally isolate the microhotplate.

\section{Fabrication}

A process flow diagram delineating these steps is shown in Figure 2.1 on the following page. The detailed fabrication processes are described in the following paragraphs. 


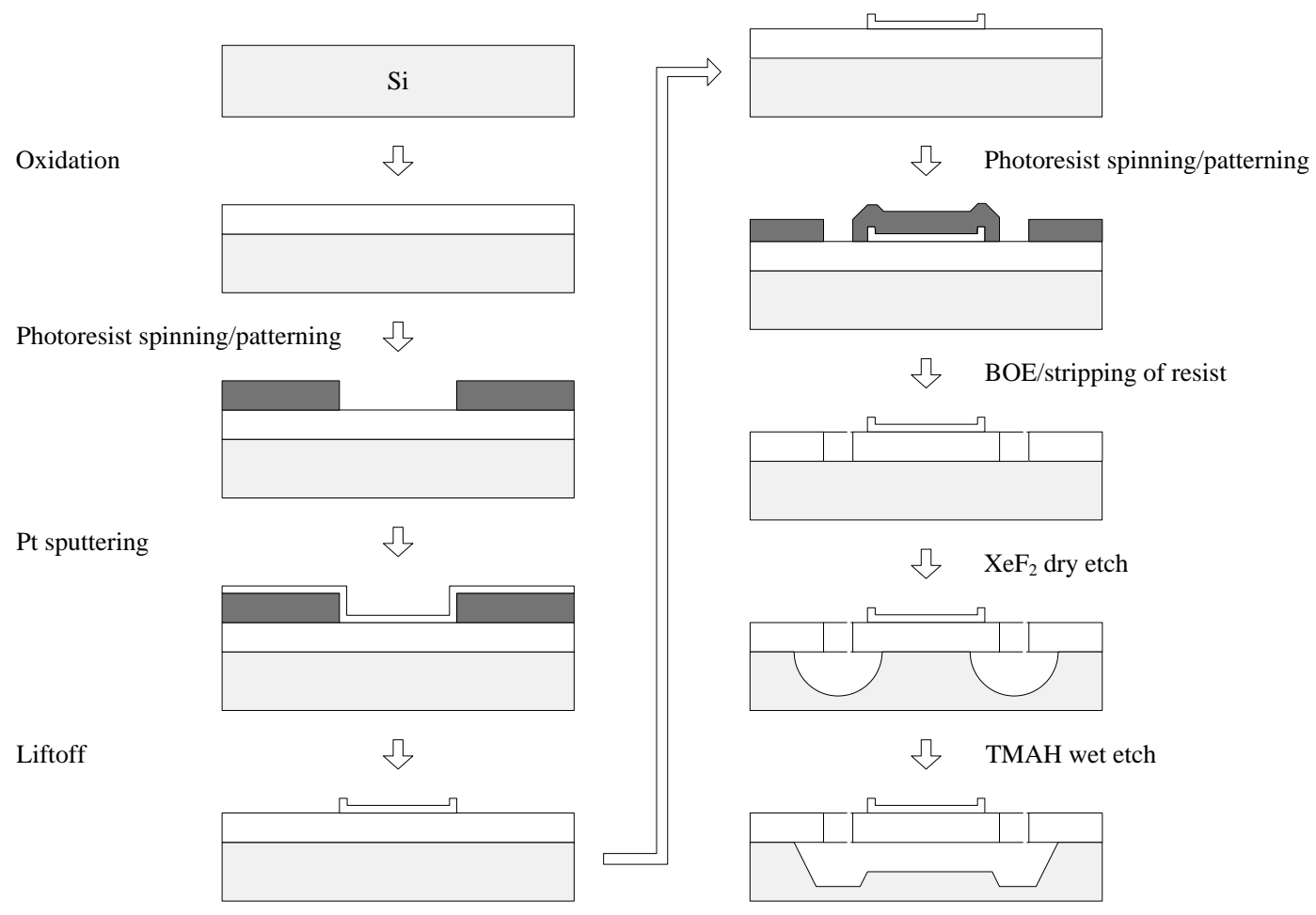

FIGURE 2.1 - Process Flow Diagram For Fabricating a Coplanar-configured Microhotplate with Platinum Microheaters

A (100)-oriented n-doped silicon wafer is used as the substrate for these devices. The microhotplate requires a layer of electrically insulating material to be deposited on the wafer surface; thermal oxide can also be used. For this research, wafers thermally oxidized at $1000^{\circ} \mathrm{C}$ to form a $500 \mathrm{~nm}$ layer of wet oxide were used, as commonly made available by cleanroom staff.

On the oxidized wafer, photoresist is spin-coated in preparation for the liftoff process. A layer of Lift-Off Resist (LOR) type 3A spun at $3000 \mathrm{rpm}$ and baked at $150^{\circ} \mathrm{C}$ for five minutes, followed by a layer of Shipley 1827 positive photoresist spun at 4000 rpm and soft baked at $115^{\circ} \mathrm{C}$ for one minute, forms a re-entrant profile desired to leave photoresist sidewalls exposed. This allows the liftoff solvent to remove unwanted metal more easily. For the intended thickness of platinum (up to $200 \mathrm{~nm}$ ), LOR 3A was chosen 
as a safer and simpler alternative to other liftoff preparation methods, including the use of the aromatic compounds toluene or chlorobenzene.

Development of the 1827 photoresist requires exposure to ultraviolet light for 14.5 seconds in a Suss photomask aligner, followed by immersion in Microposit MF-319 developing solution for 75 seconds.

Deposition of the metal layer follows the resist patterning. Sputtering is the deposition process of choice for thin films of platinum metal. A 10-nm layer of titanium is deposited first, to promote platinum adhesion to the oxide; in this process, electron beam evaporation is used to form the titanium adhesion layer, after which platinum is deposited using radio frequency (RF) sputtering. In the KJL evaporation/sputtering system utilized, sputtering at a power of $200 \mathrm{~W}$ for eight minutes resulted in a metal layer thickness of $150 \mathrm{~nm}$.

After the platinum deposition, the wafer is soaked in an $n$-methylpyrrolidone (NMP) bath to dissolve the photoresist and remove the excess metal. The liftoff process required soaking and agitation of the NMP for about two hours. Figure 2.2 below is an image of the microheater and electrode structures after liftoff, taken from a Zeiss Axioskop microscope. The microheater line width is $5 \mu \mathrm{m}$, while the width of the electrode "fingers" is $10 \mu \mathrm{m}$ in this figure. Additional devices with "finger" widths ranging from $5 \mu \mathrm{m}$ to $20 \mu \mathrm{m}$ were fabricated, though all microheaters are $5 \mu \mathrm{m}$ wide.

At this point in the fabrication process, some devices were retained, diced, and tested to determine the exact effect of not thermally isolating the microhotplate oxide membrane. The results of the testing of these "unreleased" microhotplates and a comparison to devices that continued to be processed are in the next section. 


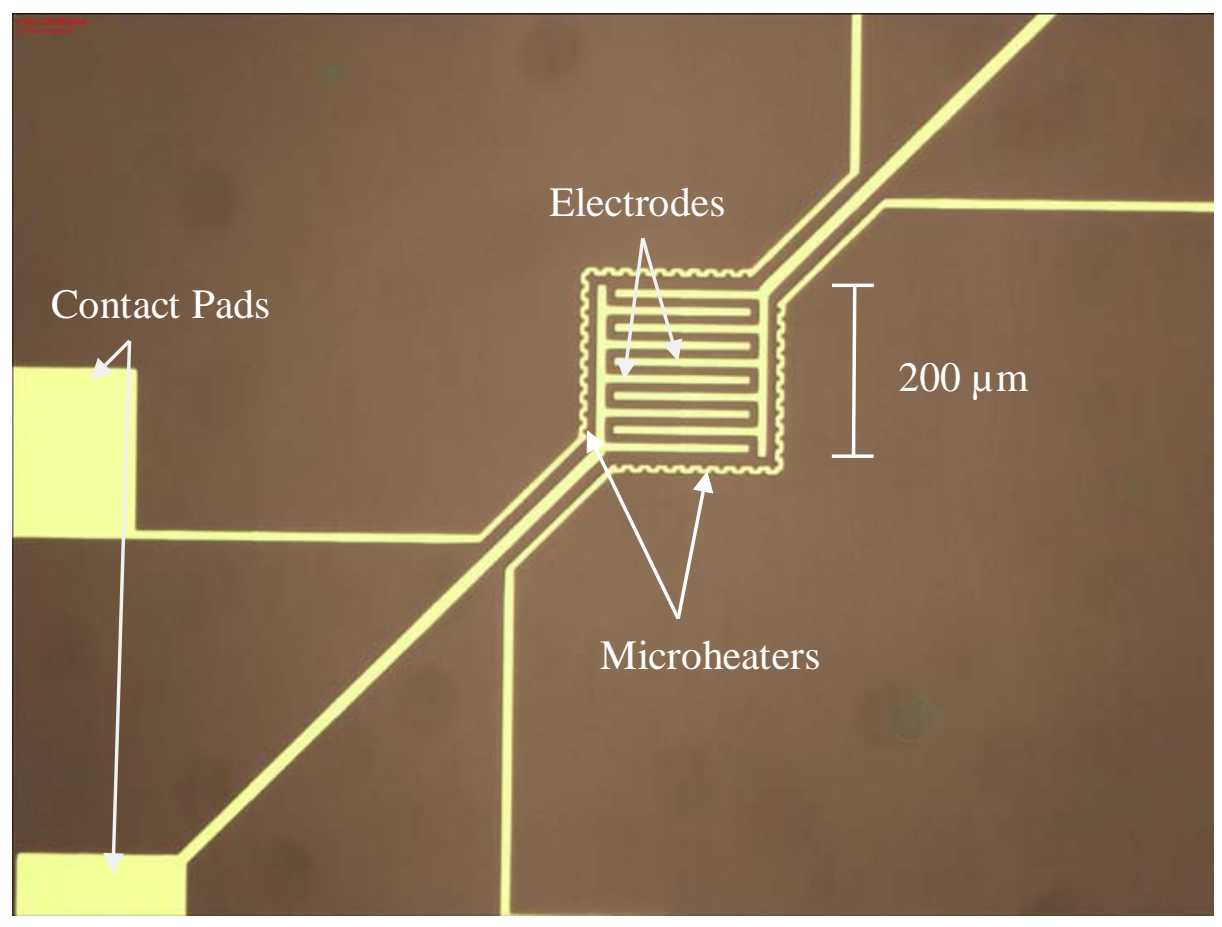

FIGURE 2.2 - Optical Micrograph of $200 \mu \mathrm{m}$ Microhotplate After Liftoff In NMP, 50x Magnification

The remainder of the fabrication process involves etching the membrane shape in the oxide and thermally isolating the microhotplate by undercutting into the silicon below the devices using a combination of wet and dry etch techniques.

Liquid-phase hexamethyldisilazane (HMDS) is first used as an adhesion agent for photoresist on the oxide. Shipley 1813 photoresist is spin-coated after the HMDS and patterned to form etch windows around the microheaters. An exposure time of 6.5 seconds in the Suss mask aligner, followed by 45 seconds of immersion in MF-319, is adequate to develop the 1813 photoresist.

After exposure, the back side of the oxidized wafer must be protected with HMDS and photoresist as well to prevent etching of the oxide on the back surface, which may otherwise result in destruction of the wafer during bulk etching of the silicon. 
The exposed oxide is etched in buffered oxide etch (BOE), a 6:1 solution of aqueous ammonium fluoride and hydrofluoric acid. Typical etch rates of oxide in this solution vary from 1000 to 1200 angstroms per minute with fluctuations in concentration and ambient temperature. A slight amount of overetching is desired to ensure that the silicon underneath is exposed. For a $500 \mathrm{~nm}$ layer of oxide, immersion in BOE for six minutes is acceptable to form etch windows in the oxide without endangering nearby features.

After etching the windows in the oxide layer, the Shipley 1813 photoresist may be stripped using acetone and methanol, as the silicon dioxide acts as the masking layer for all of the silicon etching steps.

To initiate the undercutting of the membrane, the wafer is exposed to xenon difluoride in a Xactix Xetch e1 series etching system. Gas-phase xenon difluoride is a dry, isotropic etchant for silicon with selectivity to silicon over silicon dioxide being reported to be greater than 1000:1 [39]. The isotropic etching properties of this etchant are desirable to expand the etching of the silicon beyond the $<111>$ oriented crystal planes that would otherwise restrict an anisotropic etchant.

Etching with xenon difluoride takes place in a sealed vacuum chamber. The wafer is placed in the chamber and exposed to 20 cycles of xenon difluoride at a pressure of 1.5 Torr for 30 seconds per cycle. Multiple cycles are necessary as the etchant is mostly consumed in each cycle. Figure 2.3 shows a device after 20 cycles of isotropic etching using xenon difluoride, taken from a Zeiss Axio Imager microscope.

After the isotropic etch, the wafer is submerged in a beaker of tetramethylammonium hydroxide (TMAH) at $70^{\circ} \mathrm{C}$ for two hours. TMAH is chosen over potassium hydroxide as an anisotropic etchant for higher etch rate and greater selectivity 
to silicon over silicon dioxide. A reflux condenser is attached to the beaker, and the TMAH is continuously stirred with a magnetic stir bar for the duration of the etch.

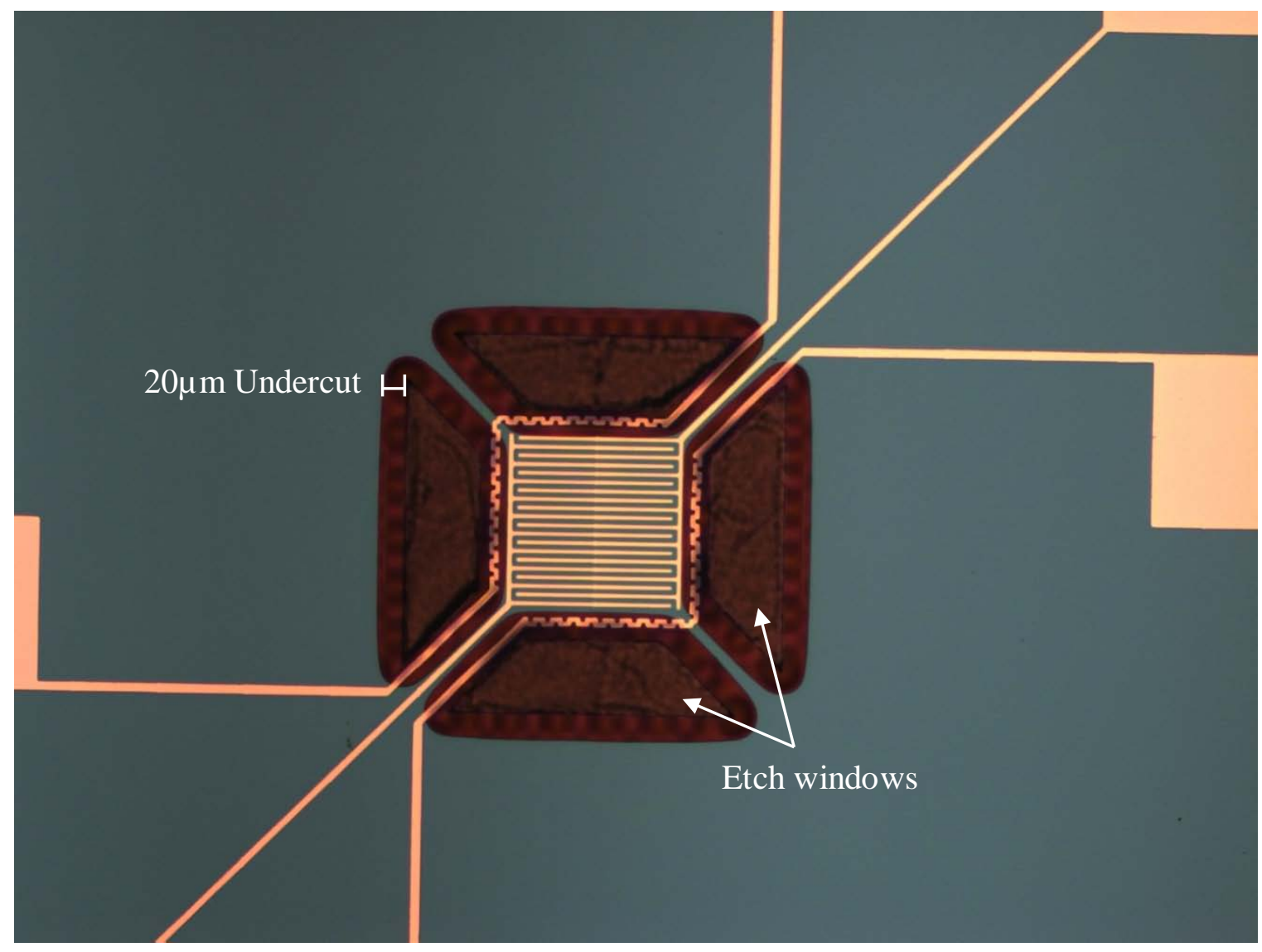

FIGURE 2.3 - Optical Micrograph of $200 \mu \mathrm{m}$ Microhotplate After 20 30-second Cycles of $\mathrm{XeF}_{2}$ Etching at 1.5 Torr, 50x Magnification

The wafer is then processed for an additional 20 cycles in xenon difluoride to complete the release of the silicon dioxide membrane from the underlying silicon.

\section{Testing Results and Discussion}

In order to test the performance of the microhotplates, a QFI InfraScope mid-wave infrared (MWIR) microscope system is employed. This system has a heated stage that can be used as a probe station and is capable of both visible and infrared microscopy with 
up to $12 x$ magnification in infrared. Figure 2.4 shows an image of a microhotplate device prior to testing one platinum microheater.

The probes are connected to a source meter, such as the Keithley Series 2400 SourceMeter used in this experiment. The source meter is able to measure the resistance of the microheaters, along with supplying a source voltage or source current, which passes through the microheater while the infrared microscope system records temperature data on the microhotplate.

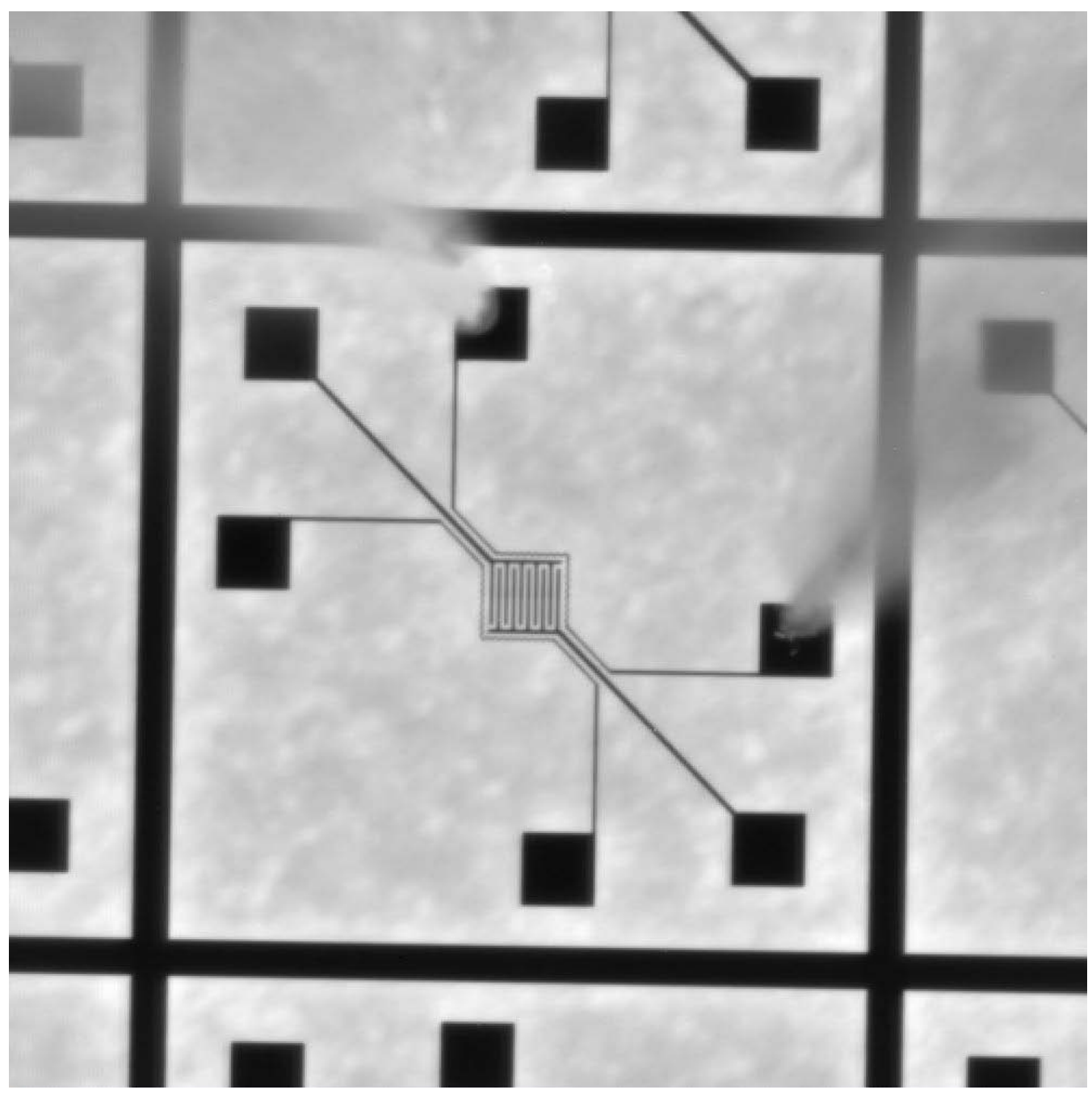

FIGURE 2.4 - MWIR Micrograph of $200 \mu \mathrm{m}$ Unreleased Microhotplate with Probes Attached, 4x Magnification 
Two sizes of microhotplates were tested. The smaller platform has an electrode area of $100 \mu \mathrm{m}$ by $100 \mu \mathrm{m}$, while the larger platform has an electrode area of $200 \mu \mathrm{m}$ by 200 $\mu \mathrm{m}$. In each case, the pairs of microheaters, all with $5 \mu \mathrm{m}$ line widths, surround the electrode area. $10 \mu \mathrm{m}$ gaps separate the electrode area and the microheaters. For microhotplates that have been thermally isolated, another $10 \mu \mathrm{m}$ gap separates the microheater from the etch window; thus, the square areas of the smaller and larger thermally isolated microhotplates, including the etch windows, are $240 \mu \mathrm{m}$ by $240 \mu \mathrm{m}$ and $440 \mu \mathrm{m}$ by $440 \mu \mathrm{m}$, respectively.

The system is kept cool by liquid nitrogen, which is poured into the MWIR camera housing. Samples are placed on an adjustable heated stage. The stage is heated to $60^{\circ} \mathrm{C}$ to improve background readings for the MWIR microscope objectives. Visible light wavelength microscope objectives are first used to position the sample, the camera, and the probes. When the sample setup is complete, the MWIR camera and objectives are put in place. The camera must first perform a background radiation reading before it can be focused. Focusing results in an image such as in Figure 2.4.

With the MWIR camera in place and focused, a reference photograph is taken to provide a basis for temperature measurement. Then, current is applied through the microheater, and the camera is used to measure the achieved temperature with respect to the reference photograph. The voltage across the microheater is also recorded in order to calculate the resistance of the microheater and the power consumption. These data for all three microheaters tested are displayed in Table 2.1: current applied (I), voltage readings (V), resistance (R) calculations, and power consumption (P). 
TABLE 2.1

CURRENT-VOLTAGE MEASUREMENTS AND RESISTANCE AND POWER CALCULATIONS FOR FABRICATED PLATINUM MICROHEATERS TESTED

\begin{tabular}{|c|c|c|c|c|}
\hline Resistor & $\begin{array}{l}\text { I (mA) } \\
\text { Meas. }\end{array}$ & $\begin{array}{l}\mathrm{V}(\mathrm{V}) \\
\text { Meas. }\end{array}$ & $\begin{array}{l}R \text { (ohm) } \\
R=V / I\end{array}$ & $\begin{array}{l}\mathbf{P}(\mathbf{m W}) \\
\mathbf{P}=\mathbf{I}^{2} \mathbf{R}\end{array}$ \\
\hline \multirow[t]{11}{*}{$100 \mu \mathrm{m}$ unreleased } & 10 & 3.04 & 304 & 30.4 \\
\hline & 20 & 6.15 & 308 & 123 \\
\hline & 30 & 9.38 & 313 & 281.4 \\
\hline & 40 & 12.8 & 320 & 512 \\
\hline & 50 & 16.4 & 328 & 820 \\
\hline & 60 & 20.3 & 338 & 1218 \\
\hline & 70 & 24.4 & 349 & 1708 \\
\hline & 80 & 29.0 & 363 & 2320 \\
\hline & 90 & 33.3 & 370 & 2997 \\
\hline & 100 & 38.8 & 388 & 3880 \\
\hline & 110 & 45.8 & 416 & 5038 \\
\hline \multirow[t]{10}{*}{$200 \mu \mathrm{m}$ unreleased } & 10 & 4.08 & 408 & 40.8 \\
\hline & 20 & 8.26 & 413 & 165.2 \\
\hline & 30 & 12.6 & 420 & 378 \\
\hline & 40 & 17.3 & 433 & 692 \\
\hline & 50 & 22.4 & 448 & 1120 \\
\hline & 60 & 27.9 & 465 & 1674 \\
\hline & 70 & 33.7 & 481 & 2359 \\
\hline & 80 & 40.0 & 500 & 3200 \\
\hline & 90 & 46.7 & 519 & 4203 \\
\hline & 100 & 56.1 & 561 & 5610 \\
\hline \multirow[t]{10}{*}{$100 \mu \mathrm{m}$ isolated } & 1 & 0.261 & 261 & 0.261 \\
\hline & 2 & 0.525 & 263 & 1.05 \\
\hline & 3 & 0.795 & 265 & 2.385 \\
\hline & 4 & 1.08 & 270 & 4.32 \\
\hline & 5 & 1.38 & 276 & 6.9 \\
\hline & 6 & 1.74 & 290 & 10.44 \\
\hline & 7 & 2.12 & 303 & 14.84 \\
\hline & 8 & 2.50 & 313 & 20 \\
\hline & 9 & 3.00 & 333 & 27 \\
\hline & 10 & 3.55 & 355 & 35.5 \\
\hline
\end{tabular}


Temperature measurements appear similar to that in Figure 2.5, in which a current of $60 \mathrm{~mA}$ is passing through a $411-\Omega$ microheater of a $200 \mu \mathrm{m}$ microhotplate. The camera software, ThermalMap, allows an image to be captured of the active microheater. A pixel-thick line trace is drawn on the image and temperature data is extracted.

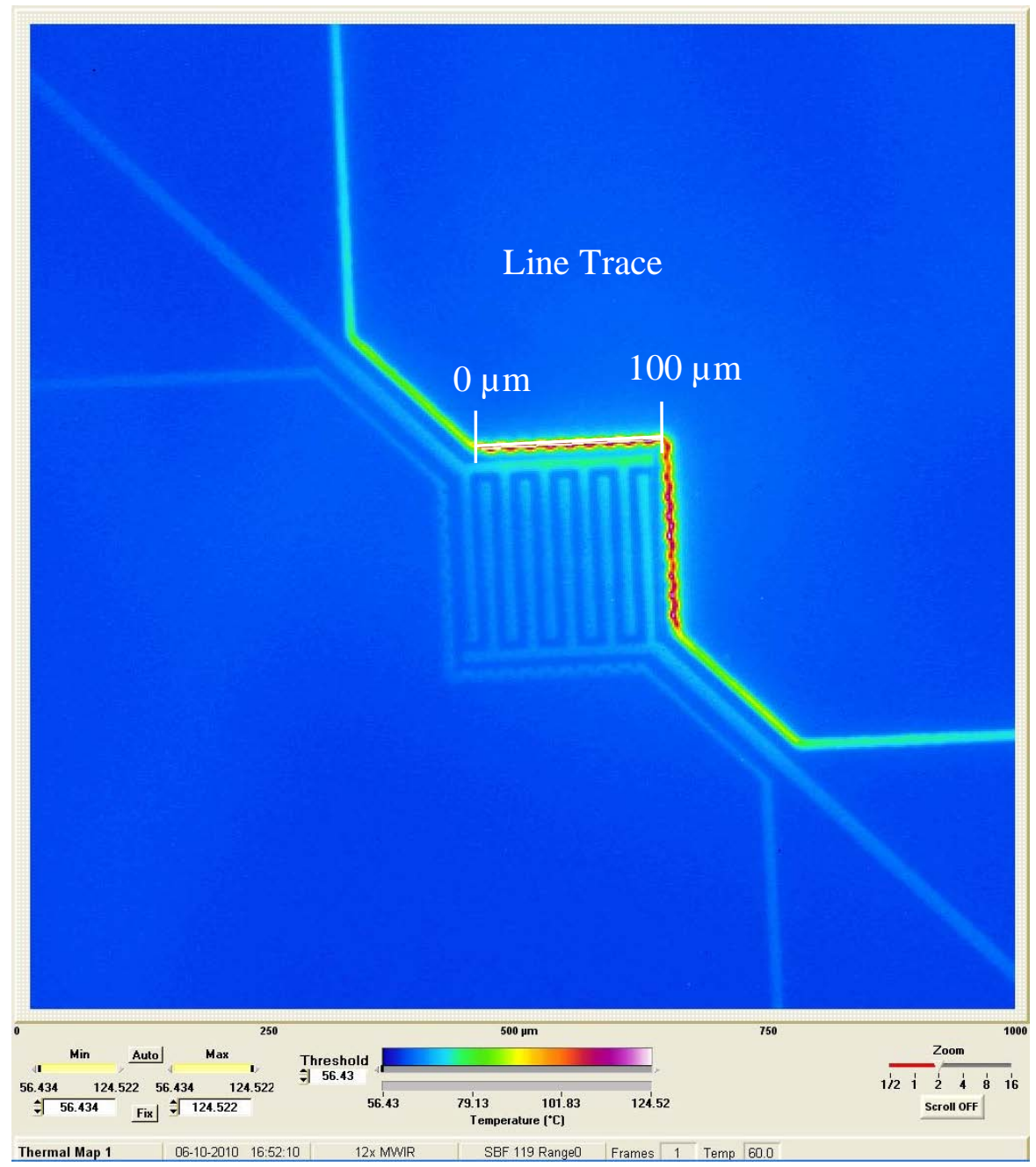

FIGURE 2.5 - MWIR Thermal Micrograph of Unreleased $200 \mu$ m Microhotplate with 60 $\mathrm{mA}$ of Current through One Microheater, 12x Magnification

For the unreleased microhotplates, temperature data is extracted from the surface of the microheaters due to lack of sufficiently measurable heating of the membrane; for 
thermally isolated microhotplates, temperature data is extracted in a line starting from the corner of the microheater and crossing the isolated membrane, as shown in Figure 2.6.

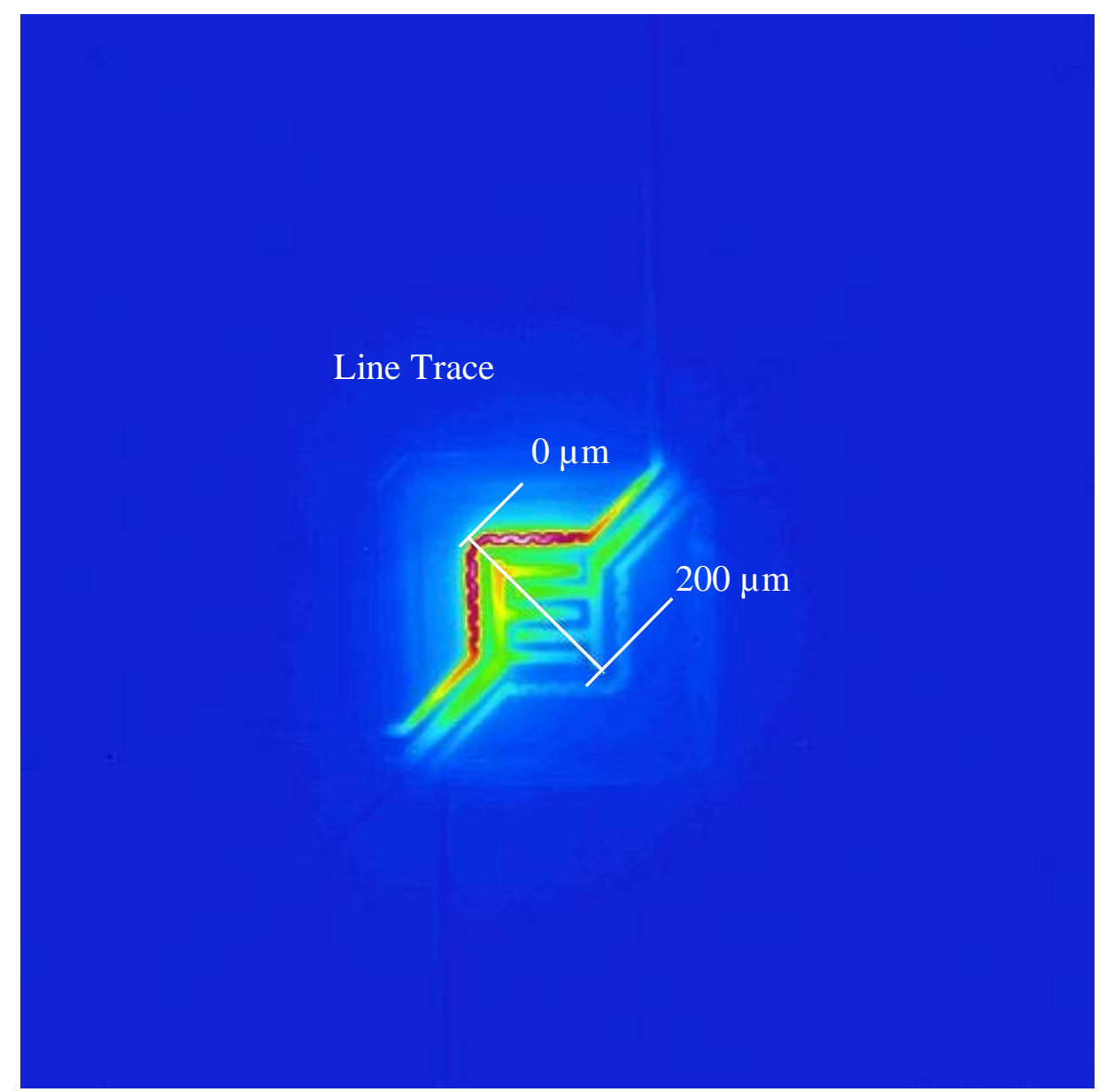

FIGURE 2.6 - MWIR Thermal Micrograph of Thermally Isolated $100 \mu \mathrm{m}$ Microhotplate with $5 \mathrm{~mA}$ of Current through One Microheater, 12x Magnification

The following figures show collections of line traces extracted from infrared images of three microhotplates when constant current is applied through one microheater. Figure 2.7 represents data collected from the surface of a microheater on a $100 \mu \mathrm{m}$ microhotplate, while Figure 2.8 shows data collected from the microheater of a $200 \mu \mathrm{m}$ microhotplate. For these two data sets, temperature line traces from the microheaters, as in Figure 2.5, were collected at constant-current intervals of $20 \mathrm{~mA}$. 


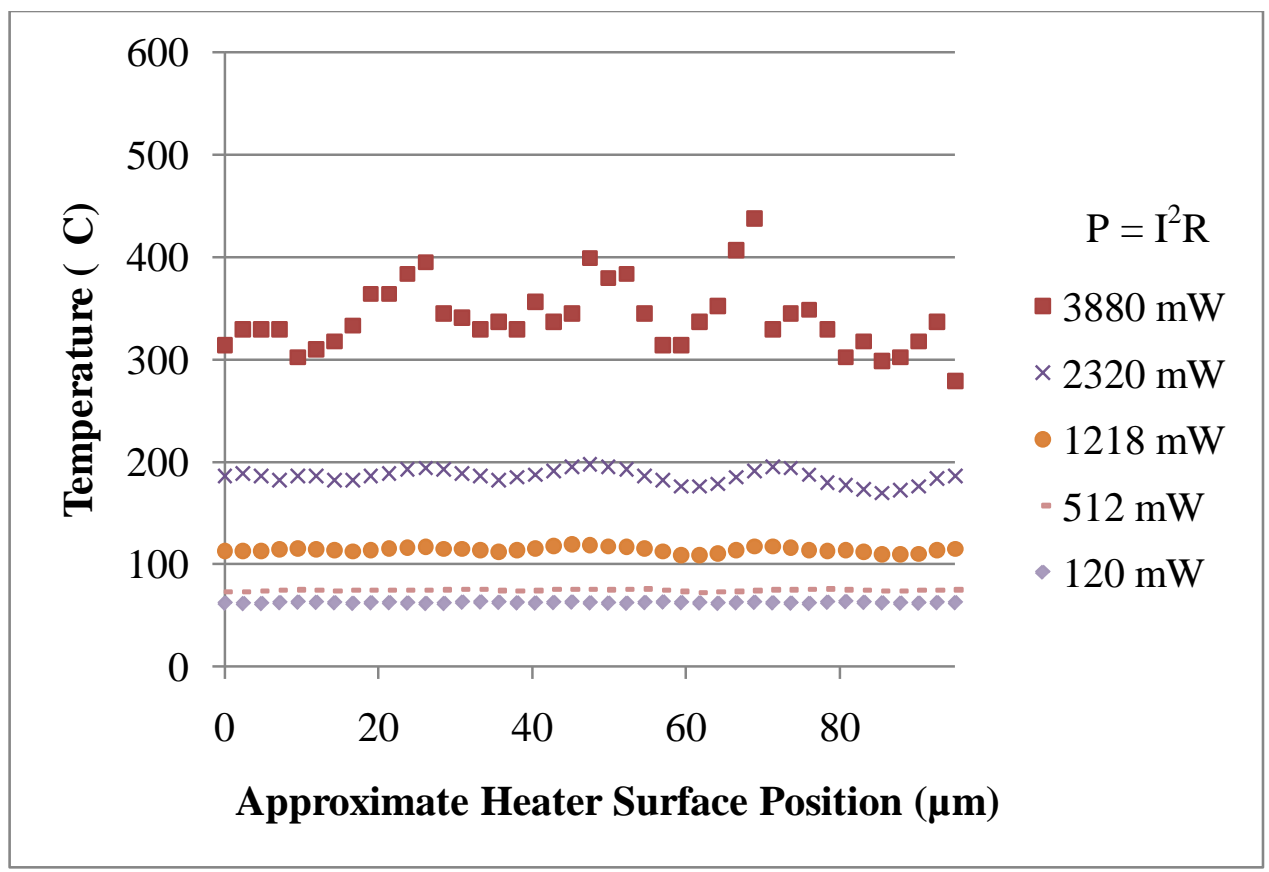

FIGURE 2.7 - Temperature Line Traces Extracted from an Unreleased $100 \mu \mathrm{m}$ Microhotplate Microheater under Constant Current Conditions from $20 \mathrm{~mA}$ to $100 \mathrm{~mA}$

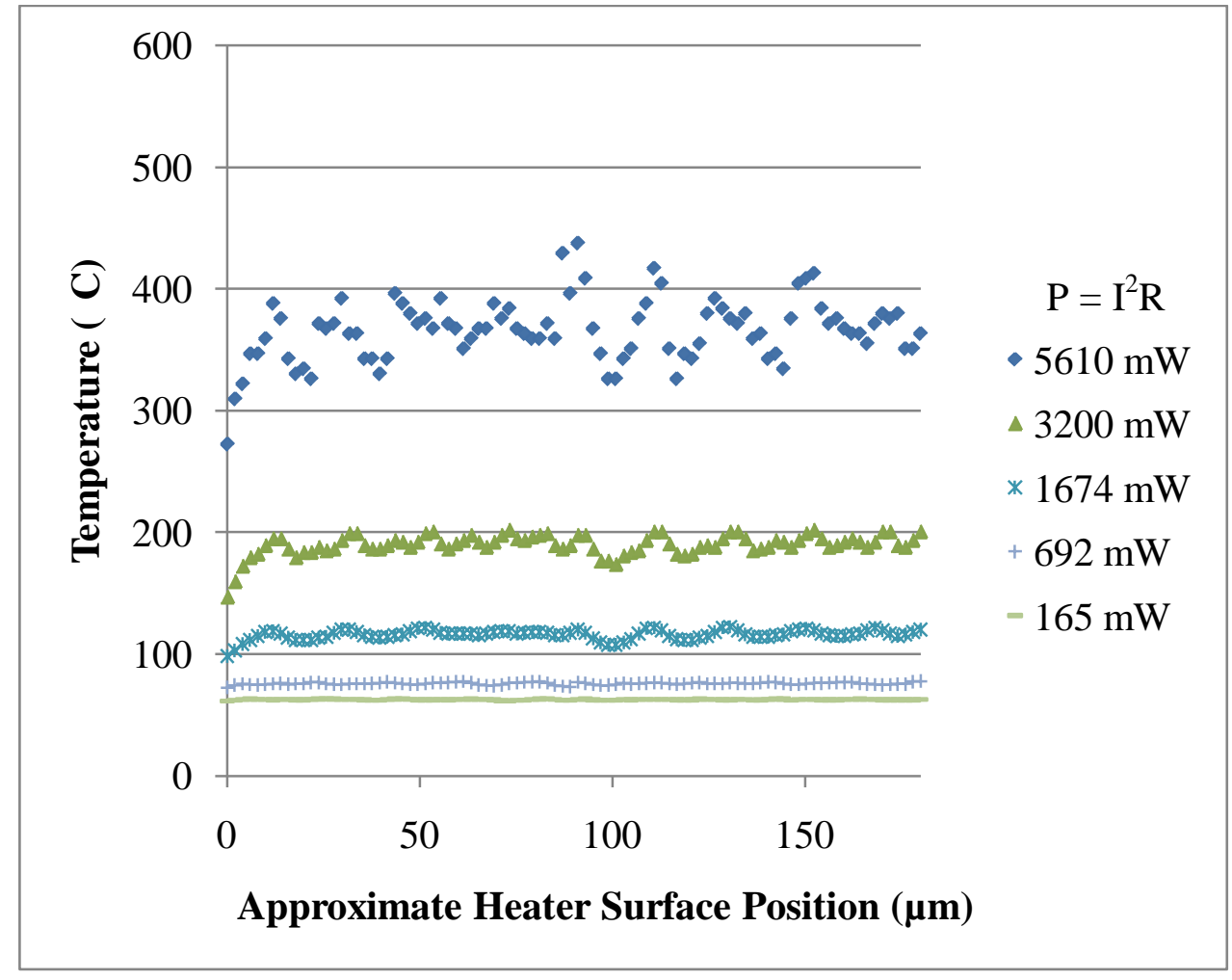

FIGURE 2.8 - Temperature Line Traces Extracted from an Unreleased $200 \mu \mathrm{m}$ Microhotplate Microheater under Constant Current Conditions from $20 \mathrm{~mA}$ to $100 \mathrm{~mA}$ 
In Figure 2.7, it can be seen that the microheater of the unreleased $100 \mu \mathrm{m}$ microhotplate requires an appreciable $1.2 \mathrm{~W}$ of power, or $60 \mathrm{~mA}$ of current, before reaching even $100^{\circ} \mathrm{C}$ when the stage temperature is set to $60^{\circ} \mathrm{C}$. As the current increased, greater variations in temperature across the microheater surface become visible due to small variations in geometry, and therefore current density, as a result of the sputtering and liftoff processes. At $100 \mathrm{~mA}$, or $3.9 \mathrm{~W}$, the microheater reaches an average temperature of $340^{\circ} \mathrm{C}$, though the heating of the surrounding oxide remained minimal due to the lack of thermal isolation from the underlying silicon.

Figure 2.8 shows a similar trend expressed by the microheater of the $200 \mu \mathrm{m}$ unreleased microhotplate, with a $60 \mathrm{~mA}$ current required to reach $100^{\circ} \mathrm{C}$ on the microheater surface. At $100 \mathrm{~mA}$ of current, or $5.6 \mathrm{~W}$, the microheater reaches a slightly higher average temperature of $360^{\circ} \mathrm{C}$. Again, however, heating of the surrounding oxide remains minimal for the unreleased microhotplates. This effect can be seen in the temperature map in Figure 2.5.

Comparing the results of these unreleased microhotplates (Figures 2.7, 2.8) to the temperature data of the thermally isolated microhotplate membrane shown in Figure 2.9, it becomes immediately apparent that the effect of the thermal isolation of the microhotplate membrane is significant. The current required to heat the microheater, as well as areas of the membrane in proximity to the microheater, is an order of magnitude less for the thermally isolated microhotplate than for the unreleased microhotplates. At only $35.5 \mathrm{~mW}$, or $10 \mathrm{~mA}$, the microheater reaches temperatures exceeding $400^{\circ} \mathrm{C}$ in localized points, and the membrane within $100 \mu \mathrm{m}$ of the microheater heats to temperatures above $250^{\circ} \mathrm{C}$. 


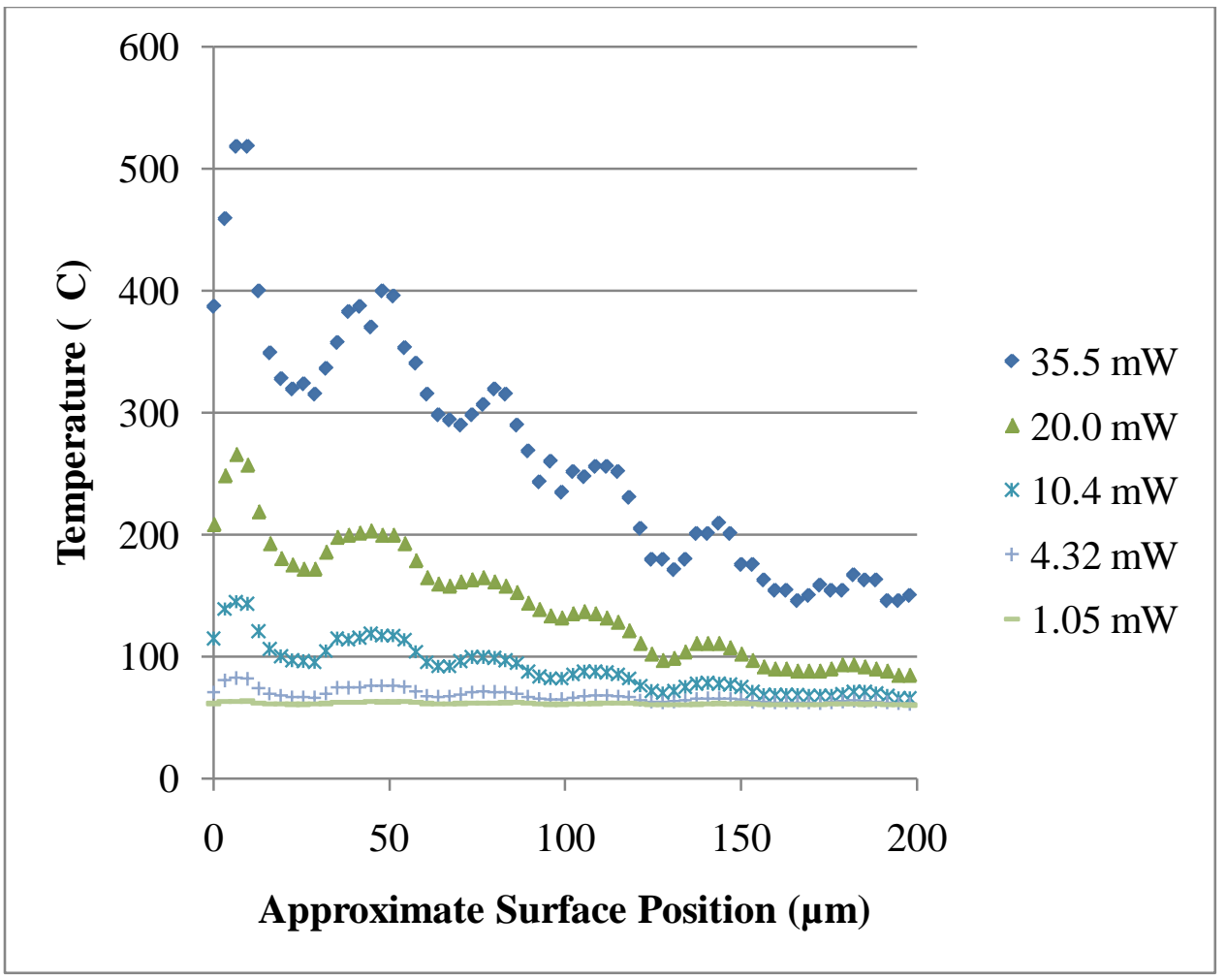

FIGURE 2.9 - Temperature Line Traces Extracted from a Thermally Isolated $100 \mu \mathrm{m}$ Microhotplate Membrane under Constant Current Conditions from $2 \mathrm{~mA}$ to $10 \mathrm{~mA}$

The intuitive explanation for this difference is simply that the thin, isolated silicon dioxide has a much lower thermal conductivity than the silicon wafer. According to Incropera and DeWitt [40], the thermal conductivity of silicon at room temperature is 148 Watts per meter per Kelvin, while that of silicon dioxide is on the order of 10 Watts per meter per Kelvin and that of air is approximately 0.03 Watts per meter per Kelvin. Both solid materials are seen to decrease slightly in thermal conductivity with increasing temperature.

In the case of the unreleased microhotplates, heat generated from the current flowing through the microheater flows by conduction through the thin oxide layer into the bulk silicon, where it is readily dispersed, resulting in little temperature increase. When the microhotplates are released, heat generated on the silicon dioxide membrane cannot 
travel immediately by conduction into the bulk silicon, but rather dissipates through the support struts of the membrane and through the highly conductive platinum electrode traces, the latter effect of which results in heating of the platinum near the microheater as seen in Figure 2.6.

\section{Summary of Test Results}

Temperature line traces were extracted from the microheater surfaces of the unreleased microhotplates, and from the microhotplate membrane of the thermally isolated microhotplate. The $100 \mu \mathrm{m}$ unreleased microhotplate microheater reached an average temperature of $340^{\circ} \mathrm{C}$ at a power consumption of $3.9 \mathrm{~W}$, while the $200 \mu \mathrm{m}$ unreleased microhotplate microheater reached an average temperature of $360^{\circ} \mathrm{C}$ at $5.6 \mathrm{~W}$. Variations in microheater resistance and temperature along the microheater profiles arose due to the geometry of the microheaters. Neither unreleased microhotplate showed significant heating of the sensor area. The thermally isolated $100 \mu \mathrm{m}$ microhotplate, however, reached over $250^{\circ} \mathrm{C}$ in the sensor area within $100 \mu \mathrm{m}$ of the microheater at a power consumption of $35.5 \mathrm{~mW}$. 


\section{SIMULATION OF MICROHOTPLATES USING PLATINUM MICROHEATERS}

CoventorWare 2008 is the finite element analysis software package used to simulate the microhotplates. This software package includes tools to design and analyze microelectromechanical systems and microfluidics systems involving coupled electrical, mechanical, and thermal physics.

Summarizing the procedure of developing a general simulation, the first step is to create a project, which will retain all files and settings associated with the simulation. Each simulation must make use of a material properties database (MPD) file, which contains information about key physical properties of all materials used in the simulation. A fabrication process is then defined using materials available in the database. Further, the user draws the device layout, builds and meshes a three-dimensional model of the device, applies boundary and initial conditions, and finally analyzes the meshed model. Based on the type of solver chosen and the applicable physics, the software presents a visualization of the results and allows the user to extract relevant data from precise points or to run queries for information from or between surfaces and volumes.

Figure 3.1 shows a process flow diagram illustrating the general method of creating a simulation. Main steps, as delineated above, are categorized in boxes, with details and 
important notes appearing to the right. The components of the software used, Designer and Analyzer, are listed on the left with applicable steps encircled.

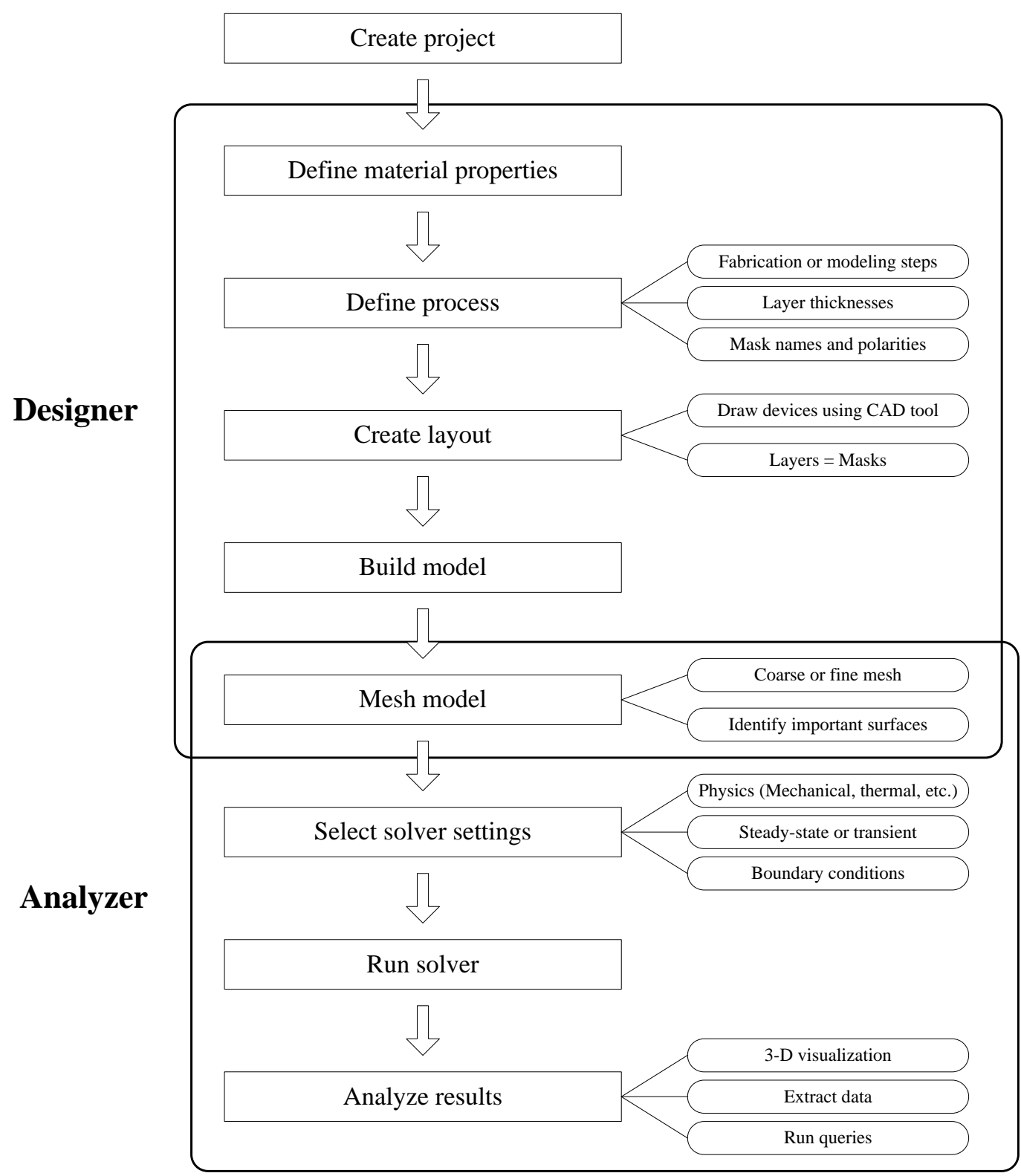

FIGURE 3.1 - General Process Flow Diagram for Creating Simulations in CoventorWare

After opening a project, the software is controlled through the use of a main window called the Function Manager, shown in Figure 3.2. The Designer tab is used first, to 
design the simulation. Following the order of options from top to bottom, the Designer is used to change the material properties applied, to define the process, to draw the layout, and to build the model.

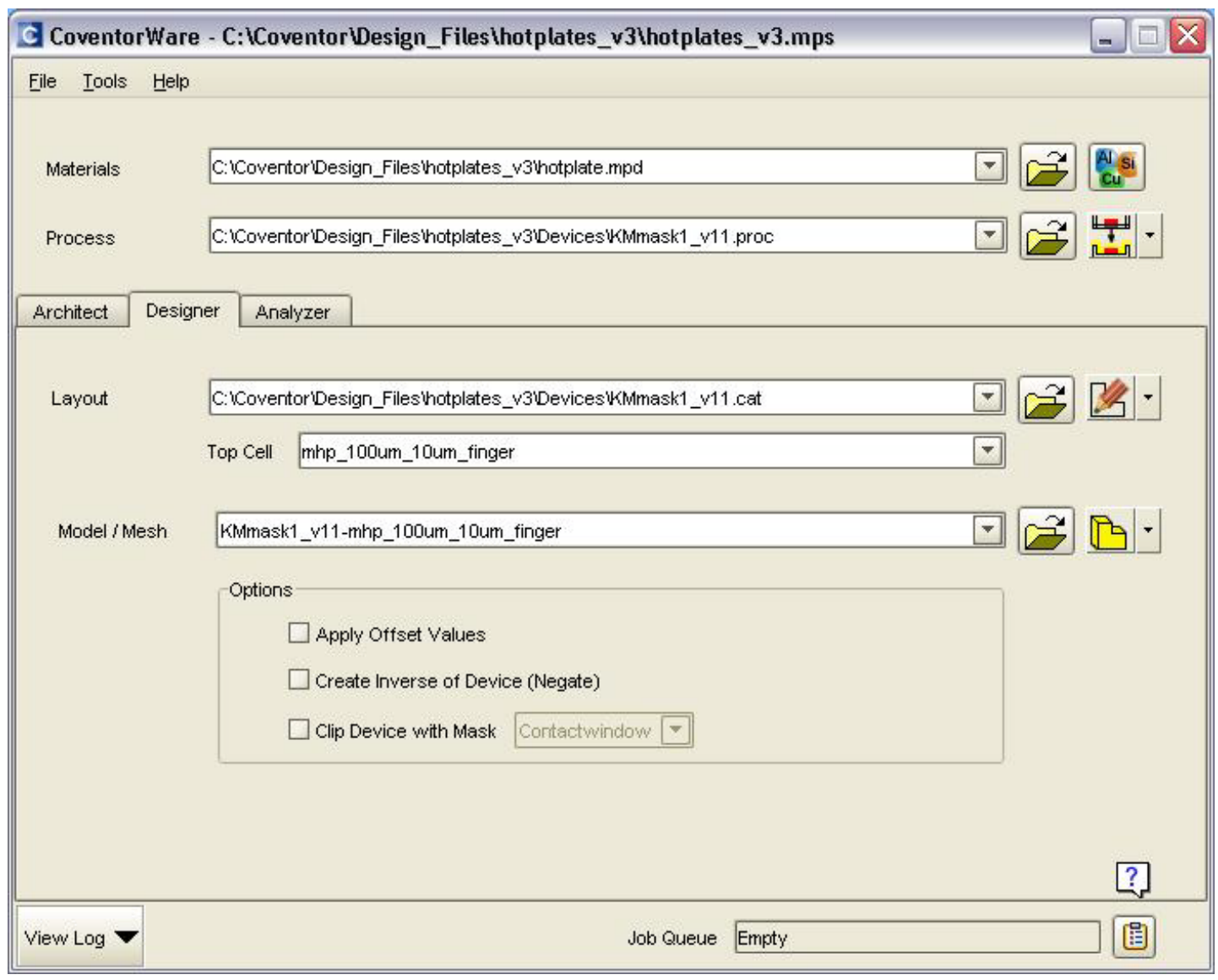

FIGURE 3.2 - CoventorWare Function Manager (Designer)

Material properties for the materials used in the simulation must be carefully monitored in order to assure the accuracy of simulation results. The properties most relevant to this study are electrical conductivity, thermal conductivity, and specific heat capacity, each of which can be specified as constant or as variable with respect to temperature, though care must be taken to provide property values with the correct units. 
Thermal property data are taken from Incropera and DeWitt [40]. The temperaturedependent electrical conductivity of platinum is calculated using current-voltage data in Table 2.1, obtained during testing of the fabricated microhotplates. This information is entered into the material properties database, which appears as in Figure 3.3.

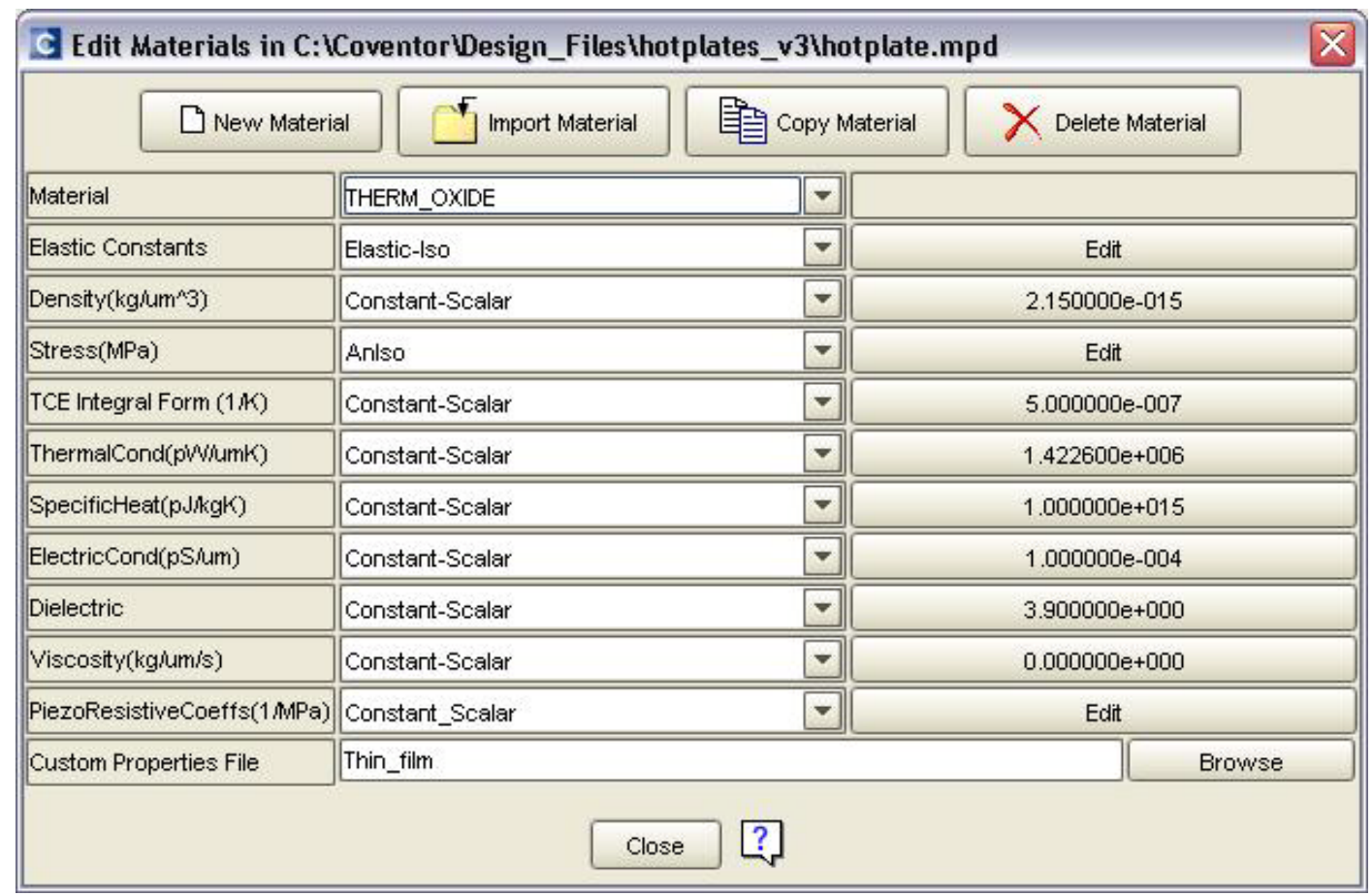

FIGURE 3.3 - Material Properties Database

Resistance calculations are used to determine the experimental resistivity of the platinum, which is converted to electrical conductivity. For a conductor, resistivity may be determined from the definition

where electrical resistivity $\rho$ is the reciprocal of electrical conductivity. The length to cross-sectional area ratio L/A is constant, and is most easily found using initial simulation results. 
The temperature-dependent resistivity required to simulate microheaters with equivalent resistance to the fabricated microheaters is calculated and applied in the simulation. The resistance, rather than the perfect geometry of the microhotplate, is simulated because, for Ohmic heating, the amount of heat generated per unit of volume is equal to the power, $\mathrm{P}$, dissipated in the resistor per unit volume, Vol, and therefore proportional to the current applied, I, and the resistance, R, of the microheater [40]:

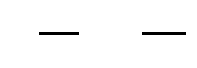

The heat generated per unit volume, Q, is considered in an energy balance. The surroundings are considered to be gas-phase, consisting of air and possibly concentrations of other gases, at near-ambient temperature and atmospheric pressure; thus, heat loss by convection is initially assumed to be negligible, and radiation heat effects are ignored. This leaves only a set of conduction heat transport equations in the form of equation 3-3

where $\mathrm{k}$ is the thermal conductivity of a material and $\mathrm{T}$ is temperature. [40]

In the definition of the microfabrication process, the user specifies the order, method, material, and thickness of each deposition and etching step in sequence. The process definition used in the simulation of the experimentally fabricated microhotplate design is in Table 3.1.

From this process definition, it can be seen that the building of the model followed a sequence with some deviation from the fabrication process. The thermal oxide is etched prior to deposition of the platinum, and the platinum is "etched" as well. These steps are organized as such for the purpose of convenience and reflect that the simulation software 
only requires a modeling process to follow, irrespective of the true applicability of the process to experimental fabrication.

TABLE 3.1

SIMULATION PROCESS DEFINITION FOR A MICROHOTPLATE WITH PLATINUM TRACES

\begin{tabular}{|l|l|l|l|l|}
\hline Step Name & Material & $\begin{array}{l}\text { Thickness } \\
(\boldsymbol{\mu m})\end{array}$ & Mask Name & $\begin{array}{l}\text { Photoresist } \\
\text { type }\end{array}$ \\
\hline Substrate & $\mathrm{Si}$ & 50 & SubstrateMask & \\
\hline Thermal Oxidation & $\mathrm{SiO}_{2}$ & 0.5 & & \\
\hline Wet Etch & & Last layer & Etchpit & - \\
\hline Sputtering & $\mathrm{Pt}$ & 0.15 & & \\
\hline "Etch” (Liftoff) & & Last layer & IDE & + \\
\hline $\begin{array}{l}\text { Anisotropic Wet } \\
\text { Etch - Frontside* }\end{array}$ & Si only & 50 & BulkEtch & - \\
\hline
\end{tabular}

*Not present in simulation of unreleased microhotplates.

The process information is entered into the Process Editor, which is shown in Figure 3.4. Different fabrication steps from those used in this study appear in the list on the right side.

The second component required to create a model is the photomask layout. The layout is either drawn directly in the CoventorWare Catapult interface, or imported from other computer-aided design software such as AutoCAD or L-EDIT. In any design software used, it is possible to draw shapes on separate layers, which must correspond to the mask names used in the process definition.

The layout used to create simulations of microhotplates using platinum microheaters was identical to the design used for the experimental photomasks, and is shown in Figure 3.5. The BulkEtch layer lies underneath the other layers and is not shown. 


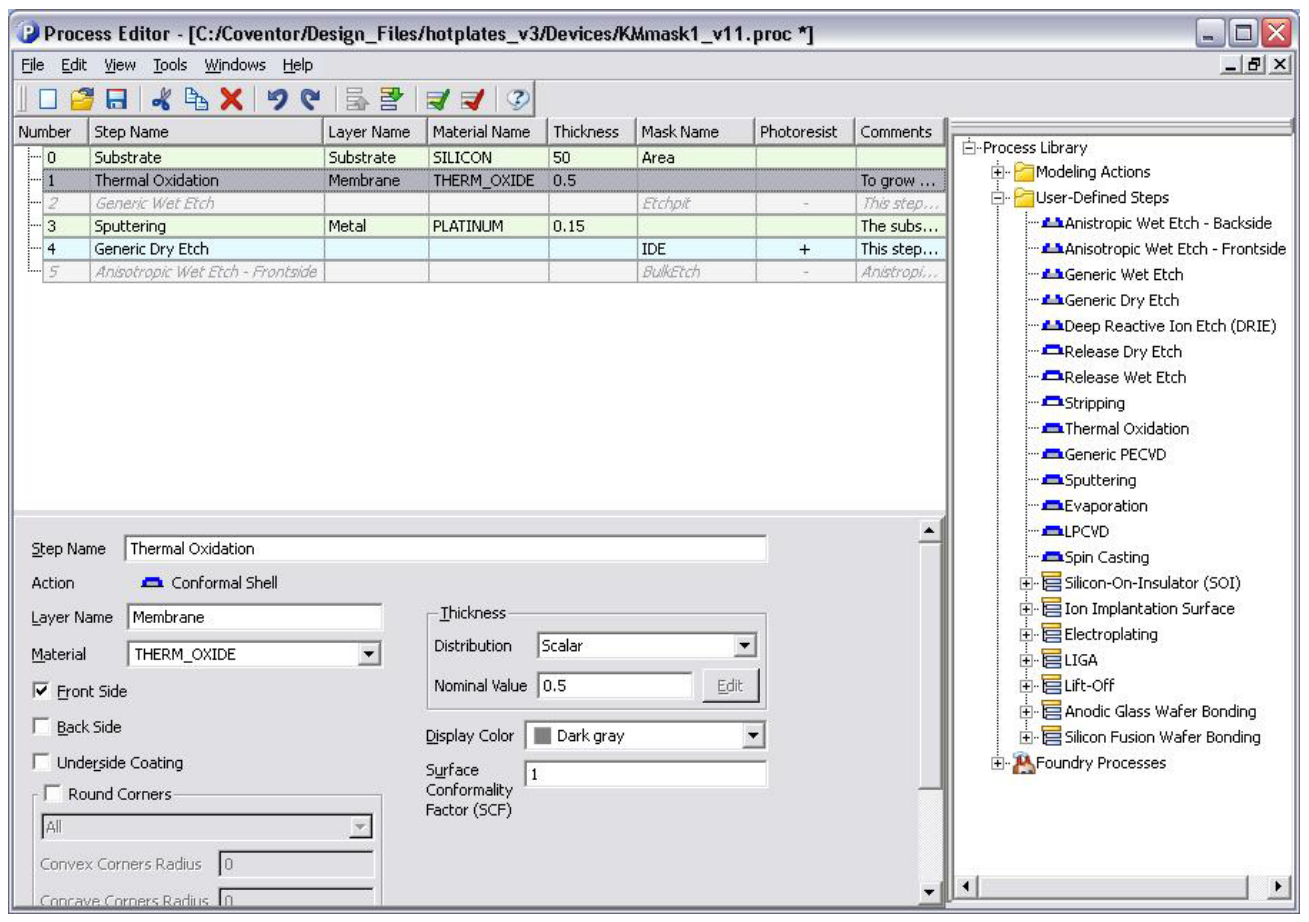

FIGURE 3.4 - CoventorWare Process Editor

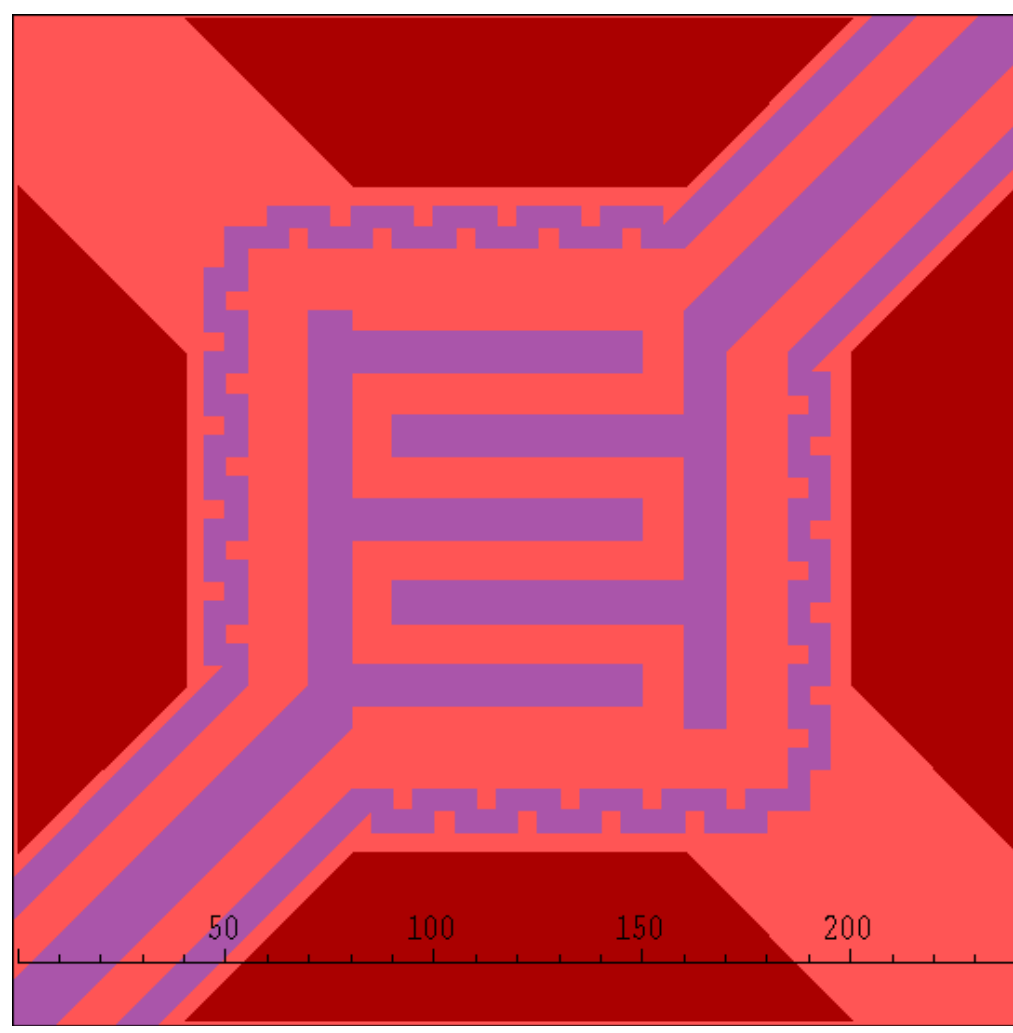

Layers/Mask Names

SubstrateMask

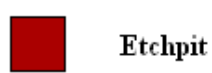

FIGURE 3.5 - Partial Layout of a $100 \mu$ m Isolated Microhotplate with Platinum Traces 
When both a process definition and a layout containing layers corresponding to mask names in the process definition are specified, the simulation software can create a three-dimensional model; using the specified process and layout results in the model shown in Figure 3.6. The model is meshed, or divided into finite elements for numerical analysis, according to the precision and calculation time desired; finer meshes require longer times for the software to evaluate governing equations, but are more precise than coarse meshes.

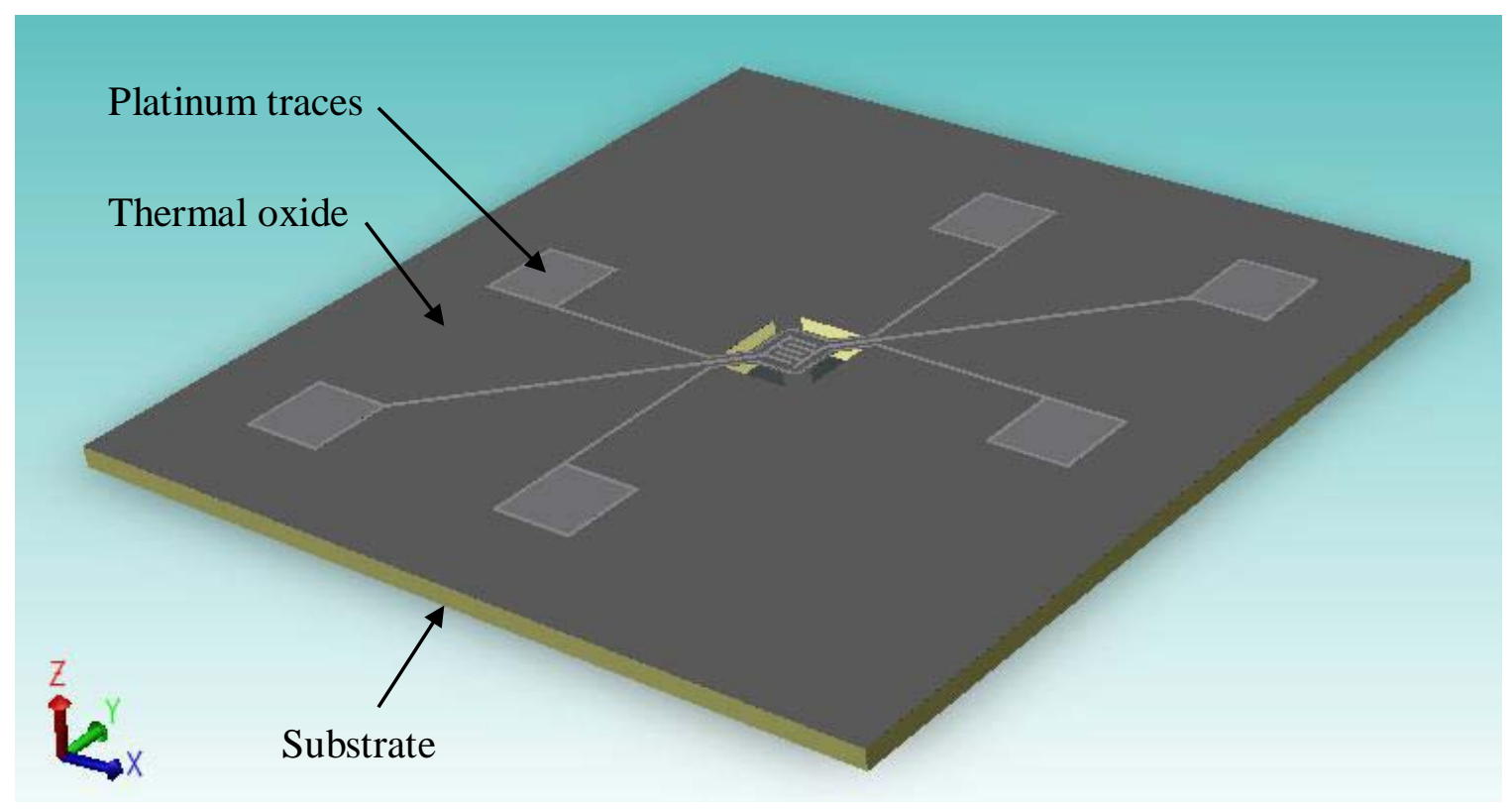

FIGURE 3.6 - Three-dimensional Model of a $100 \mu \mathrm{m}$ Isolated Microhotplate

Within the meshed model, surfaces or volumes are selected and named, which allows the selected surfaces and volumes to have boundary conditions applied at those positions. In order to be consistent with the fabricated microhotplates, the surfaces selected for boundary conditions include the contact pad areas of one microheater and the external surfaces of the silicon substrate region, as illustrated in the final mesh in Figure 3.7. 


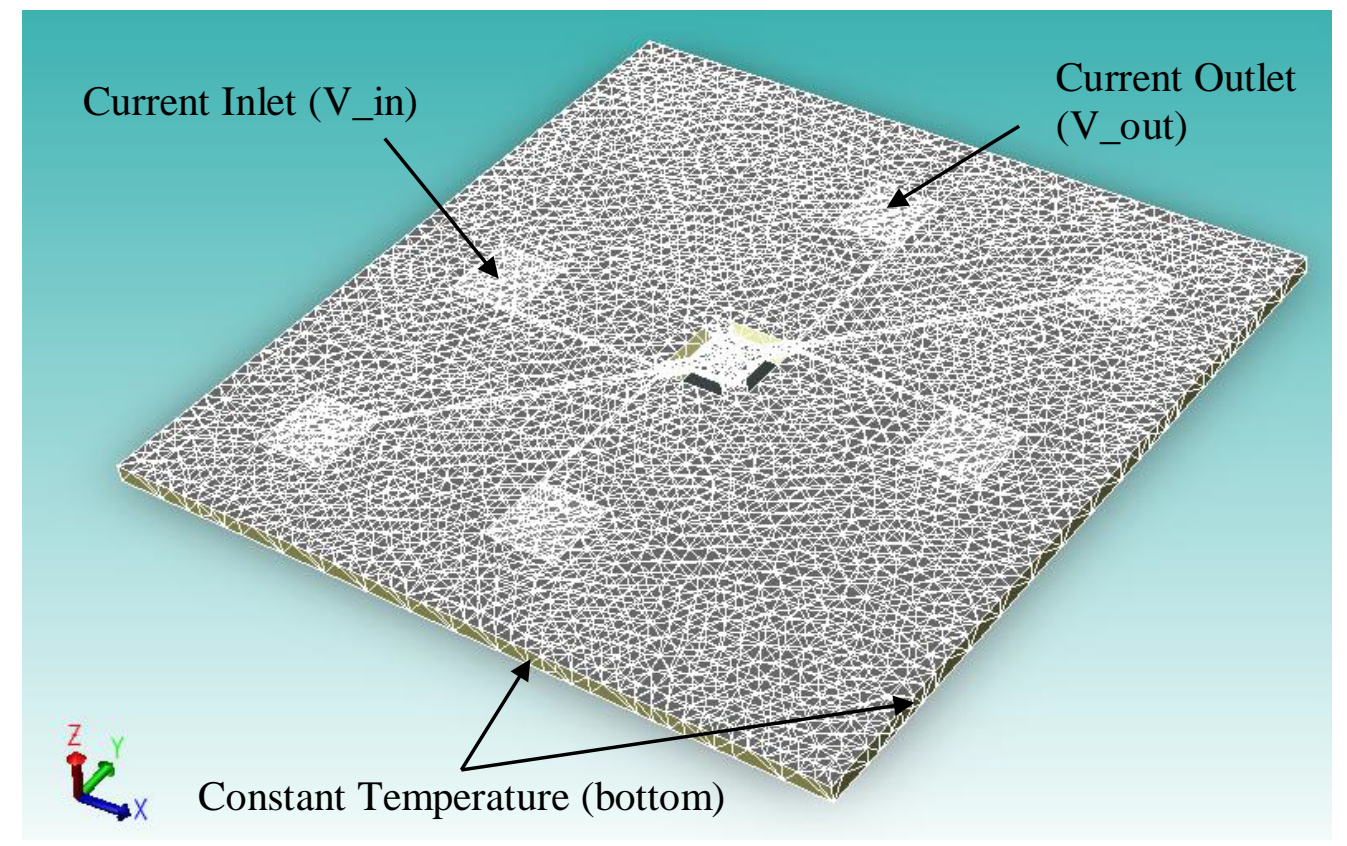

FIGURE 3.7 - Meshed Model of a $100 \mu \mathrm{m}$ Isolated Microhotplate

CoventorWare contains multiple solver packages for various types of simulations. The solver MemMech is capable of electrothermal simulations, and is the solver of choice for this application. This solver is also capable of determining stress and mechanical effects, but these effects were ignored in this study.

The contact pad areas serve as input and output regions for electrical current, which must be specified as a density relative to the cross-sectional area of the surface of entry. Each contact pad is a $180 \mu \mathrm{m}$ by $180 \mu \mathrm{m}$ square having a resulting cross-sectional area of $32,400 \mu \mathrm{m}^{2}$. Thus, to match the current used in device testing, the amount of current used (10 mA, $20 \mathrm{~mA}$, etc.) is divided by 32,400 and converted to the required units of $\mathrm{pA} / \mu \mathrm{m}^{2}$

The two contact pads must be specified separately; one acts as a current inlet, while the other acts as a current outlet. An equal magnitude of the calculated current density, 
such as $3.086 \times 10^{5} \mathrm{pA} / \mu \mathrm{m}^{2}$, which corresponds to $10 \mathrm{~mA}$, is specified at each contact pad. At the inlet, the current density value is negative, representing current entering the system; at the outlet, the current density is positive.

The silicon surfaces are held at a constant temperature of $60^{\circ} \mathrm{C}$. Though the entire silicon region is not modeled in each simulation, the heat dissipative effects of the silicon are such that the substrate is essentially at constant temperature everywhere. This is evidenced by the fact that the results of the simulation are not affected whether the entire substrate is fixed at constant temperature or only the external surfaces of the substrate are held at constant temperature.

Figure 3.8 shows the surface boundary condition window in which each of the listed boundary conditions is applied.

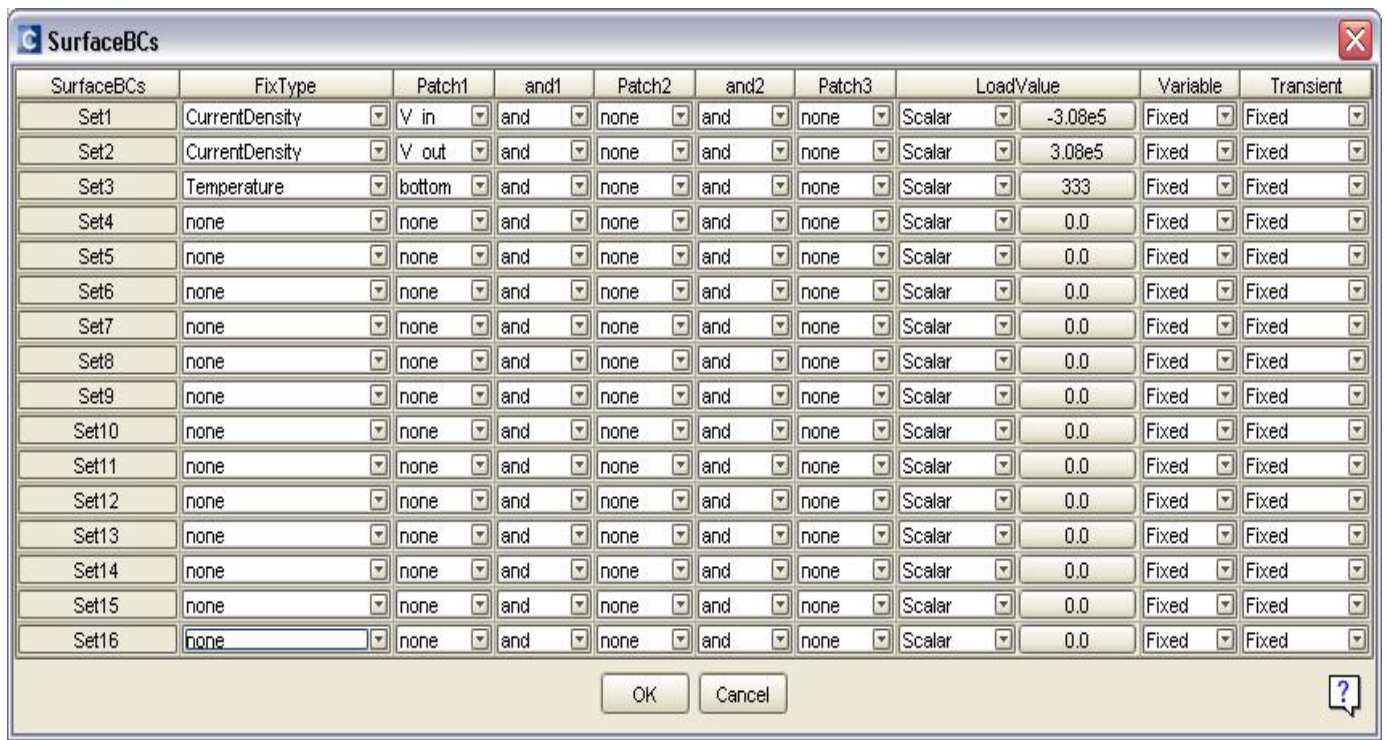

FIGURE 3.8 - CoventorWare Surface Boundary Conditions

When sufficient boundary conditions are applied, the solver calculates results using the finite elements in the mesh and presents the results for analysis. Electrical quantities 
including current density, potential, resistance, and impedance can be obtained, along with thermal data such as heat flux and temperature for a simulation of this type. The latter is of primary interest to this study, as the temperature profile for each microhotplate and set of boundary conditions is desired for comparison to experimentally tested devices.

Figures 3.9 and 3.10 show simulated temperature profile results of $100 \mu \mathrm{m}$ and 200 $\mu \mathrm{m}$ unreleased microhotplates, respectively, extracted from the surfaces of the microheaters as with the experimental testing. With a constant current of $100 \mathrm{~mA}$, the simulated microheaters of the $100 \mu \mathrm{m}$ and $200 \mu \mathrm{m}$ microhotplates reach average temperatures of $130^{\circ} \mathrm{C}$ and $210^{\circ} \mathrm{C}$, or $40 \%$ and $60 \%$ of those of the tested devices.

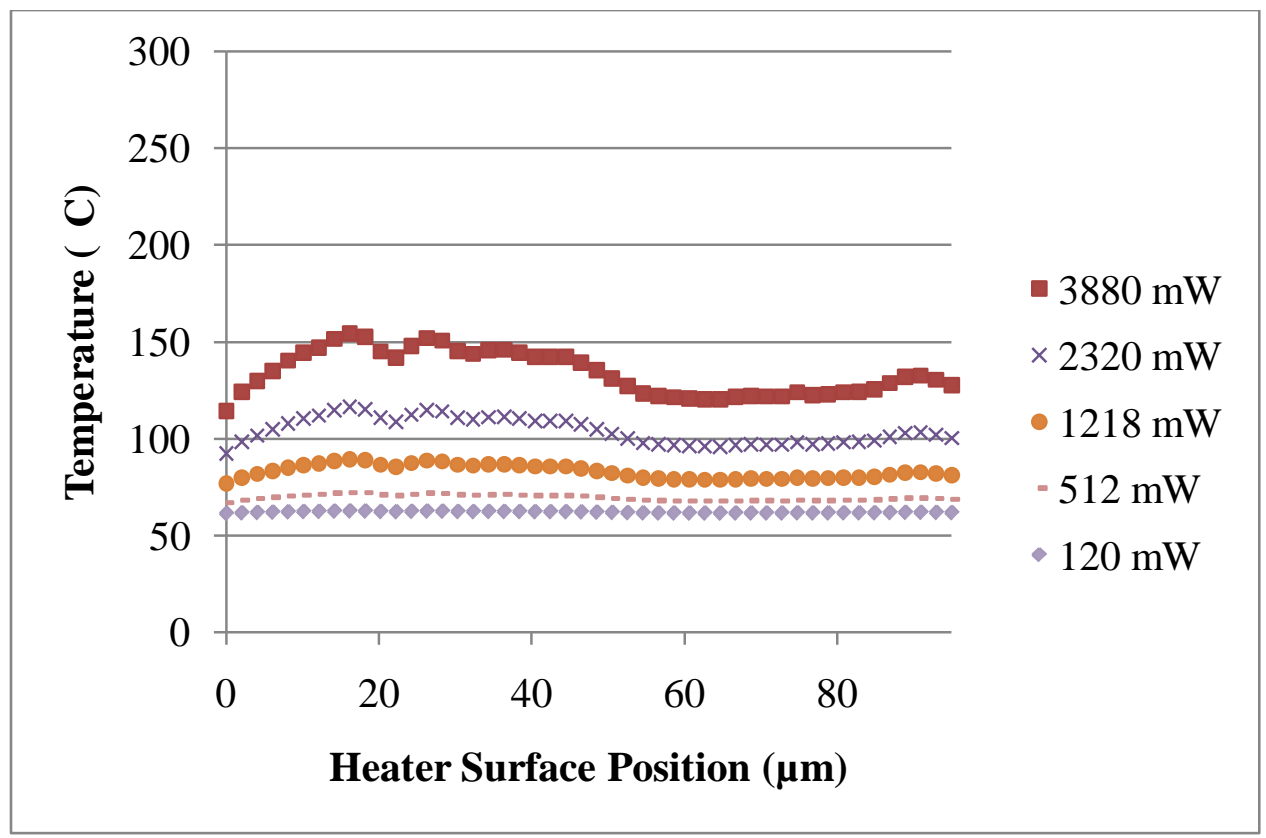

FIGURE 3.9 - Temperature Line Traces Extracted from an Unreleased $100 \mu \mathrm{m}$ Microhotplate Simulation under Constant Current Conditions from $20 \mathrm{~mA}$ to $100 \mathrm{~mA}$ 


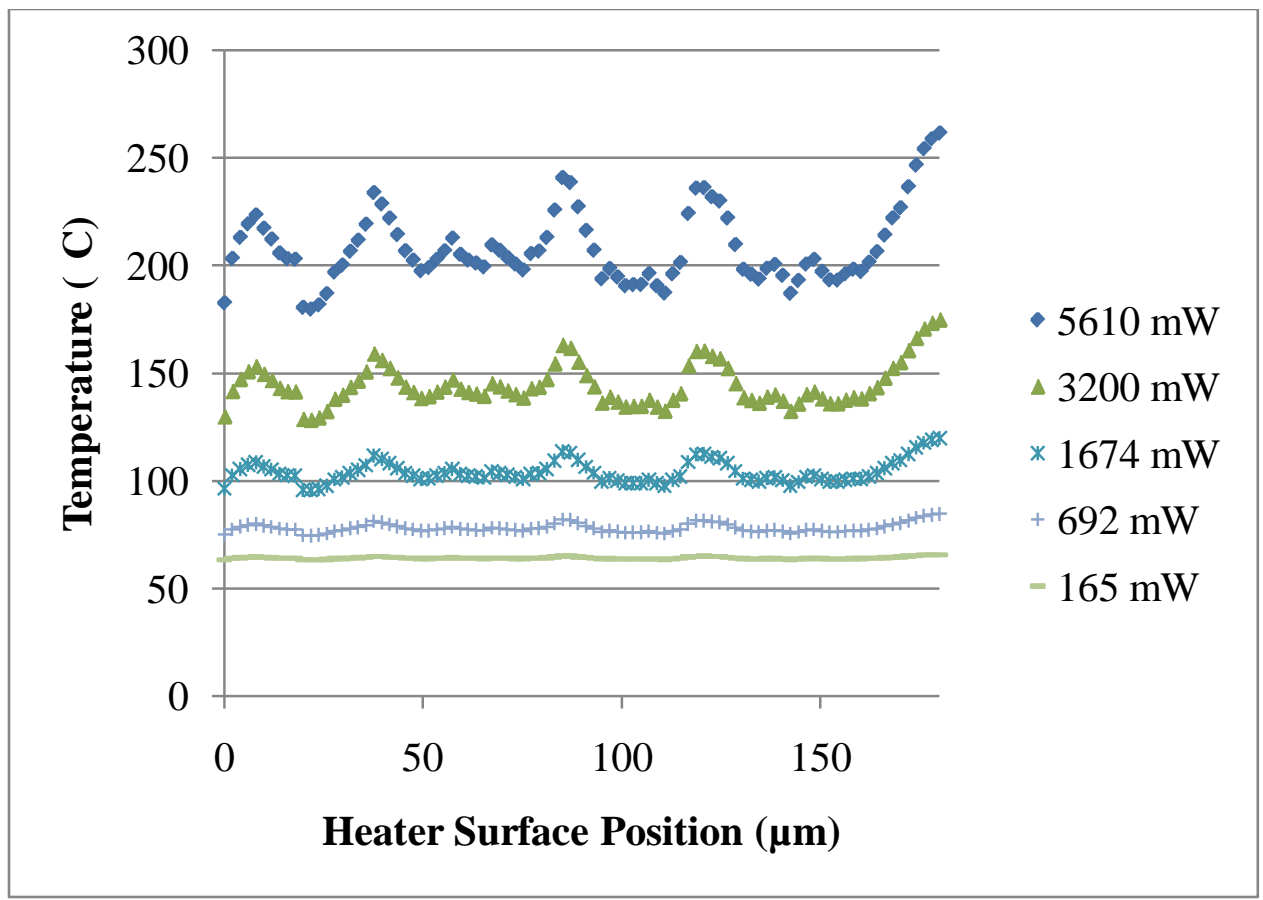

FIGURE 3.10 - Temperature Line Traces Extracted from an Unreleased $200 \mu \mathrm{m}$ Microhotplate Simulation under Constant Current Conditions from $20 \mathrm{~mA}$ to $100 \mathrm{~mA}$

Figure 3.11 shows the distribution of temperature across the microhotplate simulation. Compare the simulated temperature distribution for a $200 \mu \mathrm{m}$ unreleased microhotplate, shown in Figure 3.11, to the infrared microscope image in Figure 2.5, both at $60 \mathrm{~mA}$ of current. The simulation accurately models the poor heat distributing qualities of the unreleased microhotplates, showing a concentration of maximum temperature along the center of the microheater with minimal heating of the oxide.

The reason for the differences in temperature values is most likely that the mesh used to cover the entire device area was not fine enough to allow the software to precisely calculate the geometry of the microheaters. The result is that current appears to be lost in triangular formations around the microheaters, outlining the tetrahedral finite elements of the mesh. This current loss is supported by the software results in that the current 
entering the model at the current inlet " $\mathrm{V}$ _in" is reported as being over an order of magnitude larger than the current leaving the model at the current outlet "V_out".

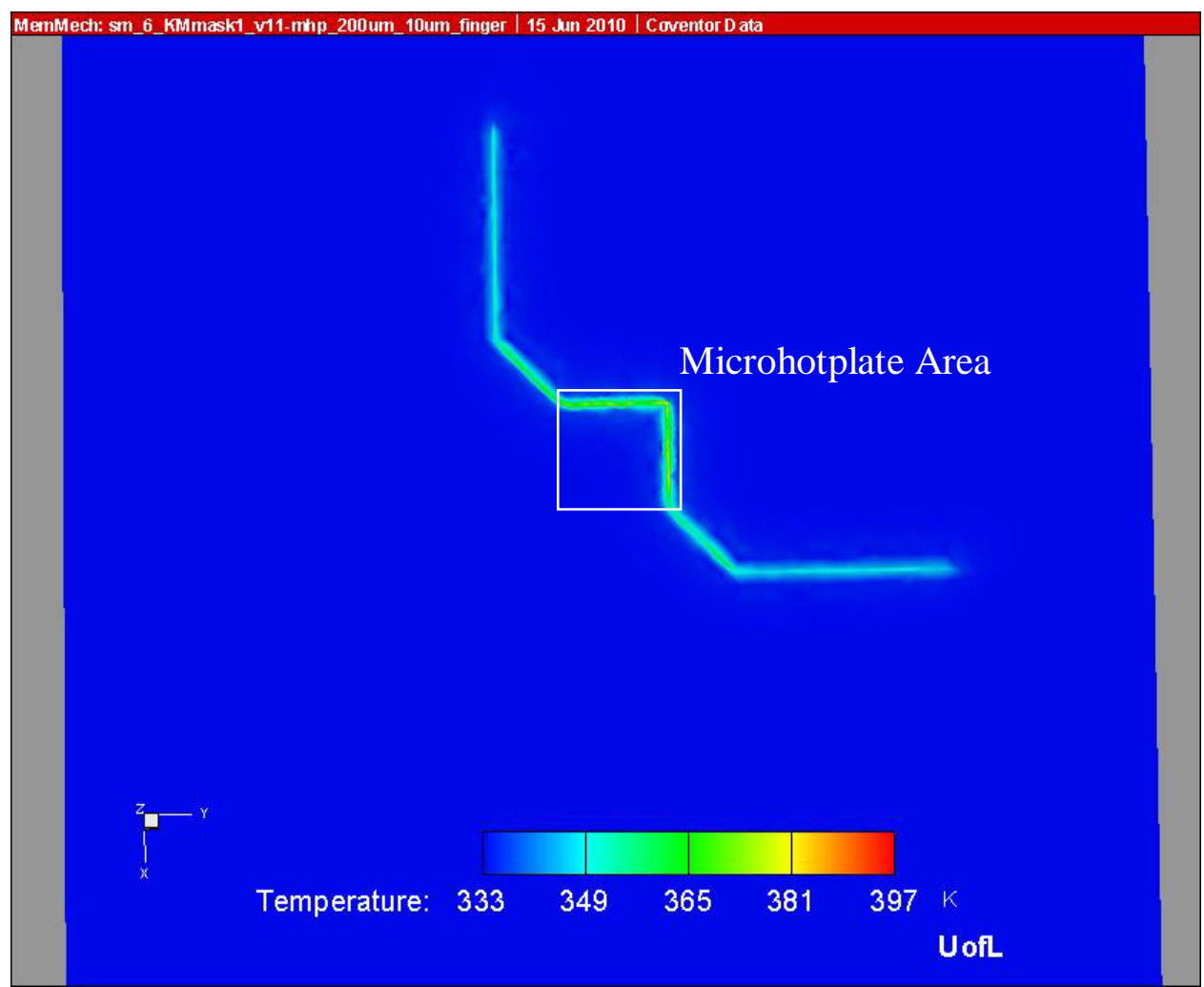

FIGURE 3.11 - Temperature Plot of a Simulated Unreleased $200 \mu \mathrm{m}$ Microhotplate with $60 \mathrm{~mA}$ of Current through One Microheater

Notwithstanding the apparent discrepancy between simulated and observed temperature ranges, the temperature distributions in the simulations mimic those experimentally observed. As expected from equation (3-2), the longer microheaters of the $200 \mu \mathrm{m}$ microhotplates, possessing greater resistance than the microheaters of the 100 $\mu \mathrm{m}$ microhotplates, dissipated more power, in turn exhibiting a higher temperature on average in both experimentally observed and simulated results. Interestingly, the simulation software also accurately modeled local temperature fluctuations across the microheater for the $200 \mu \mathrm{m}$ microhotplate; compare Figures 2.8 and 3.10. 


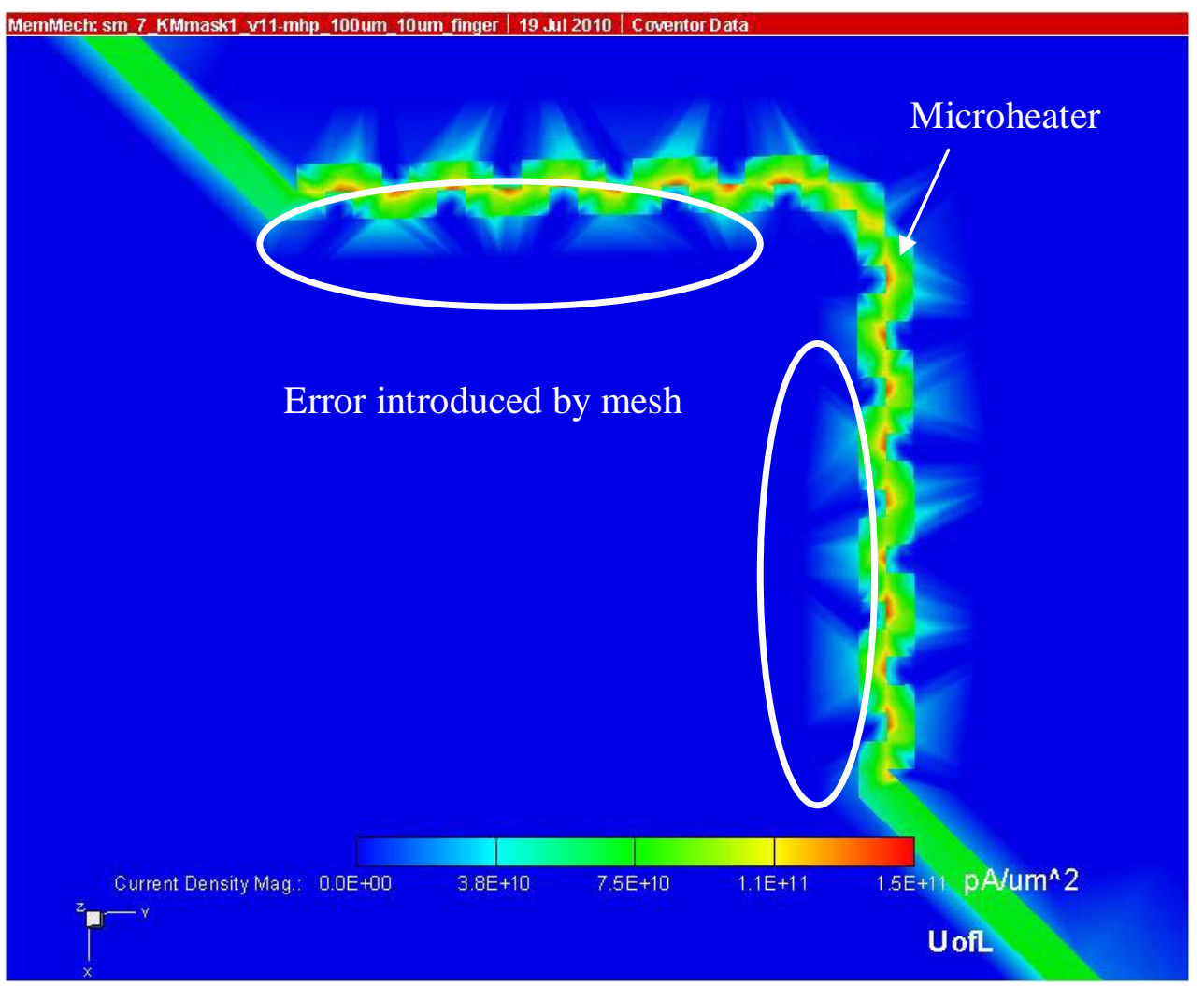

FIGURE 3.12 - Current Density Plot of a Simulated Unreleased $100 \mu \mathrm{m}$ Microhotplate with $70 \mathrm{~mA}$ of Current through One Microheater

To simulate the thermally isolated microhotplate, an anisotropic wet etch through the underlying silicon is modeled, rather than attempting to model the isotropic and anisotropic etches used in fabrication. Since only heat transfer by conduction is considered and the temperature distribution away from the microhotplate area is not useful, it is only important to ensure that the silicon is separated from the thermal oxide underneath the microhotplate area.

Figure 3.13 compiles the temperature data extracted when current density equivalent to passing 2 to $10 \mathrm{~mA}$ of current is applied across one microheater. At $10 \mathrm{~mA}$ of current, or $35.5 \mathrm{~mW}$ of power, the simulation results show a temperature peak reaching nearly 
$1400^{\circ} \mathrm{C}$ on the surface of the microheater, with the temperature decreasing gradually across the surface of the microhotplate.

Though this result is much higher than that of the experimentally tested device, the main value of this simulation is that a significant difference between the unreleased and isolated microhotplate results is to be expected; this is reflected in the experimental results.

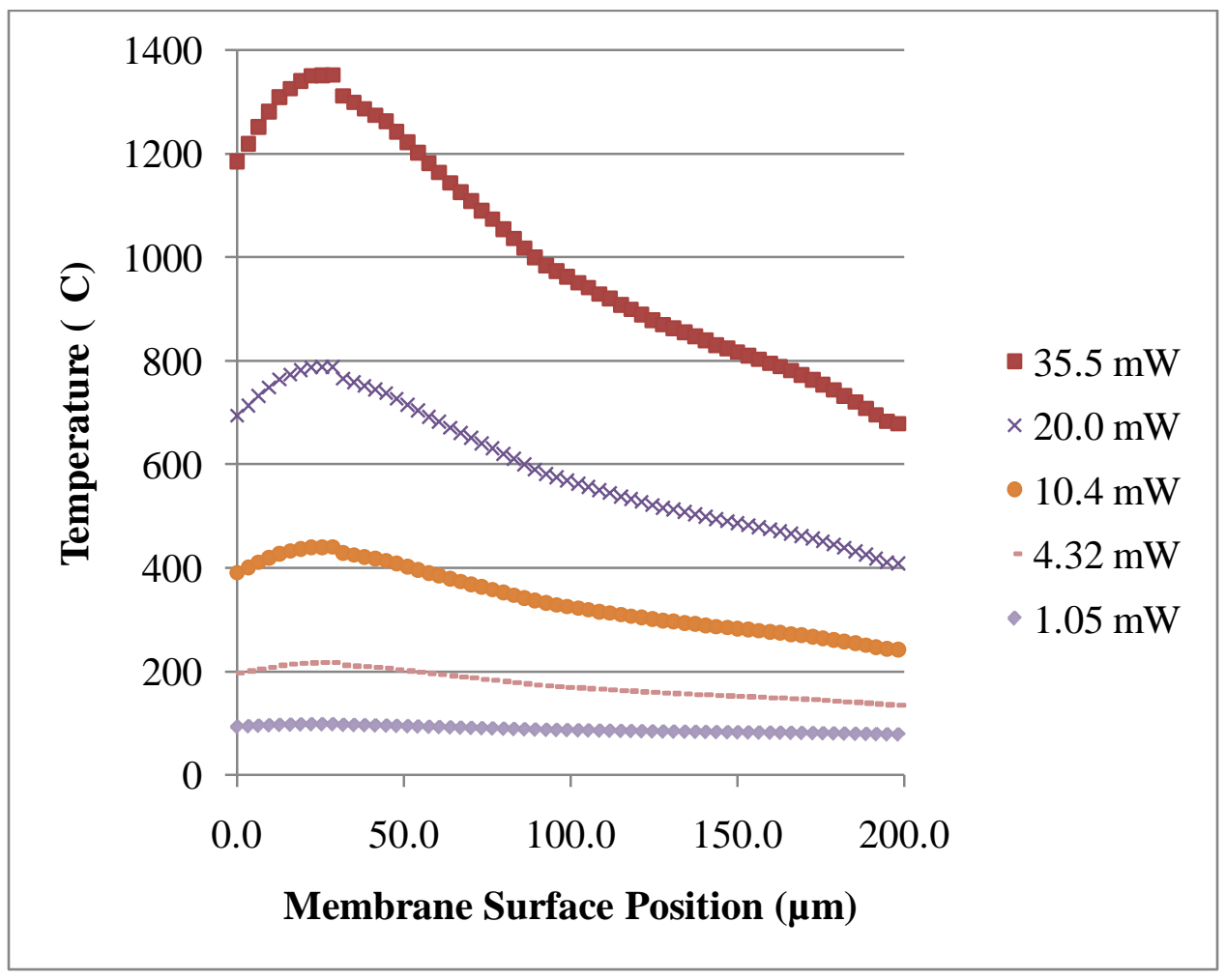

FIGURE 3.13 - Temperature Line Traces Extracted from a Thermally Isolated $100 \mu \mathrm{m}$ Microhotplate Simulation under Constant Current Conditions from $2 \mathrm{~mA}$ to $10 \mathrm{~mA}$

As seen in the temperature visualization in Figure 3.14, the simulation models a hot area inside the corner of the microheater, similar to how the hot portion of the electrode is shown in Figure 2.5. The simulation does not, however, distinguish that the platinum 
traces become hotter than the underlying oxide, nor is there an indication of conductive heat loss specifically through the platinum on the supporting legs of the membrane.

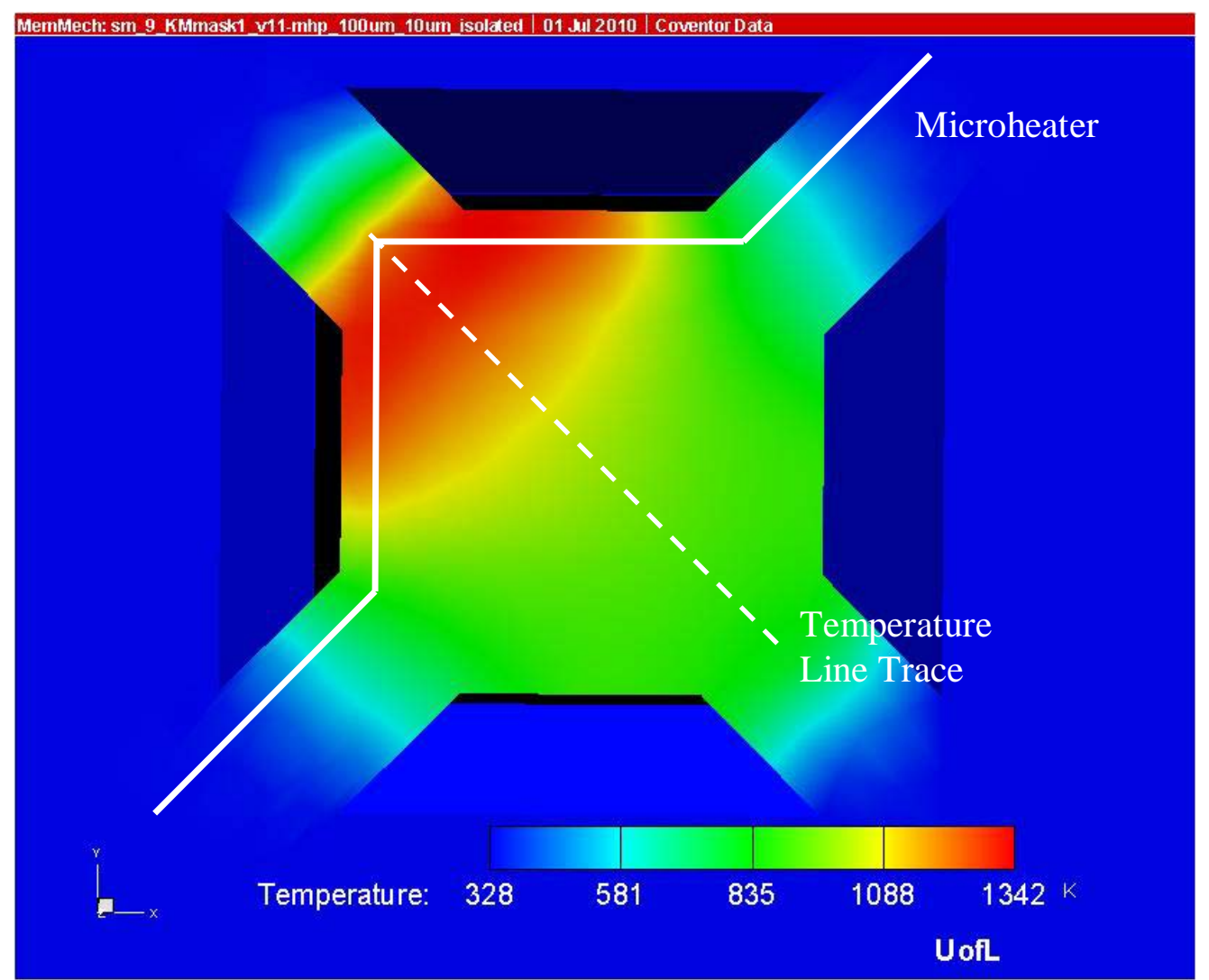

FIGURE 3.14 - Temperature Plot of a Simulated Thermally Isolated $100 \mu \mathrm{m}$ Microhotplate with $9 \mathrm{~mA}$ of Current through One Microheater

There are two most probable factors contributing to the attainment of excessively high temperatures in the simulation. These factors include the range of applicability of the temperature-dependent platinum resistivity used and lack of consideration of mechanisms for heat loss.

Resistivity of platinum is a function of temperature, as shown in the measured resistance from Table 3.1. However, the temperature functionality is only certain for the range of temperatures experimentally obtained on the tested devices. Because the 
simulation exceeds these temperatures, the applicability of the platinum electrical resistivity, among other material properties, including thermal conductivity and specific heat capacity, is nullified. The simulations not exceeding these temperatures, such as those using six milliamperes of current and below, demonstrate more believable, though still high, temperature results.

As mentioned previously, heat loss by convection and radiation were ignored in this study. However, an in-depth scale analysis of the significance of various mechanisms for heat loss was not performed. In addition to convection and radiation effects, the physical state of the oxide and platinum must be considered; at high temperatures, the sputtered platinum atoms may begin to reorganize. The properties of the platinum film may change as a result.

The rationale for neglecting convection effects stems from the suggested range of gas-phase convection heat transfer coefficients listed by Incropera and DeWitt [40] as 2 to $25 \mathrm{~W} / \mathrm{m}^{2} / \mathrm{K}$. Under these conditions, the effect of convection on the temperatures of the microheaters in the simulations was found to be no more than a few degrees. However, according to the static analysis by Solzbacher [42] et al., characteristic heat transfer coefficients for a microhotplate in room-temperature air can reach over 500 $\mathrm{W} / \mathrm{m}^{2} / \mathrm{K}$

When a maximum convection heat transfer coefficient case suggested by Solzbacher [42] et al. of $550 \mathrm{~W} / \mathrm{m}^{2} / \mathrm{K}$ is applied to a thermally isolated $100 \mu \mathrm{m}$ microhotplate simulation, with $298 \mathrm{~K}$ air removing heat from both the top and bottom surfaces of the microhotplate, the temperature effect is significant, as seen in Figure 3.15. 


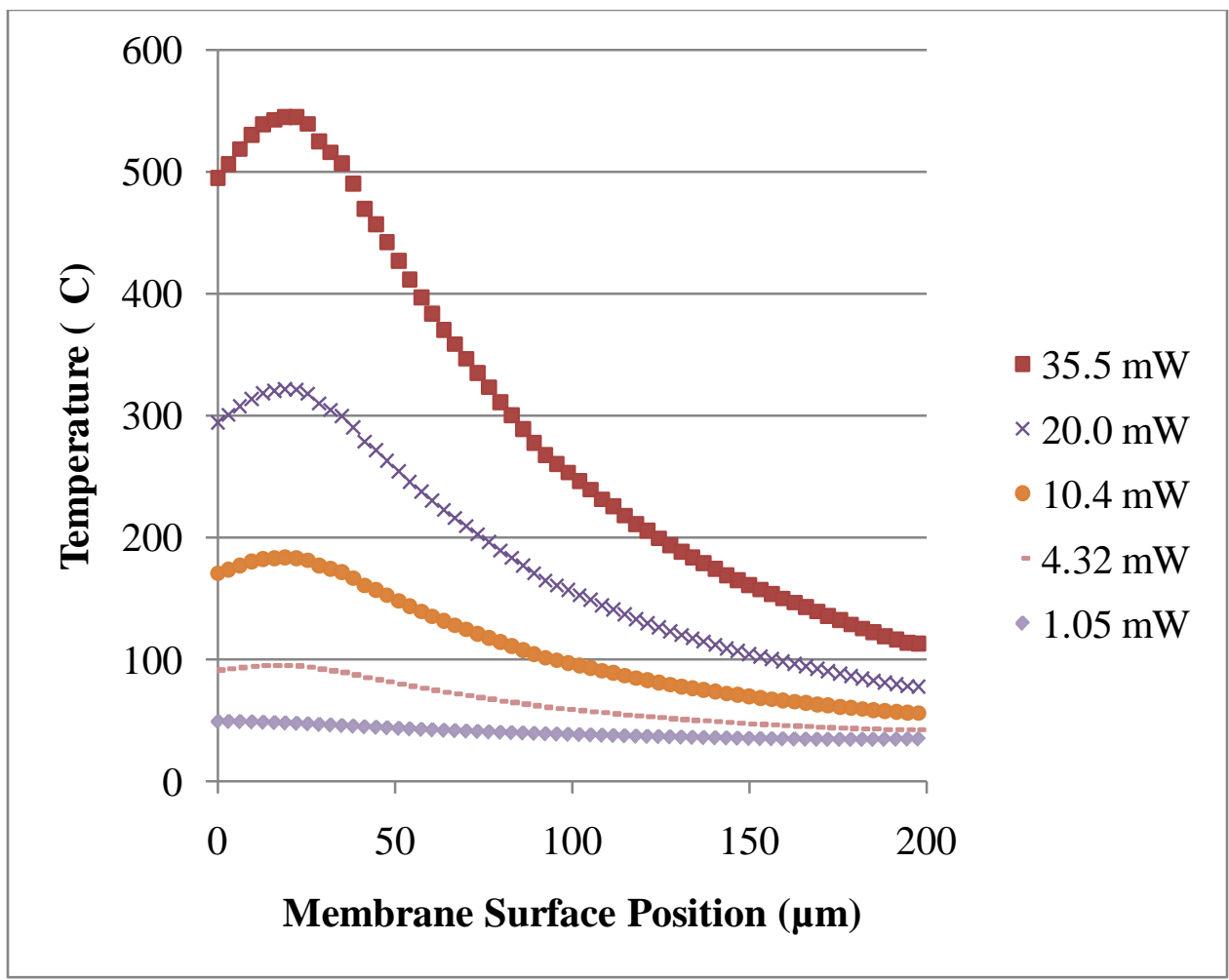

FIGURE 3.15 - Temperature Line Traces Extracted from a Thermally Isolated $100 \mu \mathrm{m}$ Microhotplate Simulation with Heat Loss by Convection

The temperature ranges demonstrated across the microhotplate in Figure 3.15 are now reasonable, with a temperature peak at $35.5 \mathrm{~mW}$ of $545^{\circ} \mathrm{C}$, compared to the $519^{\circ} \mathrm{C}$ peak of the fabricated device in Figure 2.9 at the same power consumption. An absolute percent error is determined for each data point by the formula

and an average is found by adding the percent error at each data point and dividing by the number of data points. This average error across the microhotplate at a power consumption of $35.5 \mathrm{~mW}$ is found to be $18 \%$ (see Appendix). In addition, the distribution of the hot area, shown in Figure 3.16, has begun to contract to the microheater area. 


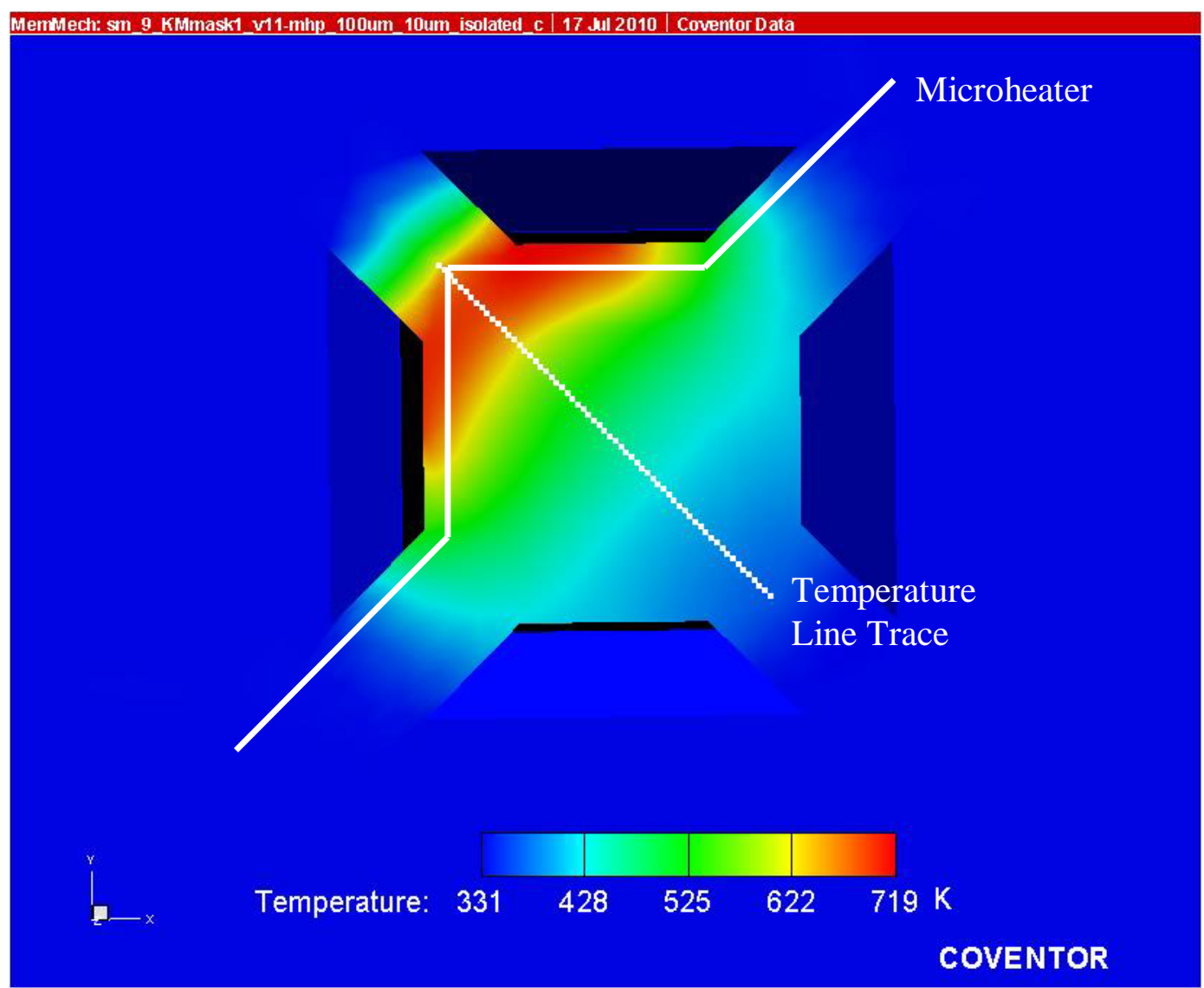

FIGURE 3.16 - Temperature Plot of a Simulated Thermally Isolated $100 \mu \mathrm{m}$ Microhotplate with $9 \mathrm{~mA}$ of Current through One Microheater and Convection Effects

A new set of microhotplate simulations have been developed in an attempt to eliminate the meshing effect shown in Figure 3.12. Only the microhotplate area is included in the model to reduce the calculation time for a finer mesh. The boundary conditions, including convection heat losses, are identical, though the current density must be changed to reflect the cross-sectional area of the microheater trace rather than that of the contact pads. Figures 3.17 and 3.18 show the temperature profile results from the $100 \mu \mathrm{m}$ and $200 \mu \mathrm{m}$ unreleased microhotplate simulations when a fine mesh is applied. 


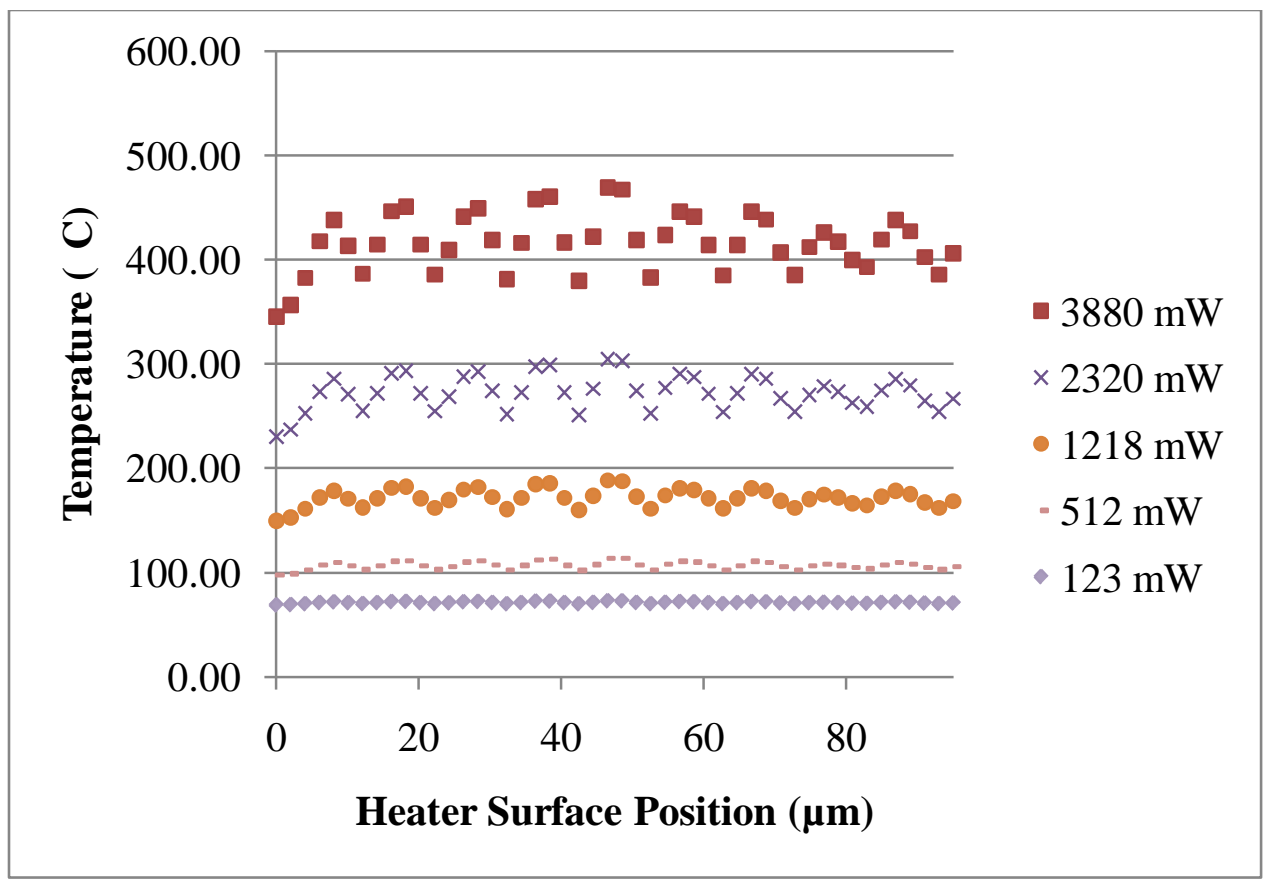

FIGURE 3.17 - Temperature Line Traces Extracted from an Unreleased $100 \mu \mathrm{m}$ Microhotplate Simulation using a Fine Mesh

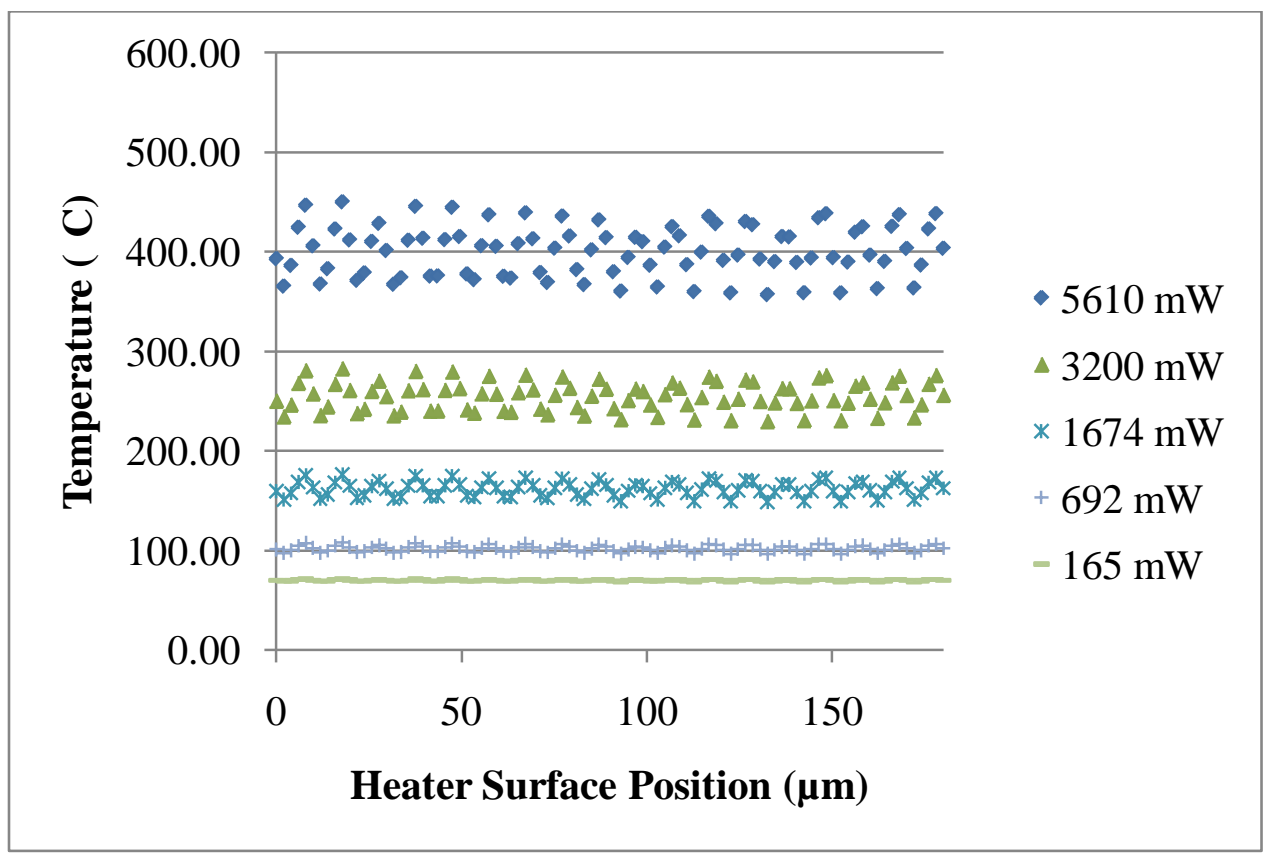

FIGURE 3.18 - Temperature Line Traces Extracted from an Unreleased $200 \mu \mathrm{m}$ Microhotplate Simulation using a Fine Mesh 
Immediately apparent is that the simulation now models the variations in temperature within the microhotplate geometry, shown by the spiking effect. Also apparent is the significant improvement in temperature exhibited by these simulations over the previous iteration. The $100 \mu \mathrm{m}$ microhotplate microheater now reaches an average temperature of $410^{\circ} \mathrm{C}$ at $3.9 \mathrm{~W}$, while the $200 \mu \mathrm{m}$ microhotplate reaches $400^{\circ} \mathrm{C}$ on average at $5.6 \mathrm{~W}$. Again compared to the tested device results of $340^{\circ} \mathrm{C}$ and $360^{\circ} \mathrm{C}$, the finer mesh simulations show a much closer approximation, reaching within $20 \%$ of the experimental averages, though now the average temperatures of the simulations are higher than the experimental results. Figure 3.19 shows the temperature distribution of the unreleased $100 \mu \mathrm{m}$ fine mesh simulation; the $200 \mu \mathrm{m}$ distribution is similar.

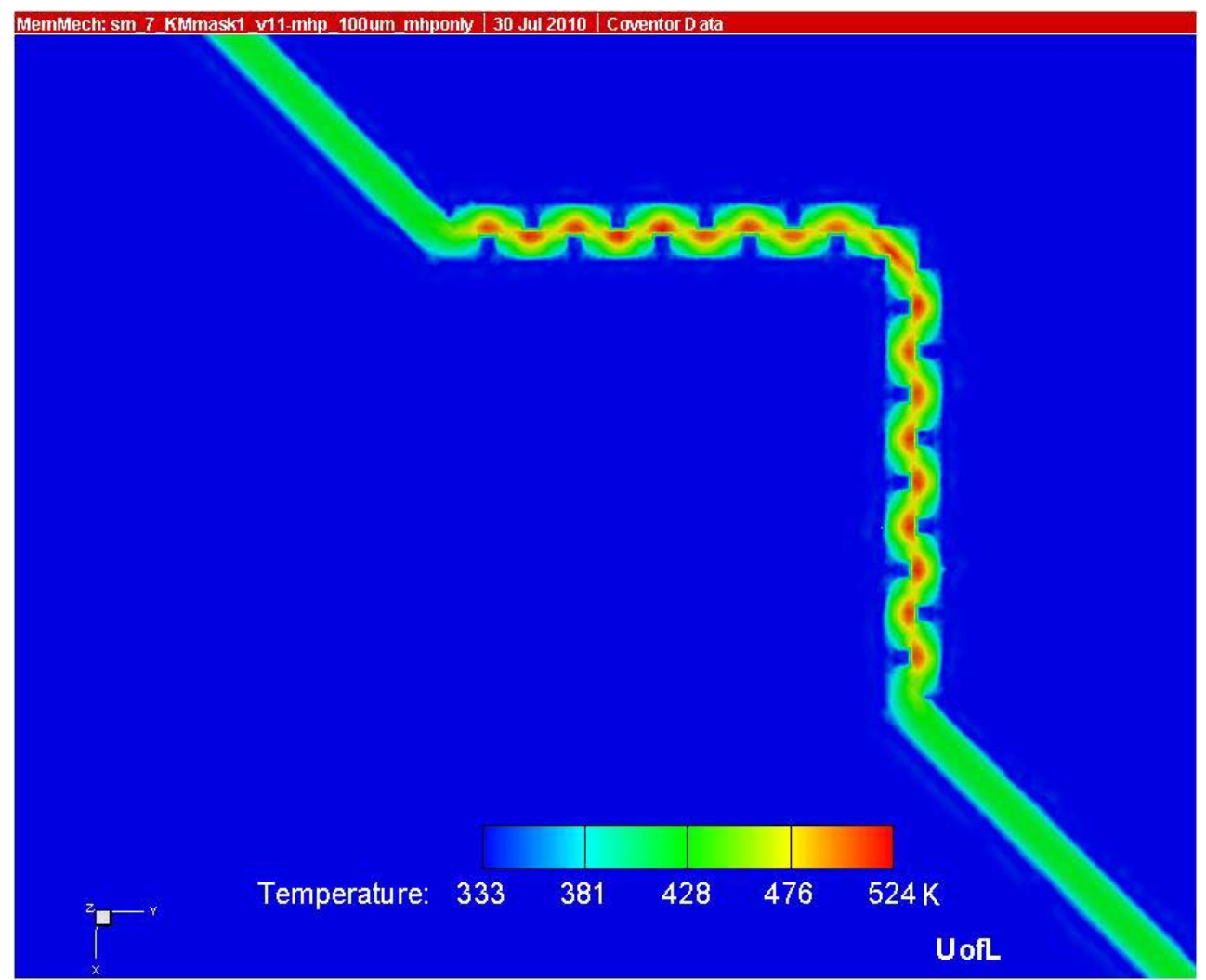

FIGURE 3.19 - Temperature Plot of a Finely Meshed Simulated Unreleased $100 \mu \mathrm{m}$ Microhotplate with $70 \mathrm{~mA}$ of Current through One Microheater 
Additionally, the current loss is not expressed in the finely meshed simulations; current magnitudes ntering and exiting the model at the specified boundaries are reported to be approximately equal, in most cases differing by one to two percent of the inlet current. See Table A.11 in appendix.

The same mesh improvement is applied to the thermally isolated microhotplate, with results shown in Figure 3.20 .

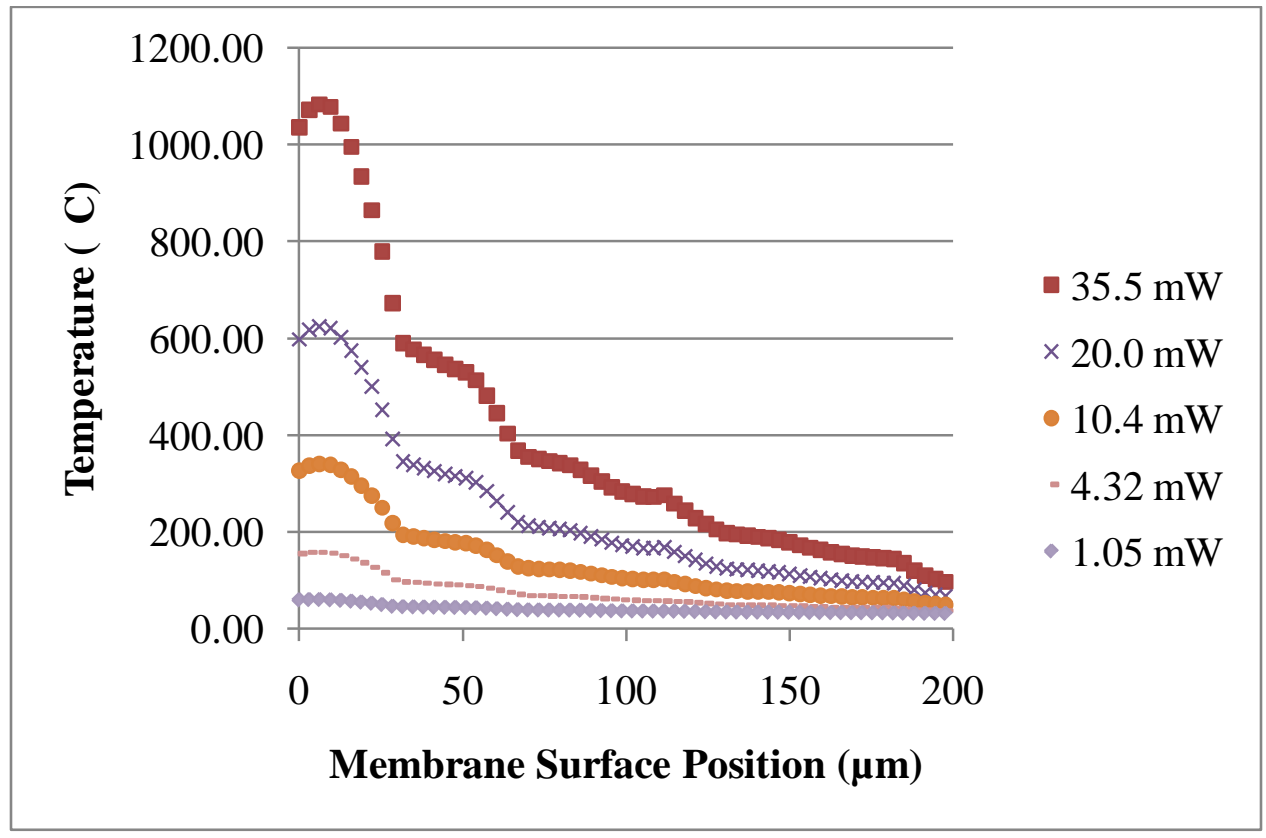

FIGURE 3.20 - Temperature Line Traces Extracted from a Finely Meshed Thermally Isolated $100 \mu \mathrm{m}$ Microhotplate Simulation with Heat Loss by Convection

In the finely meshed thermally isolated simulation, the software begins to display a closer trend to the experimental results, where the platinum of the electrodes is found to be hotter than the underlying oxide; this can be seen in Figure 3.21.

Unfortunately, the temperature is once again much hotter than experimentally observed, even with the maximum convection coefficient case of $550 \mathrm{~W} / \mathrm{m}^{2} / \mathrm{K}$ applied. One possible explanation for the high temperatures is that the resistance of the 
microheaters may be slightly higher than necessary due to the fact that a portion of the platinum trace was removed from the simulation to decrease the model size and calculation time. In addition, though the silicon is no longer in contact with the microhotplate in the tested device, the silicon wafer was not completely etched through as is modeled in the simulation, and there may be some heat losses that were not considered.

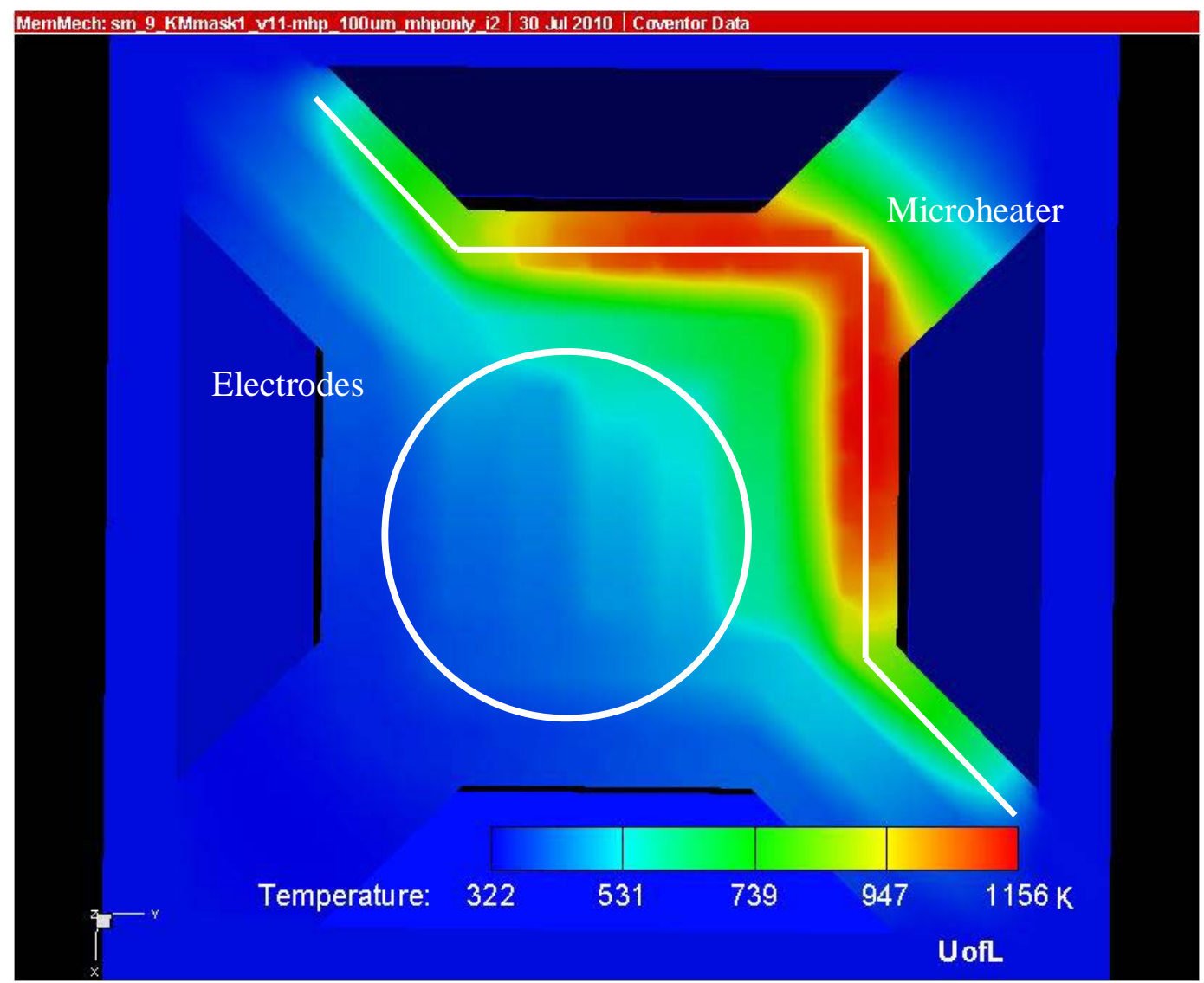

FIGURE 3.21 - Temperature Plot of a Finely Meshed Simulated Thermally Isolated 100 $\mu \mathrm{m}$ Microhotplate with $9 \mathrm{~mA}$ of Current through One Microheater and Convection Effects

\section{Summary of Simulation Results}

Simulations were performed on $100 \mu$ m unreleased, $200 \mu$ m unreleased, and $100 \mu \mathrm{m}$ thermally isolated microhotplates to compare with experimentally observed results. 
Initial simulations resulted in an average microheater temperature of $130^{\circ} \mathrm{C}$ and $210^{\circ} \mathrm{C}$ for the $100 \mu \mathrm{m}$ and $200 \mu \mathrm{m}$ unreleased microhotplates at $3.9 \mathrm{~W}$ and $5.6 \mathrm{~W}$, or $40 \%$ and $60 \%$ of the experimentally observed average temperatures. Fine meshing eliminated current loss and improved the temperature distributions of the unreleased microhotplates, bringing the average temperatures to $410^{\circ} \mathrm{C}$ and $400^{\circ} \mathrm{C}$, or within $20 \%$ of the experimental average temperatures. In all unreleased microhotplate simulations, heating of the thermal oxide membrane was negligible, as expected from the tested device results. Initial simulations of the $100 \mu \mathrm{m}$ thermally isolated microhotplate resulted in very high temperatures, peaking at nearly $1400^{\circ} \mathrm{C}$ for the $35.5 \mathrm{~mW}$ power consumption. The addition of a maximum convection coefficient case of $550 \mathrm{~W} / \mathrm{m}^{2} / \mathrm{K}$ reduced the temperatures to within $18 \%$ of the experimentally observed temperatures across the microhotplate membrane. Finer meshing improved the temperature distribution and allowed the simulation to model heating of the platinum electrodes, but increased the microhotplate temperature. 


\section{SIMULATION AND OPTIMIZATION OF MICROHOTPLATES USING SILICON CARBIDE MICROHEATERS}

The motivation for using silicon carbide $(\mathrm{SiC})$ is noted in the introduction of this work. Silicon carbide has attracted attention for use in microelectronic devices in past years because of its desirable material properties. These properties, including resistance to thermal oxidation, wide band gap, high thermal conductivity, high mechanical strength, resistance to corrosion and erosion, and resistance to high temperatures, make silicon carbide useful for applications in harsh, chemically active, or high-temperature environments. Normal silicon-based devices are not capable of operating for long periods in these environments.

The goal of the following simulations is to develop and optimize a SiC-based microhotplate platform for a gas sensor, making use of the desirable material properties inherent in silicon carbide. Specifically, it is desired to replace the platinum microheaters with microheaters formed of nitrogen-doped silicon carbide. As a semiconductor, silicon carbide possesses a much higher resistivity than most metals, including platinum, allowing for much shorter microheaters, which in turn allows the microhotplate size to be

reduced. Table 4.1 gives a comparison between the room-temperature resistivity of platinum and doped silicon carbide. 
TABLE 4.1

COMPARISON OF ROOM TEMPERATURE ELECTRICAL RESISTIVITY AND THERMAL CONDUCTIVITY OF DOPED SIC TO PLATINUM

\begin{tabular}{|c|c|c|}
\hline Heating Element Material & $\begin{array}{l}\text { Electrical Resistivity at } \\
25^{\circ} \mathrm{C}\end{array}$ & $\begin{array}{l}\text { Thermal Conductivity at } \\
25^{\circ} \mathrm{C}\end{array}$ \\
\hline Platinum & $1.05 \times 10^{-5} \Omega \cdot \mathrm{cm}$ & $0.716 \mathrm{~W} / \mathrm{cm} / \mathrm{K}$ \\
\hline $\begin{array}{l}\text { Doped } 3 \mathrm{C}-\mathrm{SiC} \\
\left(10^{18} \text { atoms } / \mathrm{cm}^{3}\right)\end{array}$ & $2.31 \times 10^{-2} \Omega \cdot \mathrm{cm}$ & $4.9 \mathrm{~W} / \mathrm{cm} / \mathrm{K}$ \\
\hline
\end{tabular}

As Table 4.1 shows, the resistivity of heavily-doped SiC is about three orders of magnitude greater than that of platinum. In general, the thickness of PECVD-deposited SiC can reach one or two microns, while a metal such as platinum can only be sputtered to a thickness of about 200 nanometers due to high film residual stress; as reported in Chapter II, the platinum/titanium traces fabricated in this work were $150 \mathrm{~nm}$ thick.

Referring to equation (3-1) for a rectangular resistor, where resistance is proportional to resistivity and length and inversely proportional to cross-sectional area, it becomes apparent that, for microheaters of equal width, platinum heating elements still must be at least 100 times longer than doped SiC heating elements to reach the same resistance.

From equation (3-2), recall that heat generated by a resistor is equivalent to the power dissipated, which is proportional to the resistance of the microheater. Therefore, a relatively high resistance is desirable, and a microheater made of doped silicon carbide will reach the resistance of a platinum microheater in a much more compact volume.

These assertions can be easily proven using a one-dimensional analytical calculation. Considering rectangular bar resistors of length L, width w, and thickness t, under boundary conditions such that each end of the length of the bar $(L=0, L=L)$ is 
held at a constant temperature of 300 Kelvin, equation (3-3) may be solved to find temperature, $\mathrm{T}$, as a function of distance, $\mathrm{x}$, along the resistor [33]:

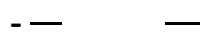

The heat generated per unit volume, $\mathrm{Q}$, can be calculated using equations (3-1) and (3-2) combined, where the volume, denoted Vol, is taken as the product of length, width, and thickness:

Then, Figure 4.1 shows the expected temperatures reached in resistors of each material having lengths of $1000 \mu \mathrm{m}$, widths of $10 \mu \mathrm{m}$, and thicknesses of $0.2 \mu \mathrm{m}$, when $100 \mu \mathrm{A}$ is applied to each. The silicon carbide resistor reaches $450 \mathrm{~K}$ at the center, while negligible heating occurs in the platinum resistor; this is the result of the much higher resistance of silicon carbide in the same volume.

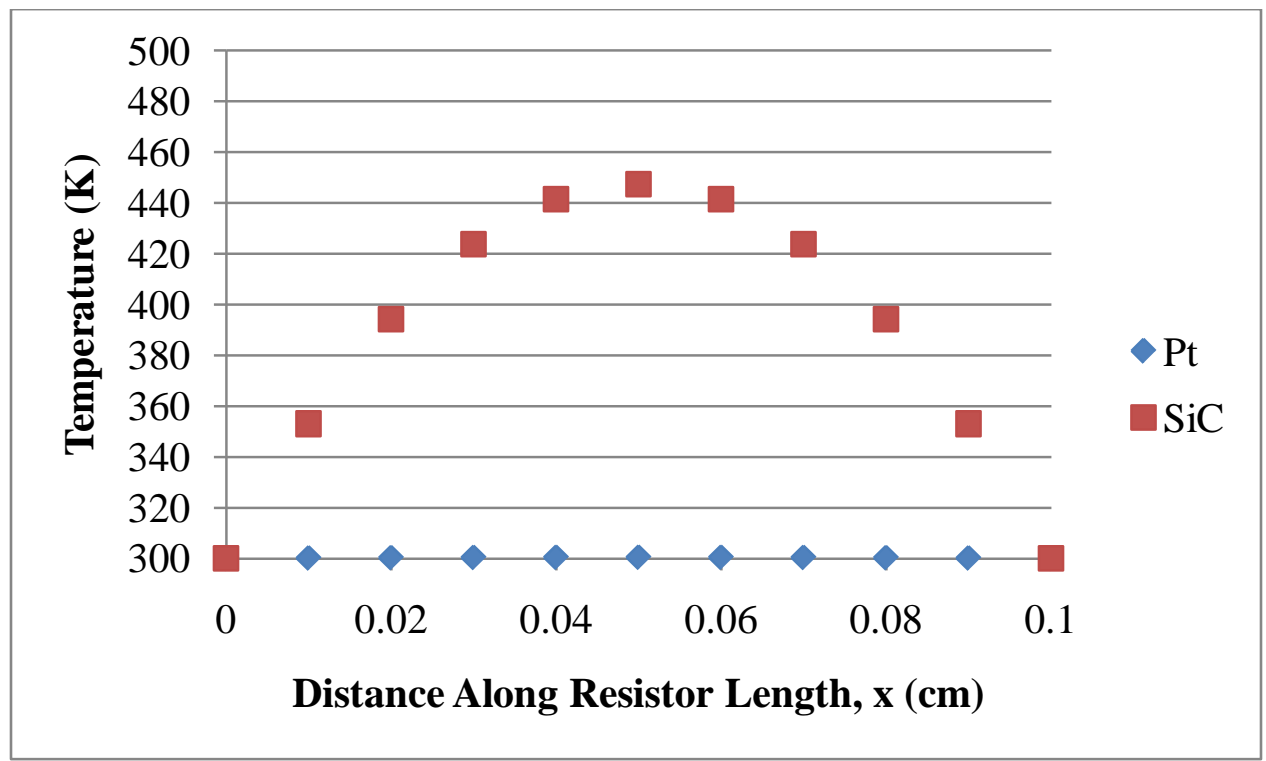

FIGURE 4.1 - One-dimensional Analytical Solution of Heat Equation for Identical 2000 $\mu \mathrm{m}^{3}$ Rectangular Resistors with $100 \mu \mathrm{A}$ Applied 
When the properties from Table 3.1 are used, simple CoventorWare simulations of these resistors, as shown in Figure 4.2, result in nearly identical results as the analytical solution displayed in Table 4.2 .

TABLE 4.2

ANALYTICAL AND SIMULATED ONE-DIMENSIONAL TEMPERATURE PROFILES OF PLATINUM AND SILICON CARBIDE RESISTORS

\begin{tabular}{|r|c|c|c|c|}
\hline & \multicolumn{2}{|c|}{$\begin{array}{c}\text { Analytical solution } \\
\text { from (4-1) }\end{array}$} & \multicolumn{2}{|c|}{$\begin{array}{c}\text { CoventorWare } \\
\text { results }\end{array}$} \\
\hline $\mathbf{x ~ ( c m )}$ & Pt & SiC & Pt & \multicolumn{1}{c|}{ SiC } \\
\hline 0 & 300.0 & 300.0 & 300.0 & 300.0 \\
\hline 0.01 & 300.2 & 353.0 & 300.2 & 353.0 \\
\hline 0.02 & 300.3 & 394.3 & 300.3 & 394.3 \\
\hline 0.03 & 300.4 & 423.8 & 300.4 & 423.8 \\
\hline 0.04 & 300.4 & 441.4 & 300.4 & 441.4 \\
\hline 0.05 & 300.5 & 447.3 & 300.5 & 447.3 \\
\hline 0.06 & 300.4 & 441.4 & 300.4 & 441.4 \\
\hline 0.07 & 300.4 & 423.8 & 300.4 & 423.8 \\
\hline 0.08 & 300.3 & 394.3 & 300.3 & 394.3 \\
\hline 0.09 & 300.2 & 353.0 & 300.2 & 353.0 \\
\hline 0.1 & 300.0 & 300.0 & 300.0 & 300.0 \\
\hline
\end{tabular}

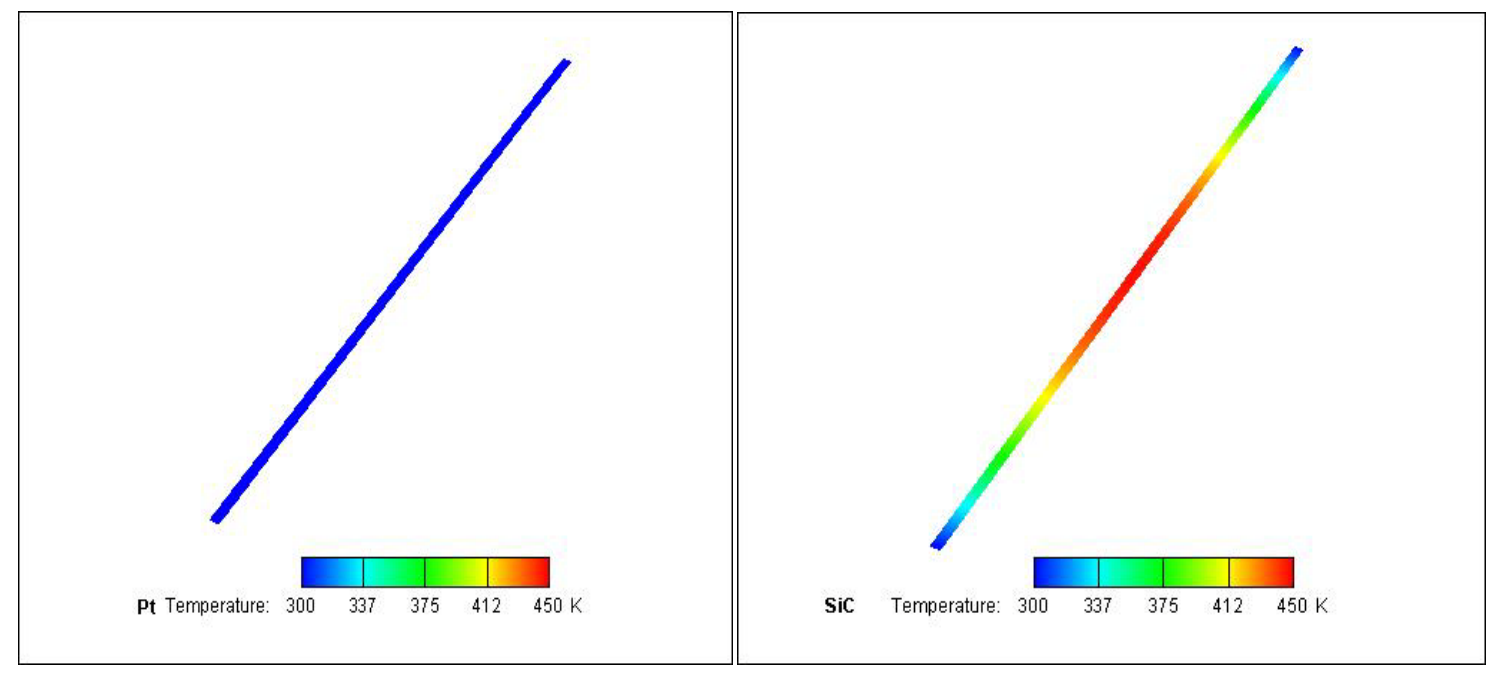

FIGURE 4.2 - Simulated Temperature Profiles of Simple Platinum and Silicon Carbide $2000 \mu \mathrm{m}^{3}$ Resistors with $100 \mu \mathrm{A}$ Applied 
The procedure for simulating microhotplates using silicon carbide is identical to the procedure outlined in Chapter III, but specifying different materials in the process definition, along with different layouts. Table 4.3 shows the process definition for a coplanar-configured microhotplate, which is explained below.

TABLE 4.3

SIMULATION PROCESS DEFINITION FOR A COPLANAR-CONFIGURED MICROHOTPLATE USING SILICON CARBIDE TRACES

\begin{tabular}{|l|l|l|l|l|}
\hline Step Name & Material & $\begin{array}{l}\text { Thickness } \\
(\boldsymbol{\mu m})\end{array}$ & Mask Name & $\begin{array}{l}\text { Photoresist } \\
\text { type }\end{array}$ \\
\hline Substrate & $\mathrm{Si}$ & 50 & SubstrateMask & \\
\hline Thermal Oxidation & $\mathrm{SiO}_{2}$ & 1 & & \\
\hline Wet Etch & & Last layer & MembraneMask & + \\
\hline PECVD & $\mathrm{SiC}$ & 1 & & \\
\hline Dry Etch & & Last layer & HeaterMask & + \\
\hline Sputtering & $\mathrm{Pt}$ & 0.2 & & \\
\hline "Etch” (Liftoff) & & Last layer & SensorMask & + \\
\hline $\begin{array}{l}\text { Anisotropic Wet } \\
\text { Etch - Frontside }\end{array}$ & Si only & 50 & SubstrateMask & - \\
\hline
\end{tabular}

Figure 4.3 illustrates the four-microheater arrangement designed to provide a uniform temperature distribution across the sensor area of the microhotplate. Each microheater is composed of silicon carbide, while the central interdigitated electrode structure is still composed of low-resistivity metal. Figure 4.4 shows the dimensions of the resulting three-dimensional model created from the process definition in Table 4.3 combined with the layout in Figure 4.3.

Process definitions and layouts are each interchangeable. Comparisons are drawn by creating different iterations of microhotplate models and subjecting the meshed models to similar tests. In this way, an optimum microhotplate configuration may be designed. 


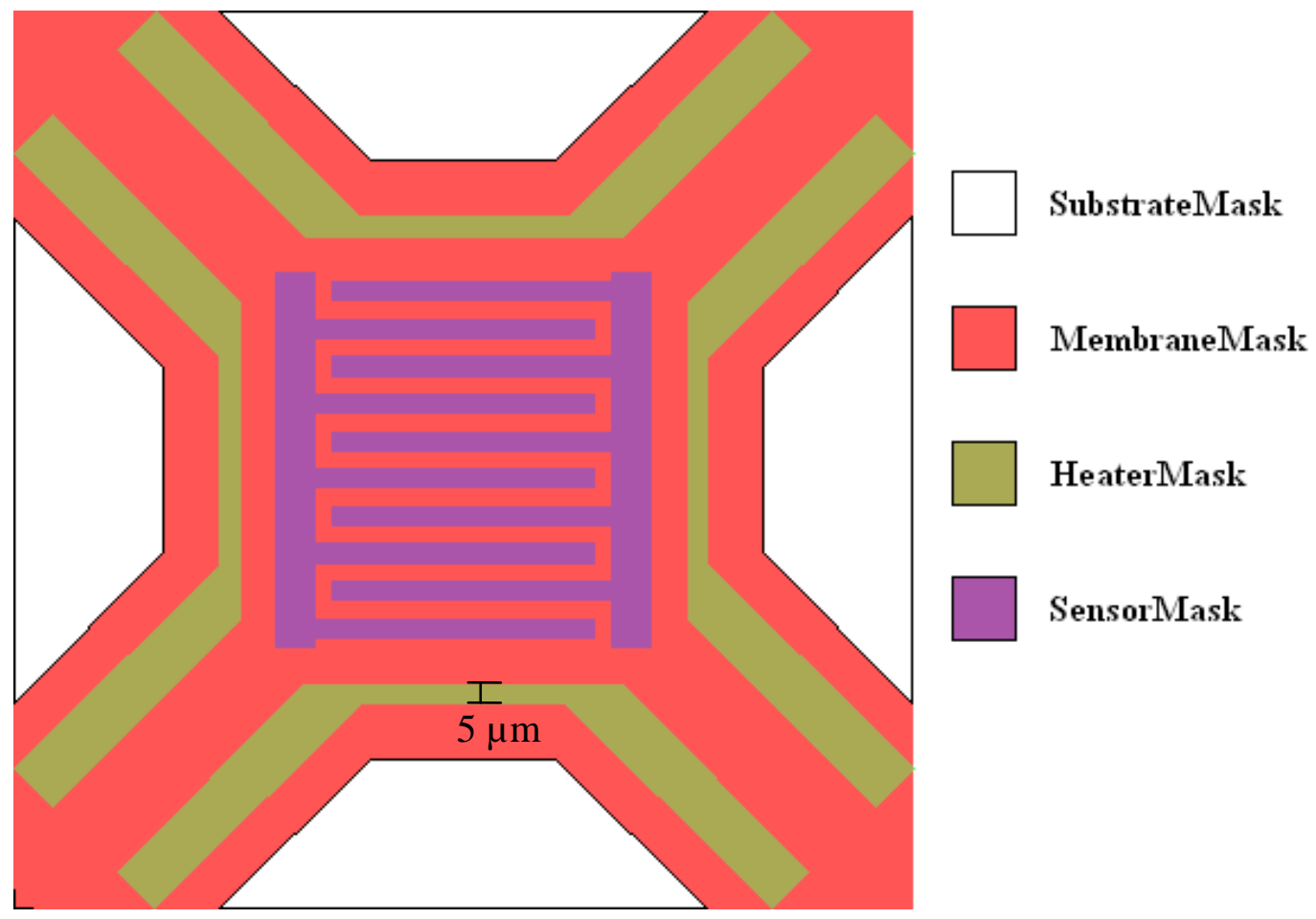

FIGURE 4.3 - Layout of a $100 \mu$ Isolated Microhotplate with 4.5-k $\Omega$ Silicon Carbide Microheaters

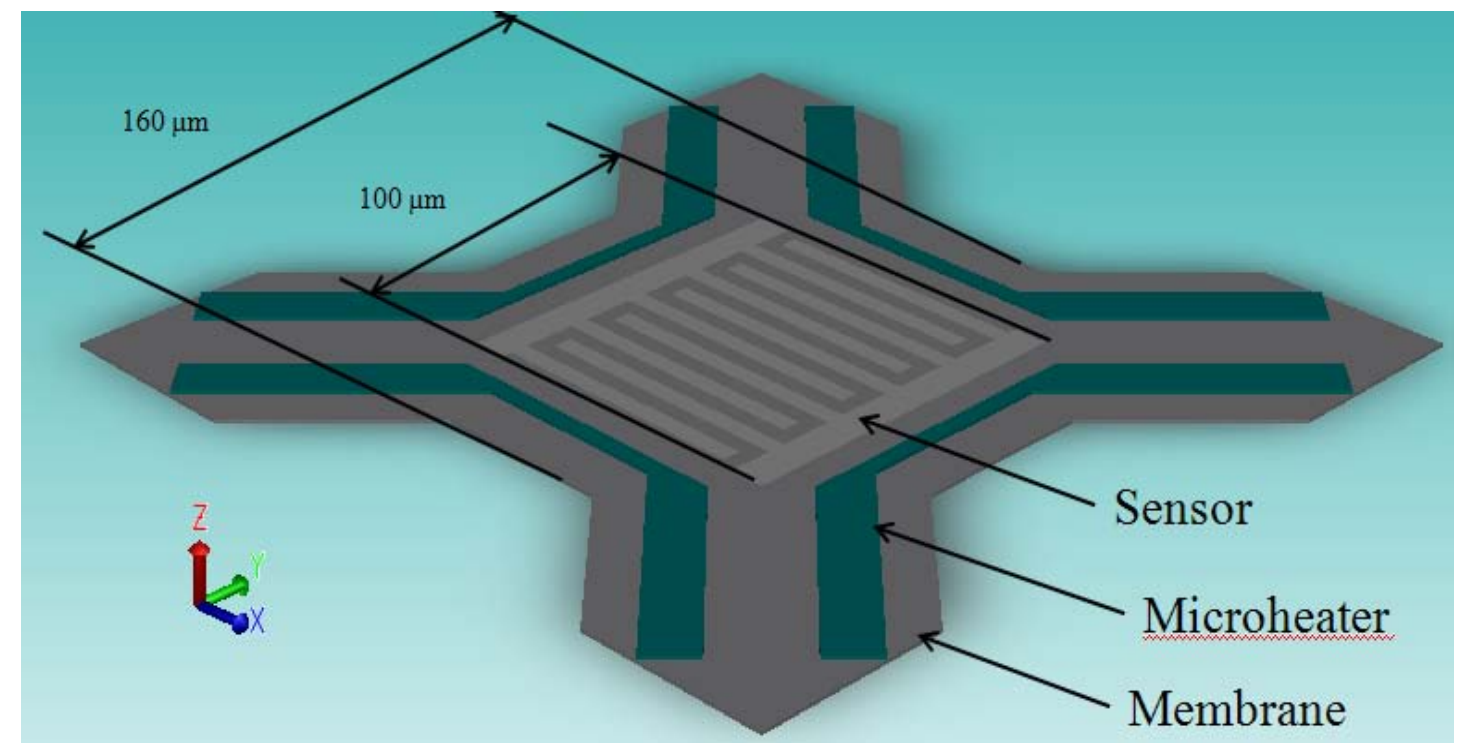

FIGURE 4.4 - Dimensions of Coplanar-configured $100 \mu \mathrm{m}$ Isolated Microhotplate Model with Silicon Carbide Microheaters 
One significant design comparison is between that of the "coplanar" microhotplate configuration and the "stacked" microhotplate configuration. This refers to the relative locations of the microheaters and electrodes for gas sensing. In a coplanar configuration, as in Figures 4.3 and 4.4, the microheaters and sensors are deposited on the same plane, while in a stacked configuration, an extra insulating layer separates the sensing element from the microheaters.

The results of a comparison of one microhotplate of each configuration, both using silicon carbide, are presented here. The coplanar microhotplate is identical to that outlined in Figures 4.3 and 4.4. The stacked microhotplate has a similar design, but a 1 $\mu \mathrm{m}$ layer of PECVD silicon dioxide separates the microheaters from the sensing element, and the thermally isolated area (not including the four support legs) has been reduced by a factor of 1.78. The sensor area and the resistance of each microheater were held constant. Figure 4.5 shows the dimensions of the stacked-configuration microhotplate model, with the insulating layer of CVD silicon dioxide hidden.

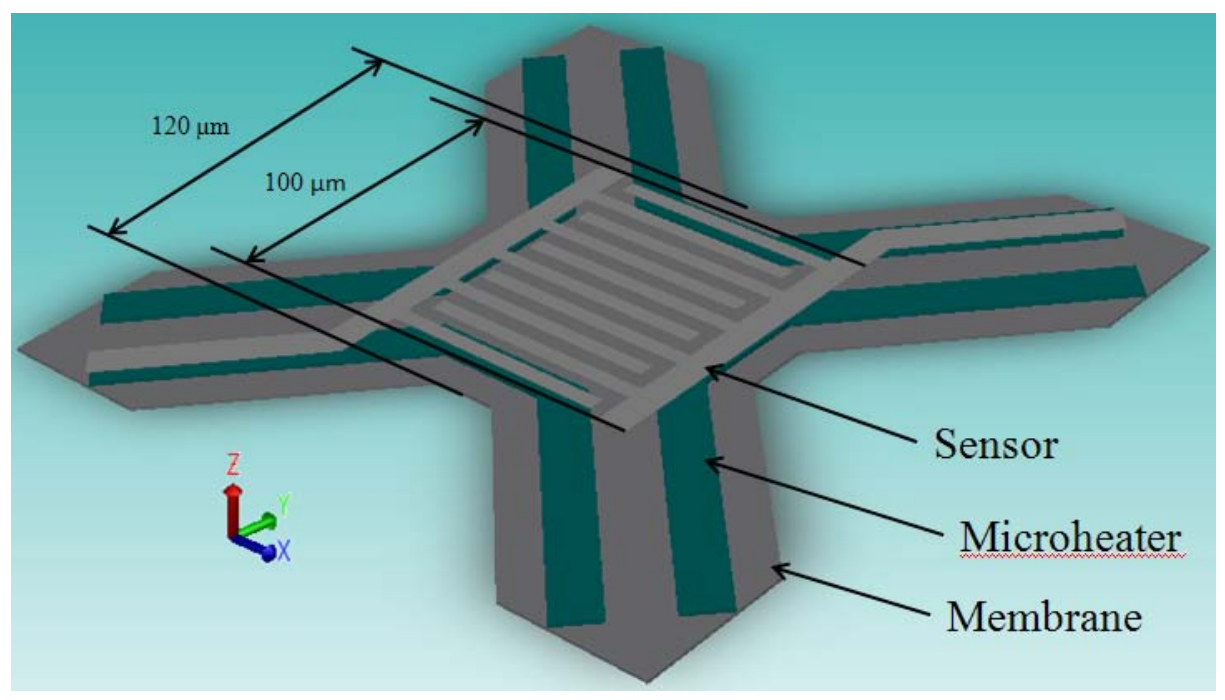

FIGURE 4.5 - Dimensions of Stacked-configured $100 \mu \mathrm{m}$ Isolated Microhotplate Model with Silicon Carbide Microheaters 
For sensing elements occupying a given area on the surface of the wafer, the advantage of a coplanar-type microhotplate is in the ease of fabrication, particularly if the heating and sensing elements are composed of the same material. However, a larger area surrounding the sensing element must be thermally isolated from the substrate in order to allow the heating elements to fit beside the sensor. Conversely, an advantage of the stacked microhotplate configuration is that the heating elements can be placed directly underneath the sensor, allowing the thermally isolated area to be smaller.

Figure 4.6 shows an analysis of the coplanar-configured microhotplate when a potential of eight volts is applied across the microheaters, for a total power consumption of $60 \mathrm{~mW}$. The ends of the support legs are fixed at a temperature of $300 \mathrm{~K}$; the " $\mathrm{X}$ " and "Y” label the data points extracted across the microhotplate surface, and the temperatures read at those points are plotted in Figure 4.7.

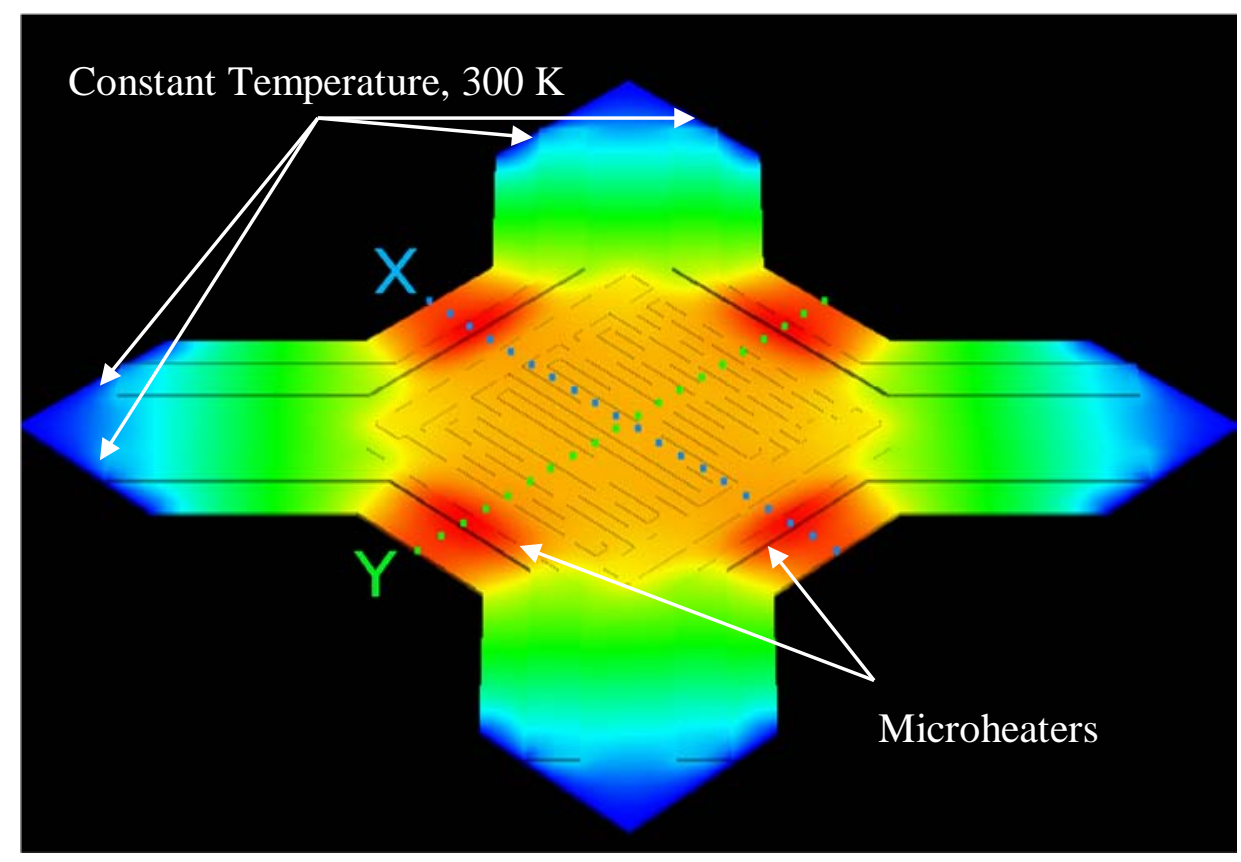

FIGURE 4.6 - Temperature Plot of a Simulated Coplanar Microhotplate with SiC Microheaters Using $60 \mathrm{~mW}$ of Power 


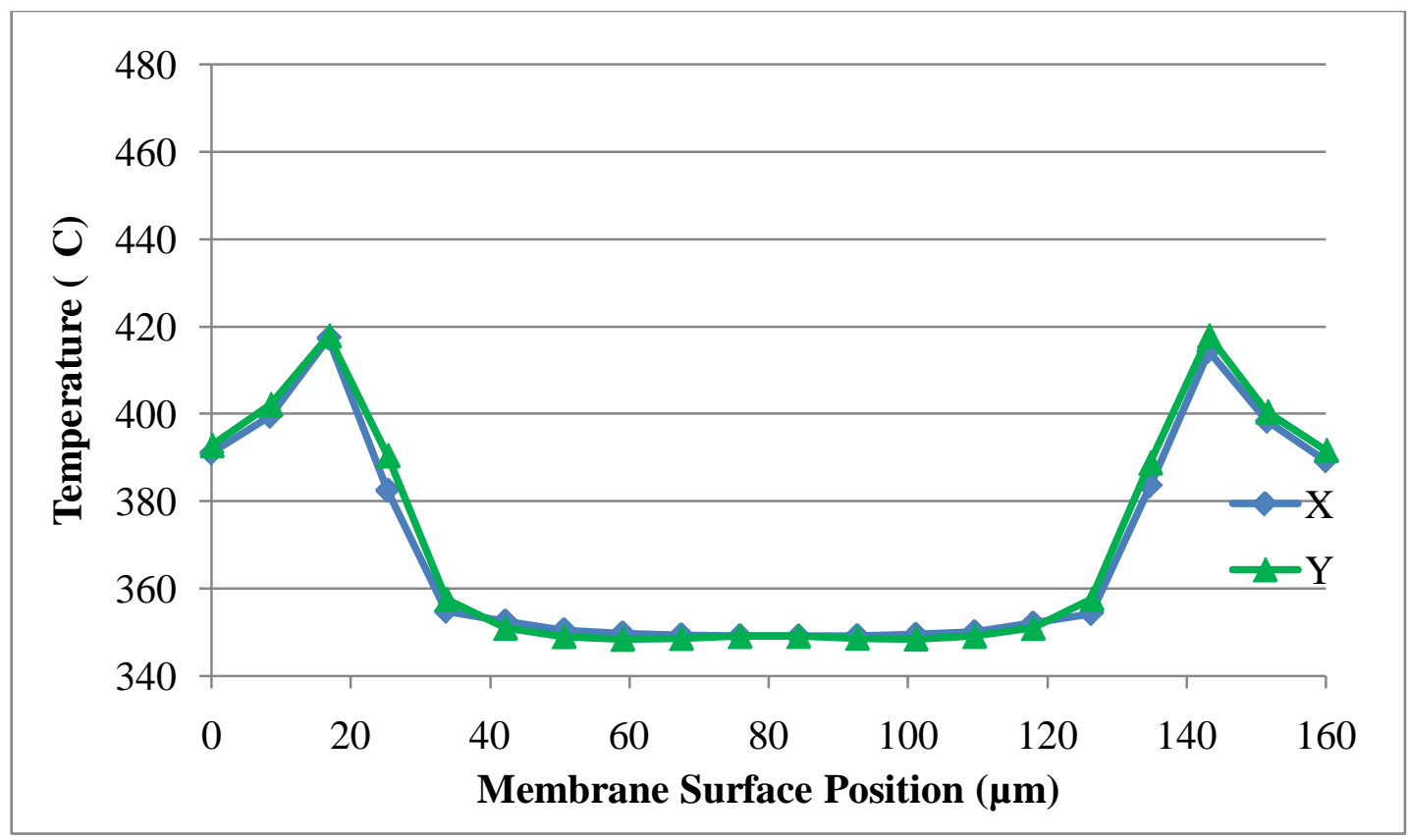

FIGURE 4.7 - Temperature Profile across Coplanar Microhotplate with SiC Microheaters Using $60 \mathrm{~mW}$ of Power

The sensor area of the coplanar microhotplate, which is between the 30 and $130 \mu \mathrm{m}$ marks of the membrane surface position plot in Figure 4.7, reaches an average temperature of $350^{\circ} \mathrm{C}$ under these conditions in the simulation. Though the temperature may not be proven accurate without a fabricated and tested device, the temperature distribution in Figure 4.6 indicates an even temperature profile, with a temperature variation of less than $10^{\circ} \mathrm{C}$ across the sensor area, although hot spots are observed directly over the microheaters.

The same boundary conditions are applied to the stacked-configuration microhotplate. Compare Figure 4.8 to Figure 4.6; data is extracted from the " $\mathrm{X}$ " and " $\mathrm{Y}$ " lines as previously, and temperature readings are plotted in Figure 4.9.

As seen in Figure 4.9, the stacked-configuration microhotplate, having a smaller area to heat, reaches a significantly higher average temperature of $450^{\circ} \mathrm{C}$ in the 
simulation. As with the coplanar-configured microhotplate, the temperature variation across the sensor area, between $10 \mu \mathrm{m}$ and $110 \mu \mathrm{m}$, is less than $10^{\circ} \mathrm{C}$.

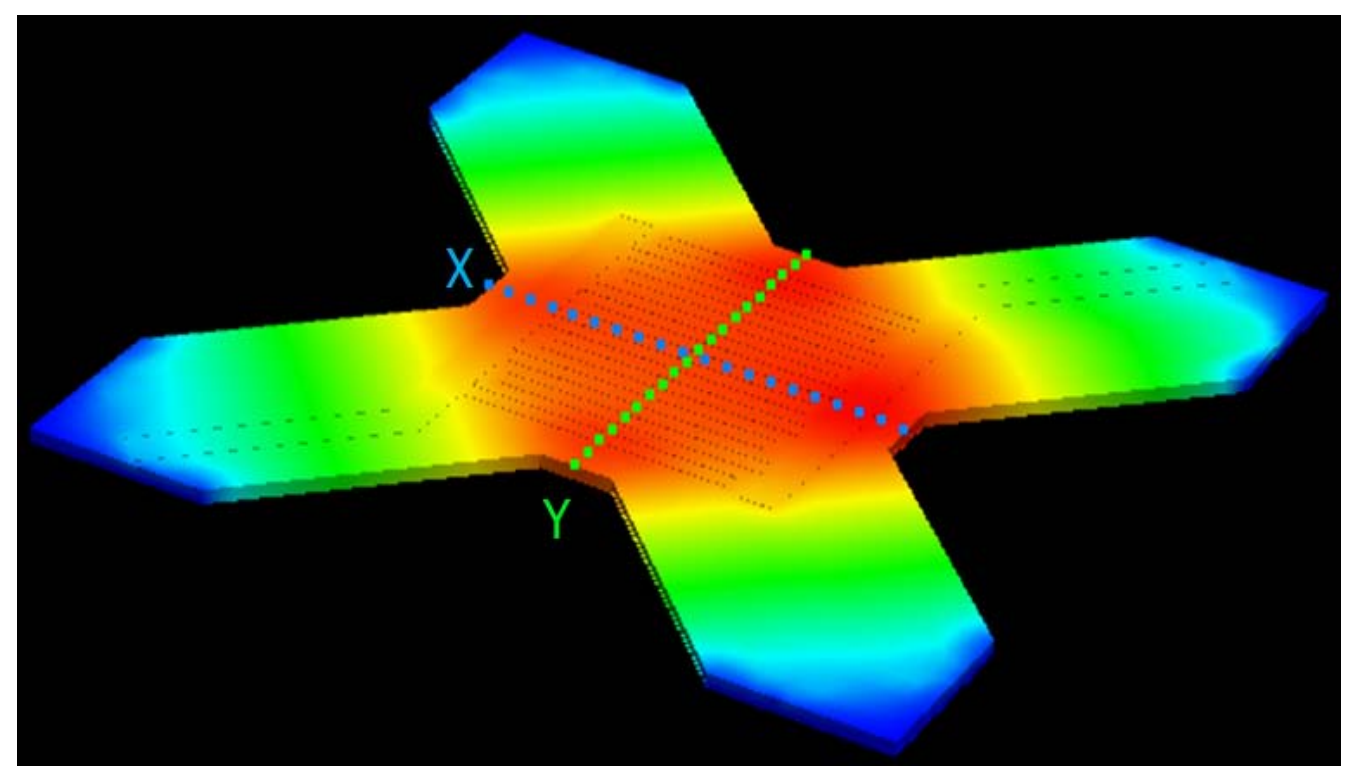

FIGURE 4.8 - Temperature Plot of a Simulated Stacked Microhotplate with SiC Microheaters Using $60 \mathrm{~mW}$ of Power

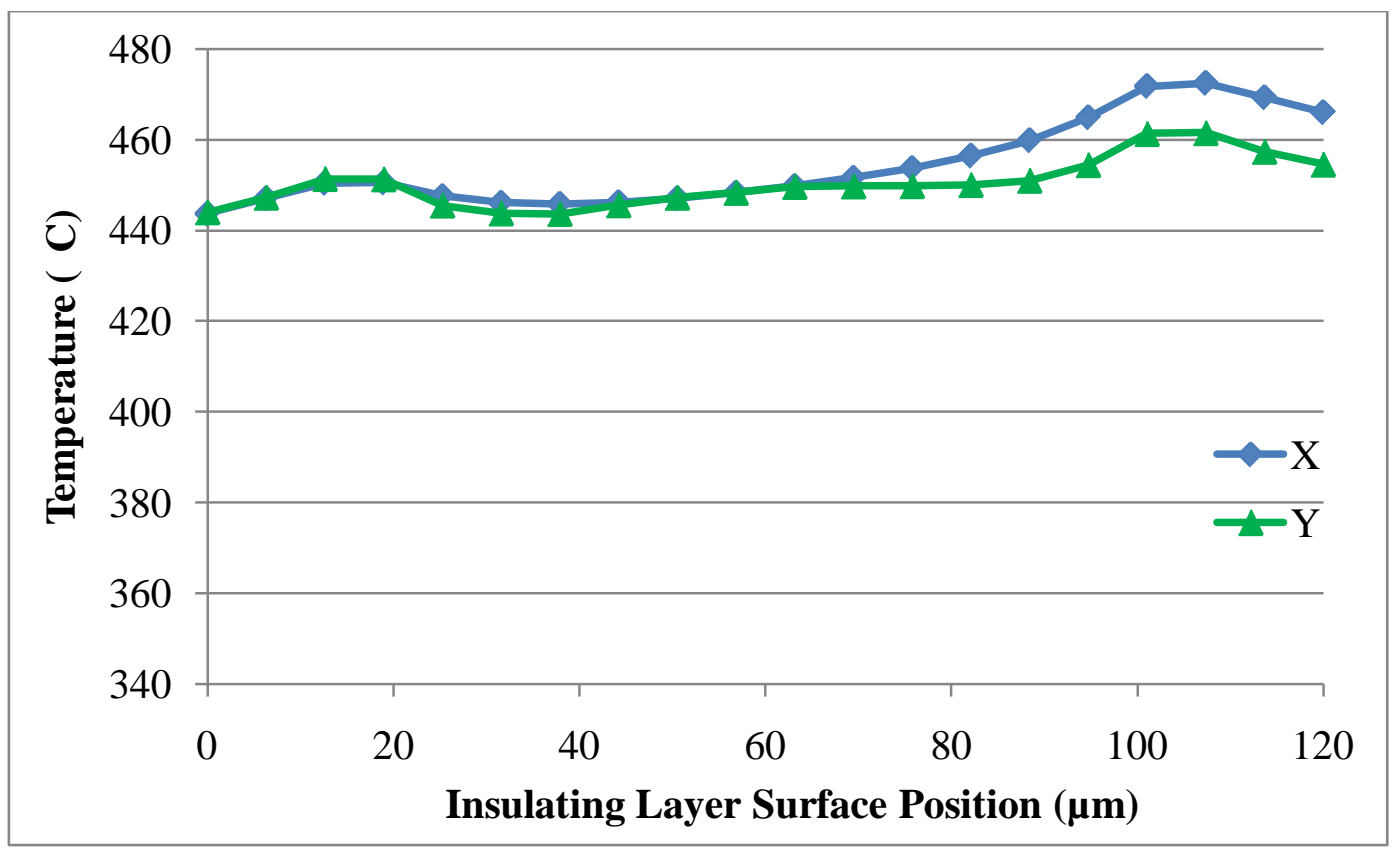

FIGURE 4.9 - Temperature Profile across Stacked Microhotplate with SiC Microheaters Using $60 \mathrm{~mW}$ of Power 
Though the absolute temperature cannot be confirmed without experimentation and consideration of the effects of convective heat loss, these simulations provide evidence that the reduced membrane size of the stacked microhotplate configuration significantly increases the microhotplate temperature attainable for a given power consumption. In addition, the symmetric microheater structure surrounding the sensor area of the microhotplate helps to achieve a uniform temperature distribution.

\section{Summary of SiC Simulation Results}

The higher resistivity of doped silicon carbide than that of platinum reduces the size requirement of the microhotplate microheaters. Coplanar and stacked configurations of microhotplates were compared, using a constant sensor area of $100 \mu \mathrm{m}$ by $100 \mu \mathrm{m}$ and four rectangular bar microheaters. At a power consumption of $60 \mathrm{~mW}$, the coplanar microhotplate sensor area was shown to reach an average of $350^{\circ} \mathrm{C}$, while the stacked microhotplate sensor area reached an average of $450^{\circ} \mathrm{C}$. It was concluded that the stacked microhotplate configuration of these microhotplate simulations allows the thermally isolated area to be reduced, which increases the temperature attainable for a given power consumption. 


\section{CONCLUSIONS}

Fabricated $150 \mathrm{~nm}$ thick platinum microheaters on unreleased silicon dioxide membranes with sensor areas of $10,000 \mu \mathrm{m}^{2}$ and $40,000 \mu^{2}$ each required a power consumption of over $1 \mathrm{~W}$ to reach a temperature above $100^{\circ} \mathrm{C}$. Power usages of $3.9 \mathrm{~W}$ and $5.6 \mathrm{~W}$ resulted in an average microheater temperatures of $340^{\circ} \mathrm{C}$ and $360^{\circ} \mathrm{C}$ across the $100 \mu \mathrm{m}$ and $200 \mu \mathrm{m}$ microheaters respectively. Coarsely meshed simulations using the same resistances reached average microheater temperatures of $130^{\circ} \mathrm{C}$ and $210^{\circ} \mathrm{C}$, or $40 \%$ and $60 \%$ of those experimentally observed. Fine meshing improved the averages to within $20 \%$. Heating of the unreleased microhotplate membranes was minimal.

A test on a thermally isolated microhotplate membrane showed temperatures of over $300^{\circ} \mathrm{C}$ at $35.5 \mathrm{~mW}$ of power. Initial simulation temperatures reached $1400^{\circ} \mathrm{C}$; when a convection coefficient of $550 \mathrm{~W} / \mathrm{m}^{2} / \mathrm{K}$ was applied, an $18 \%$ average error compared to fabricated results was found. Fine meshing improved the temperature distribution, but increased temperature, possibly due to additional heat losses not previously considered.

Simulations of $10,000 \mu \mathrm{m}^{2}$ sensor area thermally isolated microhotplates using $10^{18}$ atoms $/ \mathrm{cm}^{3}$ nitrogen doped silicon carbide microheaters reached average temperatures of $350^{\circ} \mathrm{C}$ and $450^{\circ} \mathrm{C}$ with less than $10^{\circ} \mathrm{C}$ variation for coplanar and stacked configurations when $60 \mathrm{~mW}$ of power is distributed across four symmetric bar microheaters. 


\section{RECOMMENDATIONS}

To further this study, experimentally fabricated devices using silicon carbide microheaters would be invaluable to compare to the simulations in Chapter IV, in an attempt to prove the theoretical conclusions resulting from the simulations. Additional iterations of both simulated and fabricated devices would improve the power consumption of these devices, especially when considering geometries not shown in this work. Smaller isolated membranes may reduce power consumption, though the influence of the size of the microhotplate on the gas sensor sensitivity must be considered.

Mechanical effects were not considered in microhotplate design. Films of silicon dioxide formed using thermal oxidation have internal stress; silicon dioxide deposited by chemical vapor deposition may improve the stability of the microhotplate membranes. Also, fabricated devices using other insulating or membrane materials than silicon dioxide should prove to have relevant results. A layer of high thermal conductivity material can be used as a temperature distributor for the gas sensor.

As in reference [30], testing of the fabricated devices need not be restricted to one

method. Usage of different methods of temperature analysis, including melt crayon particles, thermocouples, and on-chip temperature sensors, may provide a more accurate temperature average than solely relying on infrared microscopy. 


\section{APPENDIX}

TEMPERATURE DATA 
TABLE A.1

\section{OBSERVED TEMPERATURE DATA FROM FABRICATED 308- $\Omega$ MICROHEATER ON $100 \mu \mathrm{m}$ UNRELEASED MICROHOTPLATE}

\begin{tabular}{|c|c|c|c|c|c|c|c|c|c|c|c|c|}
\hline \multicolumn{2}{|c|}{ Position } & \multicolumn{11}{|c|}{ Temperature $\left({ }^{\circ} \mathrm{C}\right)$ observed at: } \\
\hline Pixel\# & $\begin{array}{l}\text { Pos. } \\
(\mu \mathrm{m})\end{array}$ & $\begin{array}{l}5038 \\
\mathrm{~mW}\end{array}$ & $\begin{array}{l}3880 \\
\mathrm{~mW}\end{array}$ & $\begin{array}{l}2997 \\
\mathrm{~mW}\end{array}$ & $\begin{array}{l}2320 \\
\mathrm{~mW}\end{array}$ & $\begin{array}{l}1708 \\
\mathrm{~mW}\end{array}$ & $\begin{array}{l}1218 \\
\mathrm{~mW}\end{array}$ & $\begin{array}{l}820 \\
\mathrm{~mW}\end{array}$ & $\begin{array}{l}512 \\
\mathrm{~mW}\end{array}$ & $\begin{array}{l}281 \\
\mathrm{~mW}\end{array}$ & $\begin{array}{l}123 \\
\mathrm{~mW}\end{array}$ & $\begin{array}{l}30.4 \\
\mathrm{~mW}\end{array}$ \\
\hline 0 & 0 & 424.94 & 313.74 & 232.25 & 186.20 & 147.19 & 113.09 & 85.88 & 72.78 & 65.12 & 61.89 & 61.97 \\
\hline 1 & 2 & 465.69 & 329.23 & 233.82 & 188.76 & 148.08 & 113.09 & 87.09 & 73.15 & 64.46 & 61.50 & 61.11 \\
\hline 2 & 5 & 465.69 & 329.23 & 232.25 & 186.20 & 148.08 & 113.09 & 88.29 & 73.88 & 64.73 & 61.50 & 60.71 \\
\hline 3 & 7 & 436.58 & 329.23 & 235.39 & 182.36 & 144.52 & 114.31 & 89.09 & 74.61 & 66.30 & 62.37 & 60.05 \\
\hline 4 & 10 & 465.69 & 302.12 & 233.82 & 186.20 & 143.63 & 115.54 & 89.09 & 75.16 & 68.01 & 62.86 & 59.72 \\
\hline 5 & 12 & 471.51 & 309.86 & 230.68 & 186.20 & 144.52 & 114.31 & 89.89 & 74.61 & 67.35 & 62.66 & 60.45 \\
\hline 6 & 14 & 448.23 & 317.61 & 229.12 & 182.36 & 143.63 & 113.70 & 90.30 & 74.06 & 66.43 & 62.28 & 61.24 \\
\hline 7 & 17 & 448.23 & 333.10 & 229.12 & 182.36 & 143.63 & 112.47 & 90.30 & 74.43 & 65.78 & 61.69 & 61.64 \\
\hline 8 & 19 & 442.40 & 364.09 & 236.95 & 186.20 & 145.41 & 113.70 & 89.89 & 74.61 & 65.91 & 62.28 & 61.51 \\
\hline 9 & 21 & 442.40 & 364.09 & 241.66 & 188.76 & 148.97 & 115.54 & 89.09 & 74.43 & 66.57 & 62.37 & 60.78 \\
\hline 10 & 24 & 459.87 & 383.45 & 243.23 & 192.61 & 153.42 & 116.15 & 89.09 & 74.61 & 65.78 & 61.98 & 60.71 \\
\hline 11 & 26 & 483.15 & 395.07 & 241.66 & 193.89 & 155.20 & 116.76 & 89.49 & 74.80 & 64.86 & 61.59 & 60.91 \\
\hline 12 & 29 & 500.62 & 344.72 & 236.95 & 192.61 & 150.75 & 114.92 & 90.70 & 75.16 & 65.25 & 61.59 & 60.91 \\
\hline 13 & 31 & 471.51 & 340.85 & 235.39 & 188.76 & 144.52 & 114.92 & 91.10 & 75.53 & 67.09 & 62.86 & 60.18 \\
\hline 14 & 33 & 494.79 & 329.23 & 233.82 & 186.20 & 144.52 & 113.70 & 89.89 & 75.34 & 67.88 & 63.05 & 59.85 \\
\hline 15 & 36 & 494.79 & 336.97 & 230.68 & 182.36 & 142.74 & 111.86 & 88.69 & 74.25 & 67.09 & 62.66 & 60.58 \\
\hline 16 & 38 & 459.87 & 329.23 & 235.39 & 184.92 & 145.41 & 113.70 & 89.49 & 73.70 & 66.17 & 62.18 & 61.24 \\
\hline 17 & 40 & 483.15 & 356.34 & 240.09 & 187.48 & 148.97 & 115.54 & 91.10 & 74.25 & 65.78 & 61.98 & 62.24 \\
\hline 18 & 43 & 430.76 & 336.97 & 246.36 & 191.32 & 150.75 & 117.99 & 91.90 & 75.71 & 66.57 & 62.47 & 62.04 \\
\hline 19 & 45 & 459.87 & 344.72 & 249.50 & 195.17 & 153.42 & 119.21 & 91.50 & 75.71 & 66.83 & 62.96 & 61.24 \\
\hline 20 & 48 & 745.10 & 398.95 & 247.93 & 197.73 & 156.09 & 118.60 & 91.10 & 75.53 & 66.04 & 62.18 & 60.98 \\
\hline 21 & 50 & 745.10 & 379.58 & 246.36 & 195.17 & 154.31 & 117.37 & 90.70 & 75.16 & 65.38 & 61.89 & 61.18 \\
\hline 22 & 52 & 436.58 & 383.45 & 238.52 & 192.61 & 151.64 & 116.76 & 91.50 & 75.53 & 65.38 & 61.79 & 60.71 \\
\hline 23 & 55 & 419.12 & 344.72 & 235.39 & 186.20 & 146.30 & 115.54 & 91.50 & 75.89 & 67.09 & 62.47 & 59.72 \\
\hline 24 & 57 & 448.23 & 313.74 & 229.12 & 182.36 & 141.85 & 112.47 & 89.89 & 74.80 & 67.49 & 63.05 & 59.98 \\
\hline 25 & 59 & 459.87 & 313.74 & 221.28 & 175.96 & 138.29 & 108.80 & 87.89 & 73.52 & 66.57 & 62.37 & 60.58 \\
\hline 26 & 62 & 454.05 & 336.97 & 222.85 & 175.96 & 140.07 & 108.80 & 87.49 & 72.42 & 65.38 & 62.08 & 61.18 \\
\hline 27 & 64 & 465.69 & 352.47 & 227.55 & 178.52 & 142.74 & 110.64 & 88.29 & 72.97 & 64.86 & 61.69 & 62.10 \\
\hline 28 & 67 & 483.15 & 406.69 & 236.95 & 184.92 & 145.41 & 113.70 & 90.30 & 73.33 & 66.04 & 62.28 & 61.84 \\
\hline 29 & 69 & 494.79 & 437.68 & 244.79 & 191.32 & 150.75 & 117.37 & 91.10 & 74.25 & 66.17 & 62.66 & 60.71 \\
\hline 30 & 71 & 494.79 & 329.23 & 244.79 & 195.17 & 154.31 & 117.37 & 91.10 & 75.16 & 66.17 & 62.18 & 60.25 \\
\hline 31 & 74 & 477.33 & 344.72 & 240.09 & 193.89 & 153.42 & 116.15 & 91.10 & 75.16 & 65.25 & 61.89 & 60.84 \\
\hline 32 & 76 & 483.15 & 348.59 & 232.25 & 187.48 & 147.19 & 113.70 & 91.10 & 75.53 & 66.04 & 61.59 & 60.45 \\
\hline 33 & 78 & 459.87 & 329.23 & 225.98 & 179.80 & 140.96 & 113.09 & 89.89 & 75.89 & 67.22 & 62.76 & 59.98 \\
\hline 34 & 81 & 430.76 & 302.12 & 222.85 & 177.24 & 139.18 & 113.70 & 89.09 & 74.98 & 68.40 & 63.35 & 59.72 \\
\hline 35 & 83 & 442.40 & 317.61 & 216.57 & 173.40 & 136.51 & 111.86 & 89.09 & 74.61 & 67.09 & 62.66 & 61.11 \\
\hline 36 & 86 & 424.94 & 298.24 & 215.01 & 169.56 & 135.62 & 109.41 & 89.49 & 73.88 & 65.65 & 62.18 & 61.97 \\
\hline 37 & 88 & 424.94 & 302.12 & 216.57 & 172.12 & 136.51 & 109.41 & 89.49 & 74.06 & 65.25 & 61.89 & 62.37 \\
\hline 38 & 90 & 436.58 & 317.61 & 224.41 & 175.96 & 140.07 & 110.02 & 89.09 & 74.43 & 65.52 & 61.89 & 61.71 \\
\hline 39 & 93 & 454.05 & 336.97 & 236.95 & 183.64 & 146.30 & 113.70 & 89.89 & 74.80 & 66.30 & 62.37 & 60.51 \\
\hline 40 & 95 & 523.90 & 278.88 & 233.82 & 186.20 & 148.08 & 114.92 & 90.70 & 75.16 & 66.30 & 62.37 & 60.05 \\
\hline Avg & & 474.49 & 340.56 & 233.86 & 185.52 & 146.17 & 114.07 & 89.80 & 74.58 & 66.18 & 62.25 & 60.90 \\
\hline
\end{tabular}


TABLE A.2

\section{OBSERVED TEMPERATURE DATA FROM FABRICATED 411- $\Omega$ MICROHEATER ON $200 \mu \mathrm{m}$ UNRELEASED MICROHOTPLATE}

\begin{tabular}{|c|c|c|c|c|c|c|c|c|c|c|c|}
\hline \multicolumn{2}{|c|}{ Position } & \multicolumn{10}{|c|}{ Temperature $\left({ }^{\circ} \mathrm{C}\right)$ observed at: } \\
\hline Pixel\# & $\begin{array}{l}\text { Pos. } \\
(\mu \mathrm{m})\end{array}$ & $\begin{array}{l}5610 \\
\mathrm{~mW}\end{array}$ & $\begin{array}{l}4203 \\
\mathrm{~mW}\end{array}$ & $\begin{array}{l}3200 \\
\mathrm{~mW}\end{array}$ & $\begin{array}{l}2359 \\
\mathrm{~mW}\end{array}$ & $\begin{array}{l}1674 \\
\mathrm{~mW}\end{array}$ & $\begin{array}{l}1120 \\
\mathrm{~mW}\end{array}$ & $\begin{array}{l}692 \\
\mathrm{~mW}\end{array}$ & $\begin{array}{l}378 \\
\mathrm{~mW}\end{array}$ & $\begin{array}{l}165 \\
\mathrm{~mW}\end{array}$ & $\begin{array}{l}40.8 \\
\mathrm{~mW}\end{array}$ \\
\hline 0 & 0 & 272.47 & 196.34 & 146.81 & 129.07 & 98.23 & 82.73 & 72.62 & 65.17 & 61.62 & 60.07 \\
\hline 1 & 2 & 309.62 & 209.24 & 159.53 & 136.24 & 102.93 & 85.51 & 74.43 & 65.73 & 61.98 & 59.37 \\
\hline 2 & 4 & 322.01 & 223.76 & 172.26 & 142.39 & 108.29 & 88.69 & 75.64 & 66.56 & 62.69 & 58.81 \\
\hline 3 & 6 & 346.78 & 233.43 & 179.33 & 147.51 & 111.64 & 90.28 & 75.04 & 66.84 & 63.05 & 59.79 \\
\hline 4 & 8 & 346.78 & 244.72 & 182.16 & 149.56 & 114.99 & 91.47 & 74.83 & 66.84 & 62.57 & 60.35 \\
\hline 5 & 10 & 359.16 & 252.79 & 189.23 & 152.64 & 118.34 & 92.66 & 75.24 & 67.11 & 62.57 & 60.21 \\
\hline 6 & 12 & 388.06 & 252.79 & 194.89 & 151.61 & 119.01 & 92.27 & 75.64 & 67.39 & 62.45 & 60.21 \\
\hline 7 & 14 & 375.68 & 249.56 & 194.89 & 149.56 & 117.00 & 91.47 & 76.04 & 67.81 & 62.69 & 60.50 \\
\hline 8 & 16 & 342.65 & 241.50 & 186.40 & 148.54 & 113.65 & 90.68 & 75.24 & 66.84 & 62.57 & 60.78 \\
\hline 9 & 18 & 330.26 & 236.66 & 179.33 & 147.51 & 111.64 & 89.88 & 75.64 & 66.42 & 62.45 & 60.92 \\
\hline 10 & 20 & 334.39 & 236.66 & 183.57 & 147.51 & 111.64 & 89.49 & 75.64 & 66.42 & 62.33 & 60.35 \\
\hline 11 & 22 & 326.14 & 236.66 & 183.57 & 148.54 & 111.64 & 89.88 & 76.65 & 66.84 & 62.93 & 59.51 \\
\hline 12 & 24 & 371.55 & 238.27 & 187.82 & 147.51 & 113.65 & 91.07 & 76.65 & 66.97 & 63.17 & 59.23 \\
\hline 13 & 26 & 367.42 & 239.89 & 184.99 & 148.54 & 114.32 & 91.87 & 75.64 & 67.11 & 63.41 & 60.07 \\
\hline 14 & 28 & 371.55 & 246.34 & 186.40 & 154.69 & 117.67 & 92.66 & 75.24 & 66.84 & 63.17 & 61.20 \\
\hline 15 & 30 & 392.19 & 254.40 & 193.47 & 157.76 & 120.35 & 93.46 & 75.04 & 67.11 & 62.81 & 61.20 \\
\hline 16 & 32 & 363.29 & 256.01 & 199.13 & 154.69 & 120.35 & 92.66 & 75.64 & 67.53 & 62.81 & 60.50 \\
\hline 17 & 34 & 363.29 & 251.18 & 199.13 & 152.64 & 118.34 & 91.87 & 75.64 & 67.39 & 62.93 & 60.50 \\
\hline 18 & 36 & 342.65 & 243.11 & 189.23 & 150.59 & 115.66 & 91.47 & 75.64 & 66.97 & 62.33 & 61.06 \\
\hline 19 & 38 & 342.65 & 239.89 & 186.40 & 150.59 & 114.32 & 90.68 & 75.84 & 66.70 & 62.10 & 61.06 \\
\hline 20 & 4 & 330.26 & 241.50 & 186.40 & 148.54 & 113.65 & 91.07 & 76.24 & 65.87 & 62.22 & 60.07 \\
\hline 21 & 42 & 342.65 & 241.50 & 189.23 & 149.56 & 114.32 & 91.47 & 77.05 & 66.28 & 62.69 & 59.37 \\
\hline 22 & 44 & 396.32 & 244.72 & 193.47 & 150.59 & 115.66 & 92.66 & 76.24 & 67.11 & 63.05 & 58.95 \\
\hline 23 & 45 & 388.06 & 243.11 & 192.06 & 151.61 & 116.33 & 92.27 & 75.64 & 67.11 & 63.29 & 60.07 \\
\hline 24 & 47 & 379.80 & 247.95 & 187.82 & 153.66 & 119.01 & 93.06 & 75.24 & 67.11 & 62.69 & 60.92 \\
\hline 25 & 49 & 371.55 & 254.40 & 192.06 & 155.71 & 121.02 & 93.06 & 75.04 & 67.11 & 62.45 & 61.20 \\
\hline 26 & 51 & 375.68 & 256.01 & 199.13 & 155.71 & 121.70 & 93.46 & 75.64 & 67.39 & 62.45 & 60.92 \\
\hline 27 & 53 & 367.42 & 254.40 & 200.54 & 154.69 & 120.35 & 93.46 & 76.45 & 67.81 & 62.33 & 60.64 \\
\hline 28 & 55 & 392.19 & 247.95 & 190.64 & 151.61 & 117.67 & 92.66 & 76.24 & 66.97 & 62.69 & 60.92 \\
\hline 29 & 57 & 371.55 & 246.34 & 186.40 & 152.64 & 117.00 & 92.66 & 76.65 & 66.56 & 62.33 & 60.78 \\
\hline 30 & 59 & 367.42 & 247.95 & 190.64 & 150.59 & 117.00 & 92.66 & 77.05 & 66.70 & 62.57 & 60.21 \\
\hline 31 & 61 & 350.91 & 246.34 & 193.47 & 149.56 & 117.00 & 93.06 & 77.66 & 66.84 & 62.81 & 59.23 \\
\hline 32 & 63 & 359.16 & 246.34 & 197.71 & 148.54 & 117.00 & 91.87 & 76.45 & 67.25 & 63.05 & 59.37 \\
\hline 33 & 65 & 367.42 & 244.72 & 192.06 & 147.51 & 115.66 & 91.47 & 74.83 & 66.97 & 62.93 & 60.21 \\
\hline 34 & 67 & 367.42 & 244.72 & 187.82 & 150.59 & 117.00 & 91.07 & 74.23 & 66.56 & 62.81 & 61.34 \\
\hline 35 & 69 & 388.06 & 249.56 & 192.06 & 151.61 & 118.34 & 91.07 & 74.03 & 66.97 & 62.45 & 61.48 \\
\hline 36 & 71 & 375.68 & 251.18 & 197.71 & 150.59 & 119.01 & 91.47 & 74.83 & 67.11 & 61.74 & 60.50 \\
\hline 37 & 73 & 383.93 & 249.56 & 201.96 & 150.59 & 119.01 & 92.27 & 76.04 & 67.67 & 61.62 & 60.07 \\
\hline 38 & 75 & 367.42 & 244.72 & 194.89 & 150.59 & 117.00 & 92.27 & 76.24 & 67.25 & 61.98 & 60.64 \\
\hline 39 & 77 & 363.29 & 246.34 & 193.47 & 153.66 & 117.67 & 93.06 & 76.85 & 67.11 & 61.98 & 60.92 \\
\hline 40 & 79 & 359.16 & 247.95 & 196.30 & 154.69 & 118.34 & 93.06 & 77.25 & 66.97 & 62.93 & 59.93 \\
\hline 41 & 81 & 359.16 & 249.56 & 197.71 & 153.66 & 118.34 & 93.06 & 77.45 & 67.39 & 63.17 & 59.37 \\
\hline
\end{tabular}




\begin{tabular}{|c|c|c|c|c|c|c|c|c|c|c|c|}
\hline 42 & 83 & 371.55 & 247.95 & 199.13 & 150.59 & 117.67 & 92.27 & 76.24 & 67.53 & 63.29 & 59.93 \\
\hline 43 & 85 & 359.16 & 243.11 & 189.23 & 147.51 & 115.66 & 91.07 & 74.23 & 67.11 & 62.81 & 60.64 \\
\hline 44 & 87 & 429.34 & 243.11 & 186.40 & 147.51 & 115.66 & 90.28 & 73.62 & 66.42 & 62.22 & 61.20 \\
\hline 45 & 89 & 396.32 & 246.34 & 189.23 & 147.51 & 117.67 & 89.88 & 73.22 & 66.00 & 61.98 & 61.20 \\
\hline 46 & 91 & 437.60 & 256.01 & 197.71 & 155.71 & 120.35 & 94.25 & 76.85 & 67.39 & 62.81 & 60.50 \\
\hline 47 & 93 & 408.70 & 251.18 & 197.71 & 150.59 & 117.67 & 92.66 & 76.04 & 67.25 & 63.05 & 60.21 \\
\hline 48 & 95 & 367.42 & 241.50 & 186.40 & 149.56 & 112.98 & 90.28 & 75.04 & 66.14 & 62.33 & 61.06 \\
\hline 49 & 97 & 346.78 & 231.82 & 176.50 & 147.51 & 109.63 & 88.29 & 74.23 & 65.59 & 62.10 & 60.92 \\
\hline 50 & 99 & 326.14 & 230.21 & 176.50 & 144.44 & 107.62 & 87.10 & 74.43 & 65.45 & 62.10 & 60.35 \\
\hline 51 & 101 & 326.14 & 226.98 & 173.67 & 143.41 & 107.62 & 87.90 & 75.24 & 66.00 & 62.10 & 59.51 \\
\hline 52 & 103 & 342.65 & 231.82 & 180.75 & 143.41 & 109.63 & 89.49 & 76.04 & 66.70 & 62.81 & 59.23 \\
\hline 53 & 105 & 350.91 & 236.66 & 183.57 & 148.54 & 112.31 & 91.07 & 75.44 & 66.97 & 62.33 & 59.65 \\
\hline 54 & 107 & 375.68 & 244.72 & 184.99 & 153.66 & 117.00 & 93.06 & 75.84 & 67.39 & 62.93 & 60.64 \\
\hline 55 & 109 & 388.06 & 257.63 & 193.47 & 156.74 & 121.02 & 94.25 & 76.04 & 67.53 & 62.69 & 60.92 \\
\hline 56 & 111 & 416.96 & 260.85 & 200.54 & 157.76 & 121.70 & 94.25 & 76.45 & 67.25 & 62.93 & 60.35 \\
\hline 57 & 113 & 404.57 & 256.01 & 200.54 & 153.66 & 119.68 & 93.06 & 76.45 & 67.39 & 62.93 & 60.50 \\
\hline 58 & 115 & 350.91 & 244.72 & 190.64 & 149.56 & 114.99 & 91.07 & 75.64 & 66.97 & 62.57 & 60.92 \\
\hline 59 & 117 & 326.14 & 238.27 & 182.16 & 47.51 & 112.31 & 89.88 & 75.24 & 5.70 & 62.45 & 61.06 \\
\hline 60 & 119 & 346.78 & 235.05 & 75 & 7.51 & 64 & 89.49 & 75.64 & 28 & .33 & .07 \\
\hline 61 & 1 & 3 & 236.66 & 6 & .54 & 64 & .88 & 76.24 & .56 & .33 & .37 \\
\hline 62 & 123 & 355.03 & 239.89 & 187.82 & 148.54 & 113.65 & 91.47 & 76.65 & 67.25 & 63.05 & 59.23 \\
\hline 63 & 125 & 379.80 & 241.50 & 189.23 & 148.54 & 114.99 & 91.87 & 75.64 & 67.25 & 62.93 & 60.35 \\
\hline 64 & 127 & 392.19 & 247.95 & 187.82 & 154.69 & 118.34 & 93.06 & 75.84 & 67.25 & 62.81 & 60.78 \\
\hline 65 & 129 & 383.93 & 257.63 & 194.89 & 157.76 & 121.70 & 93.86 & 75.64 & 67.39 & 62.45 & 60.92 \\
\hline 66 & 131 & 375.68 & 260.85 & 200.54 & 151.61 & 122.37 & 93.86 & 76.24 & 67.39 & 62.45 & 60.50 \\
\hline 67 & 133 & 371.55 & 256.01 & 200.54 & 148.54 & 119.68 & 93.06 & 76.04 & 67.53 & 62.57 & 60.64 \\
\hline 68 & 135 & 379.80 & 249.56 & 194.89 & 151.61 & .33 & 91.47 & 75.84 & .84 & 2.69 & 0.92 \\
\hline 69 & 36 & 359.16 & 241.50 & 184.99 & 9.56 & 32 & 7 & 75.84 & 0 & .22 & 0.78 \\
\hline 70 & 8 & 363.29 & 243.11 & 86.40 & 9.56 & 32 & 91.07 & 76.45 & 4 & .33 & 9.93 \\
\hline 71 & 140 & 342.65 & 241.50 & 187.82 & 149.56 & 114.32 & 91.47 & 77.25 & 66.42 & 62.69 & 59.51 \\
\hline 72 & 142 & 346.78 & 246.34 & 193.47 & 150.59 & 115.66 & 92.27 & 76.65 & 67.53 & 63.05 & 59.23 \\
\hline 73 & 144 & 334.39 & 247.95 & 192.06 & 152.64 & 116.33 & 92.66 & 75.84 & 67.25 & 63.05 & 59.93 \\
\hline 74 & 146 & 375.68 & 256.01 & 187.82 & 153.66 & 119.01 & 93.46 & 75.24 & 67.25 & 62.10 & 61.20 \\
\hline 75 & 148 & 404.57 & 259.24 & 193.47 & 154.69 & 120.35 & 93.06 & 75.04 & 66.70 & 62.57 & 61.06 \\
\hline 76 & 150 & 408.70 & 249.56 & 199.13 & 153.66 & 121.02 & 92.66 & 75.64 & 67.11 & 62.69 & 60.64 \\
\hline 77 & 152 & 412.83 & 246.34 & 201.96 & 153.66 & 119.68 & 92.66 & 76.04 & 67.67 & 62.69 & 60.64 \\
\hline 78 & 4 & 383.93 & 246.34 & 194.89 & 5.71 & .00 & 92.27 & 76.04 & 1 & .45 & 0.21 \\
\hline 79 & 156 & 371.55 & 239.89 & 187.82 & 156.74 & 115.66 & 91.47 & 76.24 & 66.97 & 62.33 & 60.64 \\
\hline 80 & 158 & 375.68 & 247.95 & 189.23 & 148.54 & 114.99 & 91.07 & 76.65 & 66.56 & .45 & 60.21 \\
\hline 81 & 160 & 367.42 & 247.95 & 192.06 & 148.54 & 114.99 & 91.87 & 76.65 & 67.11 & 62.69 & 59.65 \\
\hline 82 & 162 & 363.29 & 247.95 & 194.89 & 151.61 & 116.33 & 92.27 & 76.85 & 67.53 & 62.93 & 58.95 \\
\hline 83 & 164 & 363.29 & 244.72 & 192.06 & 150.59 & 117.00 & 92.66 & 75.84 & 67.25 & 63.05 & 59.93 \\
\hline 84 & 166 & 355.03 & 247.95 & 187.82 & 153.66 & 119.68 & 93.46 & 75.44 & 66.84 & 62.81 & 60.64 \\
\hline 85 & 168 & 371.55 & 252.79 & 192.06 & 154.69 & 121.70 & 93.06 & 75.04 & 66.70 & 62.57 & 60.78 \\
\hline 86 & 170 & 379.80 & 252.79 & 200.54 & 154.69 & 119.68 & 91.87 & 74.83 & 66.97 & 62.45 & 61.20 \\
\hline 87 & 172 & 375.68 & 247.95 & 200.54 & 151.61 & 117.00 & 90.68 & 75.04 & 67.25 & 62.33 & 60.64 \\
\hline 88 & 174 & 379.80 & 239.89 & 189.23 & 146.49 & 114.99 & 90.28 & 75.44 & 66.84 & 62.45 & 60.92 \\
\hline 89 & 176 & 350.91 & 239.89 & 187.82 & 149.56 & 116.33 & 92.66 & 75.44 & 66.70 & 62.45 & 60.92 \\
\hline 90 & 178 & 350.91 & 246.34 & 193.47 & 153.66 & 118.34 & 93.86 & 77.45 & 67.25 & 62.45 & 60.50 \\
\hline 91 & 180 & 363.29 & 251.18 & 200.54 & 153.66 & 120.35 & 94.25 & 77.86 & 67.53 & 62.93 & 59.65 \\
\hline & & 365.71 & 244.88 & 189.89 & 150.59 & 116.11 & 91.67 & 75.76 & 66.93 & 62.60 & 60.35 \\
\hline
\end{tabular}


TABLE A.3

\section{OBSERVED TEMPERATURE DATA FROM FABRICATED $100 \mu \mathrm{m}$ THERMALLY ISOLATED MICROHOTPLATE}

\begin{tabular}{|c|c|c|c|c|c|c|c|c|c|c|c|}
\hline \multicolumn{2}{|c|}{ Position } & \multicolumn{10}{|c|}{ Temperature $\left({ }^{\circ} \mathrm{C}\right)$ observed at: } \\
\hline Pixel\# & $\begin{array}{l}\text { Pos. } \\
(\mu \mathrm{m})\end{array}$ & $\begin{array}{l}35.5 \\
\mathrm{~mW}\end{array}$ & $\begin{array}{l}27.0 \\
\mathrm{~mW}\end{array}$ & $\begin{array}{l}20.0 \\
\mathrm{~mW}\end{array}$ & $\begin{array}{l}14.8 \\
\mathrm{~mW}\end{array}$ & $\begin{array}{l}10.4 \\
\mathrm{~mW}\end{array}$ & $\begin{array}{l}6.90 \\
\mathrm{~mW}\end{array}$ & $\begin{array}{l}4.32 \\
\mathrm{~mW}\end{array}$ & $\begin{array}{l}2.38 \\
\mathrm{~mW}\end{array}$ & $\begin{array}{l}1.05 \\
\mathrm{~mW}\end{array}$ & $\begin{array}{l}0.261 \\
\mathrm{~mW}\end{array}$ \\
\hline 0 & 0 & 387.34 & 301.65 & 208.51 & 156.37 & 114.65 & 84.93 & 70.75 & 64.33 & 61.50 & 60.18 \\
\hline 1 & 3 & 459.34 & 362.81 & 248.59 & 187.84 & 139.00 & 102.47 & 80.46 & 68.31 & 62.92 & 60.58 \\
\hline 2 & 6 & 518.63 & 405.97 & 266.01 & 196.66 & 144.88 & 106.16 & 82.40 & 69.20 & 63.18 & 60.79 \\
\hline 3 & 10 & 518.63 & 402.38 & 257.30 & 192.88 & 143.20 & 105.70 & 81.67 & 69.49 & 63.43 & 60.58 \\
\hline 4 & 13 & 400.04 & 298.05 & 218.96 & 161.40 & 120.53 & 91.86 & 73.90 & 65.51 & 61.89 & 60.28 \\
\hline 5 & 16 & 349.22 & 272.87 & 192.82 & 142.52 & 106.25 & 82.16 & 69.29 & 63.45 & 61.05 & 60.18 \\
\hline 6 & 19 & 328.04 & 258.48 & 180.63 & 133.71 & 100.37 & 78.93 & 67.83 & 63.00 & 60.92 & 60.18 \\
\hline 7 & 22 & 319.57 & 251.29 & 175.40 & 129.93 & 97.01 & 76.63 & 66.62 & 62.56 & 60.79 & 59.97 \\
\hline 8 & 26 & 323.81 & 251.29 & 171.91 & 127.41 & 96.17 & 76.16 & 66.62 & 62.56 & 60.79 & 60.28 \\
\hline 9 & 29 & 315.34 & 244.10 & 171.91 & 127.41 & 95.33 & 75.70 & 66.38 & 62.56 & 60.92 & 60.07 \\
\hline 10 & 32 & 336.51 & 262.08 & 185.85 & 138.74 & 104.57 & 81.24 & 69.53 & 04.10 & 61.50 & 60.28 \\
\hline 11 & 35 & 357.69 & 280.07 & 198.05 & 150.07 & 114.65 & 89.09 & 74.39 & 66.25 & 62.40 & 60.48 \\
\hline 12 & 38 & 383.10 & 298.05 & 199.80 & 150.07 & 113.81 & 89.09 & 74.39 & 6.54 & 2.27 & 60.68 \\
\hline 13 & 42 & 387.34 & 301 & 20 & 152.59 & 115.49 & 01 & 74.63 & 4 & 3 & 60.68 \\
\hline 14 & 45 & 370.40 & 308.85 & 203.28 & 153.85 & 118.85 & 92.32 & 76.33 & 67.43 & 2.92 & 60.38 \\
\hline 15 & 48 & 400.04 & 312.44 & 199.80 & 152.59 & 117.17 & 91.86 & 76.09 & 67.58 & 62.66 & 60.68 \\
\hline 16 & 51 & 395.81 & 312.44 & 199.80 & 152.59 & 117.17 & 91.86 & 76.33 & 67.43 & 62.79 & 60.48 \\
\hline 17 & 54 & 353.45 & 283.67 & 192.82 & 147.56 & 113.81 & 90.01 & 75.12 & 67.13 & 62.98 & 60.28 \\
\hline 18 & 57 & 340.75 & 269.28 & 178.88 & 134.96 & 103.73 & 83.55 & 71.23 & 65.07 & 62.34 & 60.18 \\
\hline 19 & 61 & 315.34 & 247.69 & 164.94 & 123.63 & 95.33 & 77.09 & 67.59 & 63.45 & 61.50 & 60.18 \\
\hline 20 & 64 & 298.40 & 236.90 & 159.71 & 119.86 & 91.97 & 75.24 & 66.86 & 62.86 & 61.11 & 60.18 \\
\hline 21 & 67 & 294.16 & 233.30 & 157.97 & 118.60 & 91.97 & 75.24 & 67.11 & 63.00 & 61.24 & 60.07 \\
\hline 22 & 70 & 289.93 & 222.51 & 161.46 & 122.37 & 96.17 & 78.47 & 69.05 & 63.89 & 7 & 60.18 \\
\hline 23 & 73 & 298.40 & 240.50 & 163.20 & 126.15 & צנ.0. & & 70.75 & 05.07 & 61.63 & 60.48 \\
\hline 24 & 77 & 306.87 & 236.90 & 164.94 & 126.15 & 99.53 & 81.70 & 71.23 & 65.22 & 61.89 & 60.79 \\
\hline 25 & 80 & 319.57 & 262.08 & 161.46 & 123.63 & 98.69 & 80.78 & 70.99 & 65.22 & 61.95 & 60.38 \\
\hline 26 & 83 & 315.34 & 247.69 & 157.97 & 122.37 & 97.01 & 80.32 & 70.50 & 65.07 & 62.14 & 60.38 \\
\hline 27 & 86 & 289.93 & 229.71 & 152.74 & 118.60 & 94.49 & 78.47 & 69.53 & 64.63 & 62.21 & 60.07 \\
\hline 28 & 89 & 268.75 & 208.12 & 144.03 & 111.04 & 87.77 & 74.32 & 66.86 & 63.15 & 61.57 & 60.07 \\
\hline 29 & 93 & 243.34 & 193.73 & 138.80 & 104.75 & 83.57 & 71.09 & 65.16 & 62.27 & 60.99 & 60.07 \\
\hline 30 & 96 & 260.28 & 208.12 & 133.58 & 102.23 & 81.89 & 70.16 & 64.44 & 61.97 & 60.86 & 60.07 \\
\hline 31 & 99 & 234.87 & 186.54 & 131.83 & 100.97 & 81.89 & 70.63 & 64.92 & 62.27 & 60.73 & 60.18 \\
\hline 32 & 102 & 251.81 & 200.93 & 135.32 & 104.75 & 85.25 & 72.93 & 66.13 & 62.86 & 60.99 & 60.38 \\
\hline 33 & 105 & 247.57 & 197.33 & 137.06 & 107.27 & 87.77 & 74.78 & 67.59 & 63.74 & 61.18 & 60.48 \\
\hline 34 & 109 & 256.04 & 204.53 & 135.32 & 106.01 & 87.77 & 74.78 & 68.08 & 63.74 & 61.50 & 60.48 \\
\hline 35 & 112 & 256.04 & 204.53 & 131.83 & 103.49 & 86.93 & 74.78 & 67.83 & 63.74 & 61.89 & 60.28 \\
\hline 36 & 115 & 251.81 & 186.54 & 128.35 & 102.23 & 85.25 & 73.39 & 67.35 & 63.89 & 61.69 & 60.07 \\
\hline 37 & 118 & 230.63 & 182.94 & 121.38 & 97.19 & 81.89 & 72.01 & 66.62 & 63.30 & 61.69 & 60.18 \\
\hline 38 & 121 & 205.22 & 164.96 & 110.92 & 88.38 & 76.01 & 68.32 & 64.19 & 62.12 & 61.18 & 59.97 \\
\hline 39 & 125 & 179.81 & 139.77 & 102.21 & 82.08 & 71.81 & 66.01 & 62.74 & 61.38 & 60.53 & 59.87 \\
\hline
\end{tabular}




\begin{tabular}{|l|l|l|l|r|r|r|r|r|r|r|l|}
\hline 40 & 128 & 179.81 & 139.77 & 96.98 & 79.57 & 70.13 & 65.09 & 62.49 & 61.24 & 60.47 & 60.07 \\
\hline 41 & 131 & 171.34 & 136.18 & 98.72 & 82.08 & 71.81 & 66.01 & 63.22 & 61.53 & 60.47 & 60.07 \\
\hline 42 & 134 & 179.81 & 143.37 & 103.95 & 87.12 & 75.17 & 68.32 & 64.19 & 62.12 & 60.60 & 60.18 \\
\hline 43 & 137 & 200.98 & 157.76 & 110.92 & 90.90 & 77.69 & 70.16 & 65.16 & 62.71 & 60.86 & 60.58 \\
\hline 44 & 141 & 200.98 & 157.76 & 110.92 & 90.90 & 78.53 & 70.63 & 65.65 & 62.86 & 61.18 & 60.38 \\
\hline 45 & 144 & 209.45 & 168.55 & 110.92 & 90.90 & 77.69 & 70.16 & 65.65 & 63.00 & 61.37 & 60.18 \\
\hline 46 & 147 & 200.98 & 161.36 & 107.44 & 88.38 & 76.85 & 69.70 & 65.41 & 62.71 & 61.31 & 60.07 \\
\hline 47 & 150 & 175.57 & 143.37 & 102.21 & 85.86 & 75.17 & 68.32 & 64.68 & 62.42 & 61.44 & 59.87 \\
\hline 48 & 153 & 175.57 & 139.77 & 96.98 & 80.83 & 70.97 & 66.01 & 63.22 & 61.68 & 61.11 & 59.87 \\
\hline 49 & 156 & 162.87 & 125.39 & 91.75 & 77.05 & 68.45 & 64.16 & 62.49 & 61.24 & 60.53 & 59.97 \\
\hline 50 & 160 & 154.40 & 121.79 & 90.01 & 75.79 & 68.45 & 64.16 & 62.25 & 61.09 & 60.53 & 60.07 \\
\hline 51 & 163 & 154.40 & 125.39 & 90.01 & 75.79 & 68.45 & 64.16 & 62.25 & 61.09 & 60.47 & 60.07 \\
\hline 52 & 166 & 145.93 & 118.19 & 88.27 & 75.79 & 68.45 & 64.16 & 62.25 & 61.09 & 60.41 & 59.97 \\
\hline 53 & 169 & 150.16 & 118.19 & 88.27 & 74.53 & 67.61 & 63.70 & 62.01 & 60.94 & 60.41 & 59.97 \\
\hline 54 & 172 & 158.63 & 125.39 & 88.27 & 74.53 & 67.61 & 63.70 & 61.77 & 60.94 & 60.53 & 59.97 \\
\hline 55 & 176 & 154.40 & 128.98 & 90.01 & 75.79 & 67.61 & 63.70 & 62.49 & 60.94 & 60.92 & 59.97 \\
\hline 56 & 179 & 154.40 & 125.39 & 93.50 & 77.05 & 69.29 & 65.09 & 63.22 & 61.24 & 61.11 & 59.97 \\
\hline 57 & 182 & 167.10 & 136.18 & 93.50 & 78.31 & 70.97 & 66.01 & 63.95 & 61.68 & 60.99 & 60.07 \\
\hline 58 & 185 & 162.87 & 132.58 & 91.75 & 78.31 & 70.97 & 66.01 & 63.46 & 61.68 & 60.79 & 60.07 \\
\hline 59 & 188 & 162.87 & 125.39 & 90.01 & 78.31 & 70.13 & 65.09 & 62.98 & 61.68 & 60.92 & 59.97 \\
\hline 60 & 192 & 145.93 & 121.79 & 88.27 & 74.53 & 67.61 & 63.70 & 62.25 & 61.24 & 60.53 & 59.87 \\
\hline 61 & 195 & 145.93 & 114.59 & 84.78 & 72.01 & 65.93 & 62.78 & 61.52 & 60.65 & 60.34 & 59.97 \\
\hline 62 & 198 & 150.16 & 118.19 & 84.78 & 70.75 & 65.93 & 62.78 & 61.28 & 60.65 & 60.21 & 59.97 \\
\hline
\end{tabular}

TABLE A.4

TEMPERATURE DATA FROM $100 \mu \mathrm{m}$ UNRELEASED MICROHOTPLATE SIMULATION

\begin{tabular}{|r|l|l|l|l|l|l|l|l|l|l|l|}
\hline & \multicolumn{10}{|c|}{ Temperature $\left({ }^{\circ} \mathrm{C}\right)$ observed at: } \\
\hline $\begin{array}{l}\text { Pos. } \\
(\mu \mathrm{m})\end{array}$ & $\begin{array}{l}5038 \\
\mathrm{~mW}\end{array}$ & $\begin{array}{l}3880 \\
\mathrm{~mW}\end{array}$ & $\begin{array}{l}2997 \\
\mathrm{~mW}\end{array}$ & $\begin{array}{l}2320 \\
\mathrm{~mW}\end{array}$ & $\begin{array}{l}1708 \\
\mathrm{~mW}\end{array}$ & $\begin{array}{l}1218 \\
\mathrm{~mW}\end{array}$ & $\begin{array}{l}820 \\
\mathrm{~mW}\end{array}$ & $\begin{array}{l}512 \\
\mathrm{~mW}\end{array}$ & $\begin{array}{l}281 \\
\mathrm{~mW}\end{array}$ & $\begin{array}{l}123 \\
\mathrm{~mW}\end{array}$ & $\begin{array}{l}30.4 \\
\mathrm{~mW}\end{array}$ \\
\hline 0 & 130.42 & 114.23 & 101.84 & 92.33 & 83.77 & 76.90 & 71.34 & 67.02 & 63.79 & 61.57 & 60.28 \\
\hline 2 & 143.48 & 124.29 & 109.61 & 98.34 & 88.19 & 80.06 & 73.47 & 68.35 & 64.52 & 61.89 & 60.35 \\
\hline 4 & 150.83 & 129.95 & 113.99 & 101.72 & 90.68 & 81.84 & 74.66 & 69.10 & 64.93 & 62.07 & 60.40 \\
\hline 6 & 157.42 & 135.03 & 117.91 & 104.76 & 92.92 & 83.43 & 75.74 & 69.77 & 65.30 & 62.23 & 60.44 \\
\hline 8 & 164.38 & 140.40 & 122.05 & 107.96 & 95.28 & 85.11 & 76.87 & 70.47 & 65.69 & 62.40 & 60.48 \\
\hline 10 & 169.85 & 144.61 & 125.31 & 110.48 & 97.13 & 86.43 & 77.76 & 71.03 & 65.99 & 62.53 & 60.51 \\
\hline 12 & 173.10 & 147.11 & 127.24 & 111.97 & 98.23 & 87.22 & 78.29 & 71.36 & 66.17 & 62.61 & 60.53 \\
\hline 14 & 178.95 & 151.62 & 130.72 & 114.66 & 100.21 & 88.63 & 79.24 & 71.95 & 66.50 & 62.75 & 60.57 \\
\hline 16 & 182.66 & 154.48 & 132.93 & 116.37 & 101.47 & 89.53 & 79.85 & 72.33 & 66.71 & 62.84 & 60.59 \\
\hline 18 & 180.26 & 152.63 & 131.50 & 115.27 & 100.66 & 88.95 & 79.46 & 72.09 & 66.57 & 62.78 & 60.58 \\
\hline 20 & 170.55 & 145.15 & 125.72 & 110.80 & 97.37 & 86.60 & 77.88 & 71.10 & 66.03 & 62.55 & 60.52 \\
\hline 22 & 166.40 & 141.95 & 123.25 & 108.89 & 95.96 & 85.60 & 77.20 & 70.68 & 65.80 & 62.44 & 60.49 \\
\hline 24 & 174.22 & 147.98 & 127.91 & 112.49 & 98.61 & 87.49 & 78.47 & 71.47 & 66.24 & 62.64 & 60.54 \\
\hline 26 & 179.40 & 151.96 & 130.99 & 114.87 & 100.37 & 88.74 & 79.32 & 72.00 & 66.53 & 62.76 & 60.57 \\
\hline 28 & 177.82 & 150.74 & 130.04 & 114.14 & 99.83 & 88.36 & 79.06 & 71.84 & 66.44 & 62.72 & 60.56 \\
\hline 30 & 170.75 & 145.30 & 125.84 & 110.89 & 97.44 & 86.65 & 77.91 & 71.12 & 66.04 & 62.55 & 60.52 \\
\hline 32 & 168.86 & 143.84 & 124.71 & 110.02 & 96.79 & 86.19 & 77.60 & 70.93 & 65.94 & 62.50 & 60.51 \\
\hline
\end{tabular}




\begin{tabular}{|c|c|c|c|c|c|c|c|c|c|c|c|}
\hline 34 & 171.30 & 145.72 & 126.17 & 111.14 & 97.62 & 86.78 & 78.00 & 71.18 & 66.07 & 62.56 & 60.52 \\
\hline 36 & 171.60 & 145.95 & 126.34 & 111.28 & 97.72 & 86.85 & 78.05 & 71.21 & 66.09 & 62.57 & 60.52 \\
\hline 38 & 169.65 & 144.45 & 125.18 & 110.39 & 97.06 & 86.38 & 77.73 & 71.01 & 65.98 & 62.52 & 60.51 \\
\hline 40 & 167.04 & 142.44 & 123.63 & 109.19 & 96.18 & 85.75 & 77.30 & 70.74 & 65.84 & 62.46 & 60.50 \\
\hline 42 & 166.99 & 142.41 & 123.60 & 109.16 & 96.16 & 85.74 & 77.30 & 70.74 & 65.83 & 62.46 & 60.50 \\
\hline 44 & 166.88 & 142.32 & 123.54 & 109.11 & 96.12 & 85.71 & 77.28 & 70.73 & 65.83 & 62.46 & 60.50 \\
\hline 46 & 163.03 & 139.35 & 121.25 & 107.34 & 94.82 & 84.78 & 76.65 & 70.34 & 65.61 & 62.36 & 60.47 \\
\hline 49 & 157.83 & 135.34 & 118.15 & 104.94 & 93.06 & 83.53 & 75.80 & 69.81 & 65.32 & 62.24 & 60.44 \\
\hline 51 & 152.56 & 131.28 & 115.02 & 102.52 & 91.27 & 82.25 & 74.95 & 69.27 & 65.03 & 62.11 & 60.41 \\
\hline 53 & 147.28 & 127.21 & 111.87 & 100.09 & 89.48 & 80.98 & 74.09 & 68.74 & 64.73 & 61.98 & 60.38 \\
\hline 55 & 142.43 & 123.48 & 108.99 & 97.86 & 87.84 & 79.81 & 73.30 & 68.24 & 64.46 & 61.86 & 60.35 \\
\hline 57 & 140.76 & 122.20 & 108.00 & 97.09 & 87.27 & 79.40 & 73.03 & 68.07 & 64.37 & 61.82 & 60.34 \\
\hline 59 & 139.88 & 121.52 & 107.47 & 96.69 & 86.97 & 79.19 & 72.88 & 67.98 & 64.32 & 61.80 & 60.33 \\
\hline 61 & 139.10 & 120.92 & 107.01 & 96.33 & 86.71 & 79.00 & 72.76 & 67.90 & 64.28 & 61.78 & 60.33 \\
\hline 63 & 138.58 & 120.51 & 106.70 & 96.09 & 86.53 & 78.87 & 72.67 & 67.85 & 64.25 & 61.77 & 60.32 \\
\hline 65 & 138.34 & 120.33 & 106.55 & 95.97 & 86.45 & 78.82 & 72.63 & 67.83 & 64.23 & 61.76 & 60.32 \\
\hline 67 & 139.98 & 121.59 & 107.53 & 96.73 & 87.01 & 79.21 & 72.90 & 67.99 & 64.32 & 61.80 & 60.33 \\
\hline 69 & 140.71 & 122.16 & 107.97 & 97.07 & 87.26 & 79.39 & 73.02 & 68.07 & 64.37 & 61.82 & 60.34 \\
\hline 71 & 140.43 & 121.94 & 107.80 & 96.94 & 87.16 & 79.32 & 72.97 & 68.04 & 64.35 & 61.81 & 60.34 \\
\hline 73 & 140.31 & 121.85 & 107.73 & 96.88 & 87.12 & 79.29 & 72.95 & 68.03 & 64.34 & 61.81 & 60.34 \\
\hline 75 & 143.12 & 124.01 & 109.40 & 98.18 & 88.07 & 79.97 & 73.41 & 68.31 & 64.50 & 61.88 & 60.35 \\
\hline 77 & 141.11 & 122.46 & 108.20 & 97.25 & 87.39 & 79.49 & 73.08 & 68.11 & 64.39 & 61.83 & 60.34 \\
\hline 79 & 141.82 & 123.01 & 108.63 & 97.58 & 87.63 & 79.66 & 73.20 & 68.18 & 64.43 & 61.85 & 60.34 \\
\hline 81 & 143.25 & 124.11 & 109.48 & 98.24 & 88.12 & 80.00 & 73.43 & 68.33 & 64.51 & 61.88 & 60.35 \\
\hline 83 & 143.54 & 124.33 & 109.65 & 98.37 & 88.21 & 80.07 & 73.48 & 68.36 & 64.52 & 61.89 & 60.35 \\
\hline 85 & 145.21 & 125.62 & 110.64 & 99.14 & 88.78 & 80.48 & 73.75 & 68.53 & 64.62 & 61.93 & 60.36 \\
\hline 87 & 149.34 & 128.80 & 113.10 & 101.04 & 90.18 & 81.47 & 74.42 & 68.94 & 64.85 & 62.03 & 60.39 \\
\hline 89 & 153.46 & 131.98 & 115.55 & 102.93 & 91.57 & 82.47 & 75.09 & 69.36 & 65.08 & 62.13 & 60.41 \\
\hline 91 & 154.36 & 132.67 & 116.08 & 103.35 & 91.88 & 82.69 & 75.24 & 69.45 & 65.13 & 62.15 & 60.42 \\
\hline 93 & 151.52 & 130.48 & 114.40 & 102.04 & 90.92 & 82.00 & 74.78 & 69.17 & 64.97 & 62.08 & 60.40 \\
\hline 95 & 147.94 & 127.72 & 112.27 & 100.39 & 89.70 & 81.14 & 74.19 & 68.80 & 64.77 & 62.00 & 60.38 \\
\hline Avg & 156.01 & 133.95 & 117.07 & 104.11 & 92.44 & 83.09 & 75.51 & 69.62 & 65.22 & 62.19 & 60.43 \\
\hline
\end{tabular}

TABLE A.5

\section{TEMPERATURE DATA FROM $200 \mu \mathrm{m}$ UNRELEASED MICROHOTPLATE SIMULATION}

\begin{tabular}{|r|l|l|l|l|l|l|l|l|l|l|}
\hline & \multicolumn{10}{|c|}{ Temperature $\left({ }^{\circ} \mathrm{C}\right)$ observed at: } \\
\hline $\begin{array}{l}\text { Pos. } \\
(\mu \mathrm{m})\end{array}$ & $\begin{array}{l}5610 \\
\mathrm{~mW}\end{array}$ & $\begin{array}{l}4203 \\
\mathrm{~mW}\end{array}$ & $\begin{array}{l}3200 \\
\mathrm{~mW}\end{array}$ & $\begin{array}{l}2359 \\
\mathrm{~mW}\end{array}$ & $\begin{array}{l}1674 \\
\mathrm{~mW}\end{array}$ & $\begin{array}{l}1120 \\
\mathrm{~mW}\end{array}$ & $\begin{array}{l}692 \\
\mathrm{~mW}\end{array}$ & $\begin{array}{l}378 \\
\mathrm{~mW}\end{array}$ & $\begin{array}{l}165 \\
\mathrm{~mW}\end{array}$ & $\begin{array}{l}40.8 \\
\mathrm{~mW}\end{array}$ \\
\hline 0 & 182.80 & 151.78 & 130.00 & 111.49 & 96.48 & 84.38 & 75.01 & 68.13 & 63.47 & 60.74 \\
\hline 2 & 203.39 & 167.18 & 141.74 & 120.14 & 102.62 & 88.49 & 77.54 & 69.52 & 64.08 & 60.89 \\
\hline 4 & 213.14 & 174.46 & 147.30 & 124.23 & 105.52 & 90.43 & 78.74 & 70.17 & 64.36 & 60.96 \\
\hline 6 & 219.43 & 179.16 & 150.89 & 126.87 & 107.39 & 91.68 & 79.52 & 70.60 & 64.55 & 61.01 \\
\hline 8 & 223.53 & 182.23 & 153.23 & 128.59 & 108.61 & 92.50 & 80.02 & 70.87 & 64.67 & 61.04 \\
\hline 10 & 217.36 & 177.62 & 149.71 & 126.01 & 106.78 & 91.27 & 79.27 & 70.46 & 64.49 & 61.00 \\
\hline 12 & 212.40 & 173.91 & 146.88 & 123.92 & 105.30 & 90.28 & 78.65 & 70.12 & 64.34 & 60.96 \\
\hline 14 & 205.94 & 169.08 & 143.20 & 121.21 & 103.38 & 88.99 & 77.86 & 69.69 & 64.15 & 60.91 \\
\hline
\end{tabular}




\begin{tabular}{|c|c|c|c|c|c|c|c|c|c|c|}
\hline 16 & 203.28 & 167.09 & 141.68 & 120.09 & 102.58 & 88.46 & 77.53 & 69.51 & 64.07 & 60.89 \\
\hline 18 & 203.01 & 166.89 & 141.53 & 119.98 & 102.50 & 88.41 & 77.50 & 69.49 & 64.06 & 60.89 \\
\hline 20 & 180.73 & 150.23 & 128.82 & 110.62 & 95.86 & 83.96 & 74.75 & 67.99 & 63.41 & 60.73 \\
\hline 22 & 179.91 & 149.62 & 128.35 & 110.28 & 95.62 & 83.80 & 74.65 & 67.93 & 63.38 & 60.72 \\
\hline 24 & 181.88 & 151.09 & 129.47 & 111.10 & 96.21 & 84.19 & 74.89 & 68.07 & 63.44 & 60.74 \\
\hline 26 & 187.03 & 154.95 & 132.41 & 113.27 & 97.74 & 85.22 & 75.53 & 68.41 & 63.59 & 60.77 \\
\hline 28 & 197.07 & 162.45 & 138.13 & 117.48 & 100.73 & 87.22 & 76.76 & 69.09 & 63.89 & 60.85 \\
\hline 30 & 200.29 & 164.86 & 139.97 & 118.83 & 101.69 & 87.87 & 77.16 & 69.31 & 63.98 & 60.87 \\
\hline 32 & 206.70 & 169.65 & 143.63 & 121.53 & 103.60 & 89.15 & 77.95 & 69.74 & 64.17 & 60.92 \\
\hline 34 & 211.82 & 173.47 & 146.55 & 123.68 & 105.13 & 90.17 & 78.58 & 70.08 & 64.32 & 60.96 \\
\hline 36 & 219.25 & 179.03 & 150.79 & 126.80 & 107.34 & 91.65 & 79.50 & 70.58 & 4.54 & 61.01 \\
\hline 38 & 233.89 & 189.98 & 159.14 & 132.95 & 111.70 & 94.57 & 81.30 & 71.57 & 64.97 & 61.12 \\
\hline 40 & 228.62 & 186.04 & 156.13 & 130.73 & 110.13 & 93.52 & 80.65 & 71.21 & 64.82 & 61.08 \\
\hline 42 & 222.10 & 181.16 & 152.42 & 127.99 & 108.19 & 92.22 & 79.85 & 70.78 & 64.63 & 61.03 \\
\hline 44 & 214.42 & 175.42 & 148.04 & 124.77 & 105.90 & 90.69 & 78.90 & 70.26 & 4.40 & 60.97 \\
\hline 45 & 206.97 & 169.85 & 143.79 & 121.64 & 103.68 & 89.20 & 77.98 & 69.76 & 4.18 & 60.92 \\
\hline 47 & 202.59 & 166.58 & 141.29 & 119.80 & 102.38 & 88.33 & 77.44 & 69.46 & 64.05 & 60.89 \\
\hline 49 & 197.69 & 162.91 & 138.49 & 117.74 & 100.92 & 87.35 & 76.84 & 69.13 & 63.91 & 60.85 \\
\hline 51 & 199.18 & 164.02 & 139.34 & 118.37 & 101.36 & 87.64 & 77.02 & 69.23 & 63.95 & 60.86 \\
\hline 53 & 202.93 & 166.83 & 141.48 & 119.94 & 102.48 & 88.39 & 77.49 & 69.48 & 64.06 & 60.89 \\
\hline 55 & 206.91 & 169.80 & 143.75 & 121.61 & 103.66 & 89.19 & 77.98 & 69.75 & 4.18 & \\
\hline 57 & 212.80 & 174.21 & 147.11 & 124.09 & 105.42 & .36 & 78.70 & 70.15 & .35 & .96 \\
\hline 59 & 205.32 & 168.61 & 142.84 & 120.95 & 103.19 & 88.87 & 77.78 & 69.65 & 64.13 & 60.91 \\
\hline 61 & 202.62 & 166.59 & 141.30 & 119.81 & 102.38 & 33 & 77.45 & 69.46 & 4.05 & 60.89 \\
\hline 63 & 201.29 & 165.60 & 140.54 & 119.25 & 101.99 & 88.06 & 77.28 & 69.37 & 64.01 & 60.88 \\
\hline 65 & 199.46 & 164.23 & 139.50 & 118.49 & 101.44 & 87.70 & 77.06 & 69.25 & 63.96 & 60.87 \\
\hline 67 & 209.68 & 171.87 & 145.33 & 122.78 & 104.49 & 89.74 & 78.32 & 69.94 & 1.26 & 94 \\
\hline 69 & 207.17 & 170.00 & 143.90 & 121.72 & 103.74 & 89.24 & 78.01 & 69.77 & 64.19 & 60.92 \\
\hline 71 & 203.84 & 167.51 & 142.00 & 120.32 & .75 & 88.57 & 77.60 & 69.55 & 64.09 & 60.90 \\
\hline 73 & 200.81 & 165.25 & 140.27 & 119.05 & 101.85 & 37.97 & 77.22 & 69.34 & 64.00 & 60.88 \\
\hline 75 & 198.05 & 163.18 & 138.70 & 117.90 & 101.03 & 87.42 & 76.88 & 69.16 & 63.92 & 60.86 \\
\hline 77 & 205.63 & 168.84 & 143.02 & 121.08 & 3.28 & 88.93 & 77.82 & 69.67 & 4.14 & 91 \\
\hline 79 & 206.80 & 169.72 & 143.69 & 121.57 & 103.63 & 89.16 & 77.96 & 69.75 & 4.18 & 60.92 \\
\hline 81 & 213.09 & 174.42 & 147.27 & 124.21 & 105.50 & 90.42 & 78.74 & 70.17 & 64.36 & 60.96 \\
\hline 83 & 225.80 & 183.93 & 154.52 & 129.55 & 109.29 & 92.95 & 80.30 & 71.02 & 64.73 & 61.06 \\
\hline 85 & 240.86 & 195.19 & 163.12 & 135.87 & 113.78 & 95.96 & 82.16 & 72.04 & 65.18 & 61.17 \\
\hline 87 & 238.51 & 193.43 & 61.78 & 134.89 & 113.08 & 95.49 & 1.87 & 71.88 & 5.11 & 15 \\
\hline 89 & 227.31 & 185.06 & .39 & 130.18 & 09.74 & 26 & 80.49 & 13 & .78 & .07 \\
\hline 91 & 216.35 & 176.87 & 149.14 & 125.58 & 106.48 & 91.07 & 79.14 & 70.39 & 64.46 & 60.99 \\
\hline 93 & 207.19 & 170.02 & 143.91 & 121.73 & 103.75 & 89.24 & 78.01 & 69.77 & 64.19 & 60.92 \\
\hline 95 & 193.96 & 160.12 & 136.36 & 116.18 & 99.81 & 86.60 & 76.38 & 68.88 & 63.80 & 60.83 \\
\hline 97 & 198 & 88 & 7 & 17 & 101.22 & 5 & 7 & 20 & 63.94 & 86 \\
\hline 99 & 80 & 160.75 & 36.84 & .53 & 100.06 & 86.77 & 76.48 & 68.94 & 63.82 & 83 \\
\hline 101 & 190.76 & 157.73 & 134.53 & 114.83 & 98.85 & 85.96 & 75.99 & 68.67 & 63.70 & 60.80 \\
\hline 103 & 191.26 & 158.10 & 134.82 & 115.04 & 99.00 & 86.06 & 76.05 & 68.70 & 63.72 & 60.81 \\
\hline 105 & 191.31 & 158.14 & 134.85 & 115.06 & 99.02 & 86.07 & 76.05 & 68.70 & 63.72 & 60.81 \\
\hline 107 & 196.33 & 161.89 & 137.71 & 117.17 & 100.51 & 87.08 & 76.67 & 69.04 & 63.87 & 60.84 \\
\hline 109 & 190.73 & 157.71 & 134.52 & 114.82 & .84 & 85.96 & 75.98 & 68.66 & 63.70 & 60.80 \\
\hline 111 & 187.34 & 155.17 & 132.59 & 113.40 & 97.83 & 85.28 & 75.56 & 68.43 & 63.60 & 60.78 \\
\hline 113 & 196.26 & 161.84 & 137.67 & 117.14 & 100.49 & 87.06 & 76.66 & 69.04 & 63.87 & 60.84 \\
\hline 115 & 201.51 & 165.77 & 140.67 & 119.35 & 102.05 & 88.11 & 77.31 & 69.39 & 64.02 & 60.88 \\
\hline
\end{tabular}




\begin{tabular}{|c|c|c|c|c|c|c|c|c|c|c|}
\hline 117 & 224.20 & 182.73 & 153.62 & 128.88 & 108.82 & 92.64 & 80.11 & 70.92 & 64.69 & 61.05 \\
\hline 119 & 235.97 & 191.53 & 160.33 & 133.82 & 112.32 & 94.98 & 81.56 & 71.71 & 65.03 & 61.13 \\
\hline 121 & 236.19 & 191.69 & 160.45 & 133.91 & 112.39 & 95.03 & 81.58 & 71.72 & 65.04 & 61.13 \\
\hline 123 & 231.99 & 188.56 & 158.06 & 132.15 & 111.14 & 94.19 & 81.07 & 71.44 & 64.92 & 61.10 \\
\hline 125 & 229.96 & 187.04 & 156.90 & 131.29 & 110.53 & 93.78 & 80.82 & 71.30 & 64.86 & 61.09 \\
\hline 127 & 222.09 & 181.15 & 152.41 & 127.99 & 108.19 & 92.21 & 79.85 & 70.77 & 64.63 & 61.03 \\
\hline 129 & 209.79 & 171.96 & 145.39 & 122.83 & 104.52 & 89.76 & 78.33 & 69.95 & 64.26 & 60.94 \\
\hline 131 & 198.38 & 163.43 & 138.88 & 118.03 & 101.12 & 87.49 & 76.93 & 69.18 & 63.93 & 60.86 \\
\hline 133 & 196.08 & 161.71 & 137.57 & 117.07 & 100.44 & 87.03 & 76.64 & 69.02 & 63.86 & 60.84 \\
\hline 135 & 193.82 & 160.02 & 136.28 & 116.12 & 99.76 & 86.58 & 76.36 & 68.87 & 63.79 & 60.82 \\
\hline 136 & 198.82 & 163.76 & 139.13 & 118.22 & 101.25 & 87.57 & 76.98 & 69.21 & 63.94 & 60.86 \\
\hline 138 & 200.58 & 165.08 & 140.14 & 118.96 & 101.78 & 87.92 & 77.20 & 69.33 & 63.99 & 60.87 \\
\hline 140 & 195.52 & 161.29 & 137.25 & 116.83 & 100.27 & 86.92 & 76.57 & 68.99 & 63.84 & 60.84 \\
\hline 142 & 187.22 & 155.08 & 132.52 & 113.34 & 97.80 & 85.26 & 75.55 & 68.43 & 63.60 & 60.78 \\
\hline 144 & 193.16 & 159.52 & 135.90 & 115.84 & 99.57 & 86.44 & 76.28 & 68.83 & 63.77 & 60.82 \\
\hline 146 & 200.78 & 165.22 & 140.25 & 119.04 & 101.84 & 87.96 & 77.22 & 69.34 & 64.00 & 60.87 \\
\hline 148 & 202.91 & 166.82 & 141.47 & 119.94 & 102.47 & 88.39 & 77.48 & 69.48 & 64.06 & 60.89 \\
\hline 150 & 197.41 & 162.70 & 138.33 & 117.62 & 100.83 & 87.29 & 76.81 & 69.11 & 63.90 & 60.85 \\
\hline 152 & 193.44 & 159.73 & 136.06 & 115.96 & 99.65 & 86.50 & 76.32 & 68.85 & 63.78 & 60.82 \\
\hline 154 & 193.35 & 159.67 & 136.02 & 115.92 & 99.62 & 86.48 & 76.31 & 68.84 & 63.78 & 60.82 \\
\hline 156 & 196.29 & 161.86 & 137.69 & 117.15 & 100.50 & 87.07 & 76.67 & 69.04 & 63.87 & 60.84 \\
\hline 158 & 198.37 & 163.42 & 138.88 & 118.03 & 101.12 & 87.48 & 76.92 & 69.18 & 63.93 & 60.86 \\
\hline 160 & 197.31 & 162.62 & 138.27 & 117.58 & 100.80 & 87.27 & 76.79 & 69.11 & 63.90 & 60.85 \\
\hline 162 & 201.63 & 165.86 & 140.74 & 119.40 & 102.09 & 88.13 & 77.33 & 69.40 & 4.02 & 60.88 \\
\hline 164 & 206.49 & 169.49 & 143.51 & 121.44 & 103.54 & 89.10 & 77.92 & 69.72 & 64.17 & 60.92 \\
\hline 166 & 214.19 & 175.25 & 147.90 & 124.67 & 105.83 & 90.64 & 78.87 & 70.24 & 64.39 & 60.97 \\
\hline 168 & 222.18 & 181.22 & 152.46 & 128.03 & 108.21 & 92.23 & 79.86 & 70.78 & 64.63 & 61.03 \\
\hline 170 & 226.86 & 184.72 & 155.13 & 129.99 & 109.61 & 93.17 & 80.44 & 71.10 & 64.77 & 61.06 \\
\hline 172 & 236.59 & 192.00 & 160.68 & 134.08 & 112.51 & 95.11 & 81.63 & 71.75 & 65.05 & 61.14 \\
\hline 174 & 246.62 & 199.50 & 166.40 & 138.29 & 115.49 & 97.11 & 82.87 & 72.43 & 65.35 & 61.21 \\
\hline 176 & 254.23 & 205.18 & 170.74 & 141.49 & 117.76 & 98.63 & 83.81 & 72.94 & 65.57 & 61.26 \\
\hline 178 & 258.84 & 208.63 & 173.37 & 143.42 & 119.13 & 99.55 & 84.38 & 73.25 & 65.71 & 61.30 \\
\hline 180 & 261.49 & 210.62 & 174.89 & 144.54 & 119.93 & 100.08 & 84.70 & 73.43 & 65.79 & 61.32 \\
\hline Avg & 208.51 & 171.00 & 144.66 & 122.29 & 104.14 & 89.51 & 78.17 & 69.86 & 64.23 & 60.93 \\
\hline
\end{tabular}

TABLE A.6

\section{TEMPERATURE DATA FROM $100 \mu \mathrm{m}$ THERMALLY ISOLATED MICROHOTPLATE SIMULATION}

\begin{tabular}{|r|l|l|l|l|l|l|l|l|l|l|}
\hline & \multicolumn{10}{|c|}{ Temperature $\left({ }^{\circ} \mathrm{C}\right)$ observed at: } \\
\hline $\begin{array}{l}\text { Pos. } \\
(\mu \mathrm{m})\end{array}$ & $\begin{array}{l}35.5 \\
\mathrm{~mW}\end{array}$ & $\begin{array}{l}27.0 \\
\mathrm{~mW}\end{array}$ & $\begin{array}{l}20.0 \\
\mathrm{~mW}\end{array}$ & $\begin{array}{l}14.8 \\
\mathrm{~mW}\end{array}$ & $\begin{array}{l}10.4 \\
\mathrm{~mW}\end{array}$ & $\begin{array}{l}6.90 \\
\mathrm{~mW}\end{array}$ & $\begin{array}{l}4.32 \\
\mathrm{~mW}\end{array}$ & $\begin{array}{l}2.38 \\
\mathrm{~mW}\end{array}$ & $\begin{array}{l}1.05 \\
\mathrm{~mW}\end{array}$ & $\begin{array}{l}0.261 \\
\mathrm{~mW}\end{array}$ \\
\hline 0 & 1184.35 & 915.28 & 693.81 & 530.06 & 390.98 & 278.71 & 196.62 & 135.49 & 93.12 & 68.11 \\
\hline 3 & 1219.20 & 941.79 & 713.46 & 544.63 & 401.25 & 285.49 & 200.86 & 137.83 & 94.15 & 68.37 \\
\hline 6 & 1252.09 & 966.81 & 732.00 & 558.38 & 410.93 & 291.89 & 204.86 & 140.04 & 95.12 & 68.61 \\
\hline 10 & 1281.23 & 988.97 & 748.43 & 570.57 & 419.51 & 297.56 & 208.40 & 142.00 & 95.98 & 68.83 \\
\hline 13 & 1308.78 & 1009.93 & 763.96 & 582.09 & 427.62 & 302.92 & 211.75 & 143.86 & 96.80 & 69.03 \\
\hline 16 & 1325.42 & 1022.59 & 773.34 & 589.05 & 432.52 & 306.16 & 213.78 & 144.98 & 97.29 & 69.15 \\
\hline
\end{tabular}




\begin{tabular}{|c|c|c|c|c|c|c|c|c|c|c|}
\hline 19 & 1340.63 & 1034.16 & 781.92 & 595.41 & 437.00 & 309.12 & 215.63 & 146.00 & 97.74 & 69.26 \\
\hline 22 & 1350.29 & 1041.51 & 787.36 & 599.45 & 439.85 & 311.00 & 216.80 & 146.65 & 98.03 & 69.33 \\
\hline 25 & 1351.34 & 1042.30 & 787.95 & 599.88 & 440.15 & 311.21 & 216.93 & 146.72 & 98.06 & 69.34 \\
\hline 29 & 1351.98 & 1042.79 & 788.32 & 600.15 & 440.34 & 311.33 & 217.01 & 146.76 & 98.08 & 69.35 \\
\hline 32 & 1311.67 & 1012.13 & 765.59 & 583.30 & 428.47 & 303.49 & 212.11 & 144.05 & 96.88 & 69.05 \\
\hline 35 & 1299.25 & 1002.68 & 758.59 & 578.10 & 424.82 & 301.07 & 210.60 & 143.22 & 96.52 & 68.96 \\
\hline 38 & 1286.83 & 993.23 & 751.59 & 572.91 & 421.16 & 298.65 & 209.08 & 142.38 & 96.15 & 68.87 \\
\hline 41 & 1274.41 & 983.78 & 744.58 & 567.72 & 417.50 & 296.24 & 207.57 & 141.54 & 95.78 & 68.78 \\
\hline 45 & 1262.06 & 974.39 & 737.62 & 562.55 & 413.86 & 293.83 & 206.07 & 140.71 & 95.42 & 68.69 \\
\hline 48 & 1242.63 & 959.61 & 726.67 & 554.43 & 408.14 & 290.05 & 203.71 & 139.41 & 94.84 & 68.54 \\
\hline 51 & 1221.68 & 943.67 & 714.85 & 545.67 & 401.97 & 285.97 & 201.16 & 138.00 & 94.22 & 68.39 \\
\hline 54 & 1202.19 & 928.85 & 703.87 & 537.52 & 396.24 & 282.18 & 198.79 & 136.69 & 93.64 & 68.25 \\
\hline 57 & 1181.44 & 913.06 & 692.17 & 528.84 & 390.12 & 278.14 & 196.27 & 135.29 & 93.03 & 68.09 \\
\hline 61 & 1163.51 & 899.42 & 682.06 & 521.34 & 384.85 & 274.65 & 194.09 & 134.09 & 92.50 & 67.96 \\
\hline 64 & 1143.53 & 884.22 & 670.80 & 512.99 & 378.96 & 270.76 & 191.66 & 132.74 & 91.91 & 67.81 \\
\hline 67 & 1125.58 & 870.57 & 660.68 & 505.48 & 373.68 & 267.27 & 189.47 & 131.53 & 91.38 & 67.68 \\
\hline 70 & 1108.32 & 857.43 & 650.95 & 498.27 & 368.59 & 263.91 & 187.37 & 130.37 & 90.87 & 67.56 \\
\hline 73 & 1090.16 & 843.62 & 640.71 & 490.67 & 363.25 & 260.38 & 185.16 & 129.15 & 90.33 & 67.42 \\
\hline 77 & 1073.46 & 830.92 & 631.29 & 483.69 & 358.33 & 257.13 & 183.13 & 128.03 & 89.84 & 67.30 \\
\hline 80 & 1054.20 & 816.27 & 620.44 & 475.64 & 352.66 & 253.38 & 180.79 & 126.73 & 89.27 & 67.16 \\
\hline 83 & 1036.29 & 802.64 & 610.34 & 468.15 & 347.38 & 249.89 & 178.61 & 125.53 & 88.74 & 67.03 \\
\hline 86 & 1017.72 & 788.51 & 599.87 & 460.38 & .91 & 46.28 & 35 & .28 & 8.19 & 89 \\
\hline 89 & 999.78 & 774.87 & 589.76 & 452.88 & 336.63 & 242.79 & 174.17 & 123.07 & 87.66 & 66.76 \\
\hline 93 & 983.88 & 762.78 & 580.79 & 446.23 & 331.95 & 239.69 & 172.24 & 122.00 & 87.19 & 66.64 \\
\hline 96 & 972.85 & 754.38 & 574.58 & 441.62 & 328.70 & 237.55 & 170.90 & 121.26 & 86.86 & 66.56 \\
\hline 99 & 962.52 & 746.52 & 568.75 & 437.30 & 325.66 & 235.53 & 169.64 & 120.57 & 86.55 & 66.48 \\
\hline 102 & 950.76 & 737.58 & 562.12 & 432.38 & 322.20 & 233.25 & 168.21 & 119.78 & 86.21 & 66.40 \\
\hline 105 & 941.07 & 730.21 & 556.66 & 428.33 & 319.34 & 231.36 & 167.03 & 119.12 & 85.92 & 66.33 \\
\hline 109 & 928.83 & 720.90 & 549.76 & 423.22 & 315.74 & 228.98 & 165.54 & 118.30 & 85.56 & 66.24 \\
\hline 112 & 920.34 & 44 & 544.97 & 419.66 & 313.24 & 227.32 & 164.51 & 7.73 & 85.31 & 66.17 \\
\hline 115 & 908.30 & 705.28 & 538.18 & 414.63 & 69 & 224.98 & 04 & 2 & 84.95 & 66.09 \\
\hline 118 & 899.13 & 698.30 & 533.01 & 410.79 & 306.99 & 223.20 & 161.93 & 116.30 & 84.68 & 66.02 \\
\hline 121 & 889.36 & 690.87 & 527.50 & 406.71 & 304.12 & 221.29 & 160.74 & 115.65 & 84.39 & 65.95 \\
\hline 124 & 878.56 & 682.66 & 521.42 & 402.19 & 300.94 & 219.19 & 159.43 & 114.92 & 84.07 & 65.87 \\
\hline 128 & 869.71 & 675.93 & 516.43 & 398.49 & 298.33 & 217.47 & 158.35 & 114.32 & 83.81 & 65.80 \\
\hline 131 & 862.56 & 670.48 & 512.40 & 395.50 & 296.22 & 216.08 & 157.48 & 113.84 & 83.60 & 65.75 \\
\hline 134 & 855.12 & 664.82 & 508.20 & 392.39 & 294.03 & 214.63 & 156.58 & 113.34 & 83.38 & 65.70 \\
\hline 137 & 847.47 & 659.00 & 503.89 & 389.19 & 291.78 & 213.14 & 155.65 & 112.83 & 83.15 & 65.64 \\
\hline 140 & 839.22 & 652.73 & 499.24 & 385.74 & 289.35 & 211.54 & 154.64 & 112.27 & 82.91 & 65.58 \\
\hline 144 & 830.41 & 646.02 & 494.27 & 382.06 & 286.76 & 209.82 & 153.57 & 111.68 & 82.65 & 65.51 \\
\hline 147 & 823.76 & 640.97 & 490.52 & 379.28 & 284.80 & 208.53 & 152.76 & 111.23 & 82.45 & 65.46 \\
\hline 150 & 817.11 & 635.91 & 486.77 & 376.50 & 282.84 & 207.23 & 151.95 & 110.79 & 82.25 & 65.42 \\
\hline 153 & 809.97 & 630.48 & 482.75 & 373.51 & 280.74 & 205.84 & 151.08 & 110.31 & 82.04 & 65.36 \\
\hline 156 & 802.68 & 624.93 & 478.64 & 370.46 & 278.59 & 204.42 & 150.20 & 109.81 & 81.83 & 65.31 \\
\hline 160 & 795.32 & 619.33 & 474.49 & 367.39 & 276.42 & 202.99 & 149.30 & 109.32 & 81.61 & 65.26 \\
\hline 163 & 788.71 & 614.30 & 470.76 & 364.62 & 274.48 & 201.71 & 148.50 & 108.88 & 81.41 & 65.21 \\
\hline 166 & 780.90 & 608.36 & 466.35 & 361.35 & 272.18 & 200.18 & 147.55 & 108.35 & 81.18 & 65.15 \\
\hline 169 & 773.08 & 602.41 & 461.95 & 358.09 & 269.88 & 198.66 & 146.60 & 107.82 & 80.95 & 65.09 \\
\hline 172 & 763.36 & 595.02 & 456.47 & 354.02 & 267.01 & 196.77 & 145.42 & 107.17 & 80.66 & 65.02 \\
\hline 176 & 754.06 & 587.94 & 451.22 & 350.13 & 264.27 & 194.96 & 144.28 & 106.54 & 80.39 & 64.95 \\
\hline 179 & 743.69 & 580.06 & 445.38 & 345.80 & 261.22 & 192.94 & 143.02 & 105.85 & 80.08 & 64.88 \\
\hline
\end{tabular}




\begin{tabular}{|l|l|l|l|l|l|l|l|l|l|l|}
182 & 732.21 & 571.33 & 438.91 & 341.00 & 257.84 & 190.71 & 141.63 & 105.08 & 79.74 & 64.79 \\
\hline 185 & 720.23 & 562.21 & 432.15 & 335.99 & 254.31 & 188.38 & 140.17 & 104.27 & 79.39 & 64.70 \\
\hline 188 & 707.96 & 552.88 & 425.24 & 330.86 & 250.70 & 185.99 & 138.68 & 103.44 & 79.02 & 64.61 \\
\hline 191 & 695.59 & 543.47 & 418.26 & 325.69 & 247.06 & 183.58 & 137.17 & 102.61 & 78.66 & 64.52 \\
\hline 195 & 682.99 & 533.88 & 411.16 & 320.42 & 243.35 & 181.13 & 135.64 & 101.76 & 78.28 & 64.43 \\
\hline 198 & 678.42 & 530.40 & 408.58 & 318.50 & 242.00 & 180.24 & 135.08 & 101.46 & 78.15 & 64.40 \\
\hline
\end{tabular}

TABLE A.7

\section{TEMPERATURE DATA FROM $100 \mu \mathrm{m}$ THERMALLY ISOLATED MICROHOTPLATE SIMULATION WITH CONVECTION}

\begin{tabular}{|c|c|c|c|c|c|c|c|c|c|c|}
\hline \multirow[b]{2}{*}{$\begin{array}{l}\text { Pos. } \\
(\mu \mathrm{m})\end{array}$} & \multicolumn{10}{|c|}{ Temperature $\left({ }^{\circ} \mathrm{C}\right)$ observed at: } \\
\hline & $\begin{array}{l}35.5 \\
\mathrm{~mW}\end{array}$ & $\begin{array}{l}27.0 \\
\mathrm{~mW}\end{array}$ & $\begin{array}{l}20.0 \\
\mathrm{~mW}\end{array}$ & $\begin{array}{l}14.8 \\
\mathrm{~mW}\end{array}$ & $\begin{array}{l}10.4 \\
\mathrm{~mW}\end{array}$ & $\begin{array}{l}6.90 \\
\mathrm{~mW}\end{array}$ & $\begin{array}{l}4.32 \\
\mathrm{~mW}\end{array}$ & $\begin{array}{l}2.38 \\
\mathrm{~mW}\end{array}$ & $\begin{array}{l}1.05 \\
\mathrm{~mW}\end{array}$ & $\begin{array}{l}0.261 \\
\mathrm{~mW}\end{array}$ \\
\hline 0 & 495.18 & 385.18 & 294.64 & 227.70 & 170.84 & 124.94 & 91.39 & 66.39 & 49.07 & 38.85 \\
\hline 3 & 506.37 & 393.60 & 300.80 & 232.17 & 173.89 & 126.84 & 92.44 & 66.82 & 49.06 & 38.58 \\
\hline 6 & 518.79 & 402.94 & 307.58 & 237.07 & 177.19 & 128.85 & 93.50 & 67.18 & 48.94 & 38.17 \\
\hline 10 & 530.59 & 411.77 & 313.98 & 241.67 & 180.25 & 130.67 & 94.42 & 67.43 & 48.72 & 37.68 \\
\hline 13 & 539.16 & 418.16 & 318.57 & 244.94 & 182.40 & 131.91 & 95.00 & 67.51 & 48.45 & 37.21 \\
\hline 16 & 542.72 & 420.78 & 320.41 & 246.19 & 183.16 & 132.28 & 95.08 & 67.37 & 48.17 & 36.84 \\
\hline 19 & 545.11 & 422.51 & 321.60 & 246.98 & 183.61 & 132.46 & 95.05 & 67.20 & 47.89 & 36.50 \\
\hline 22 & 544.97 & 422.32 & 321.38 & 246.73 & 183.34 & 132.16 & 94.75 & 66.88 & 47.57 & 36.17 \\
\hline 25 & 539.43 & 418.05 & 318.15 & 244.28 & 181.54 & 130.89 & 93.86 & 66.28 & 47.17 & 35.89 \\
\hline 29 & 525.21 & 407.21 & 310.10 & 238.29 & 177.31 & 128.07 & 92.08 & 65.27 & 46.69 & 35.73 \\
\hline 32 & 516.03 & 400.19 & 304.85 & 234.36 & 174.49 & 126.15 & 90.82 & 64.50 & 46.26 & 35.49 \\
\hline 35 & 506.85 & 393.17 & 299.61 & 230.43 & 171.67 & 124.23 & 89.55 & 63.73 & 45.83 & 35.26 \\
\hline 38 & 490.25 & 380.54 & 290.24 & 223.47 & 166.77 & 120.99 & 87.52 & 62.59 & 45.32 & 35.12 \\
\hline 41 & 469.70 & 364.92 & 278.68 & 214.91 & 160.76 & 117.04 & 85.07 & 61.27 & 44.77 & 35.03 \\
\hline 45 & 457.10 & 355.34 & 271.59 & 209.66 & 157.06 & 114.60 & 83.55 & 60.43 & 44.41 & 34.96 \\
\hline 48 & 442.40 & 344.16 & 263.31 & 203.53 & 152.75 & 111.76 & 81.79 & 59.47 & 44.01 & 34.88 \\
\hline 51 & 426.90 & 332.37 & 254.57 & 197.05 & 148.19 & 108.75 & 79.91 & 58.44 & 43.55 & 34.77 \\
\hline 54 & 411.56 & 320.71 & 245.94 & 190.64 & 143.69 & 105.78 & 78.06 & 57.42 & 43.11 & 34.67 \\
\hline 57 & 397.13 & 309.73 & 237.81 & 184.62 & 139.45 & 102.99 & 76.33 & 56.47 & 42.71 & 34.59 \\
\hline 60 & 383.88 & 299.66 & 230.34 & 179.09 & 135.56 & 100.42 & 74.73 & 55.60 & 42.34 & 34.51 \\
\hline 64 & 370.63 & 289.59 & 222.89 & 173.57 & 131.68 & 97.87 & 73.15 & 54.74 & 41.98 & 34.45 \\
\hline 67 & 358.71 & 280.54 & 216.19 & 168.62 & 128.21 & 95.59 & 71.74 & 53.98 & 41.67 & 34.40 \\
\hline 70 & 346.78 & 271.46 & 209.47 & 163.64 & 124.71 & 93.28 & 70.30 & 53.19 & 41.33 & 34.33 \\
\hline 73 & 335.03 & 262.53 & 202.86 & 158.74 & 121.27 & 91.02 & 68.90 & 52.43 & 41.02 & 34.28 \\
\hline 76 & 323.55 & 253.80 & 196.39 & 153.94 & 117.89 & 88.79 & 67.51 & 51.66 & 40.68 & 34.20 \\
\hline 80 & 311.29 & 244.48 & 189.49 & 148.83 & 114.30 & 86.42 & 66.04 & 50.86 & 40.34 & 34.13 \\
\hline 83 & 300.42 & 236.22 & 183.39 & 144.32 & 111.14 & 84.35 & 64.77 & 50.18 & 40.07 & 34.11 \\
\hline 86 & 289.28 & 227.76 & 177.12 & 139.68 & 107.88 & 82.21 & 63.45 & 49.47 & 39.78 & 34.07 \\
\hline 89 & 277.96 & 219.15 & 170.75 & 134.96 & 104.56 & 80.03 & 62.09 & 48.72 & 39.46 & 34.00 \\
\hline 92 & 267.60 & 211.27 & 164.90 & 130.62 & 101.50 & 78.00 & 60.81 & 48.01 & 39.14 & 33.91 \\
\hline 96 & 260.51 & 205.87 & 160.90 & 127.65 & 99.41 & 76.61 & 59.94 & 47.52 & 38.92 & 33.84 \\
\hline 99 & 253.56 & 200.57 & 156.97 & 124.72 & 97.34 & 75.23 & 59.07 & 47.03 & 38.69 & 33.76 \\
\hline 102 & 246.36 & 195.10 & 152.91 & 121.71 & 95.21 & 73.82 & 58.19 & 46.54 & 38.47 & 33.70 \\
\hline 105 & 239.38 & 189.77 & 148.95 & 118.76 & 93.13 & 72.43 & 57.30 & 46.03 & 38.22 & 33.61 \\
\hline
\end{tabular}




\begin{tabular}{|c|c|c|c|c|c|c|c|c|c|c|}
\hline 108 & 231.57 & 183.83 & 144.54 & 115.48 & 90.81 & 70.89 & 56.32 & 45.48 & 37.96 & 33.52 \\
\hline 112 & 225.65 & 179.31 & 141.18 & 112.98 & 89.03 & 69.70 & 55.56 & 45.04 & 37.74 & 33.43 \\
\hline 115 & 218.12 & 173.58 & 136.93 & 109.82 & 86.80 & 68.22 & 54.63 & 44.51 & 37.49 & 33.36 \\
\hline 118 & 211.33 & 168.40 & 133.07 & 106.95 & 84.76 & 66.85 & 53.75 & 44.00 & 37.24 & 33.25 \\
\hline 121 & 205.63 & 164.07 & 129.85 & 104.56 & 83.07 & 65.73 & 53.05 & 43.60 & 37.06 & 33.20 \\
\hline 124 & 199.39 & 159.32 & 126.33 & 101.95 & 81.23 & 64.51 & 52.29 & 43.18 & 36.87 & 33.15 \\
\hline 128 & 193.72 & 154.99 & 123.12 & 99.55 & 79.54 & 63.38 & 51.56 & 42.77 & 36.67 & 33.07 \\
\hline 131 & 188.51 & 151.01 & 120.15 & 97.33 & 77.95 & 62.31 & 50.87 & 42.35 & 36.44 & 32.96 \\
\hline 134 & 183.85 & 147.46 & 117.50 & 95.35 & 76.54 & 61.36 & 50.25 & 41.98 & 36.25 & 32.87 \\
\hline 137 & 179.10 & 143.83 & 114.80 & 93.34 & 75.11 & 60.40 & 49.64 & 41.62 & 36.07 & 32.79 \\
\hline 140 & 174.30 & 140.17 & 112.09 & 91.32 & 73.69 & 59.45 & 49.04 & 41.29 & 35.91 & 32.74 \\
\hline 144 & 169.35 & 136.40 & 109.29 & 89.24 & 72.22 & 58.47 & 48.42 & 40.94 & 35.75 & 32.69 \\
\hline 147 & 165.25 & 133.27 & 106.95 & 87.49 & 70.97 & 57.62 & 47.87 & 40.61 & 35.57 & 32.60 \\
\hline 150 & 161.22 & 130.20 & 104.67 & 85.79 & 69.75 & 56.81 & 47.34 & 40.30 & 35.41 & 32.53 \\
\hline 153 & 157.42 & 127.30 & 102.51 & 84.18 & 68.61 & 56.05 & 46.86 & 40.01 & 35.27 & 32.47 \\
\hline 156 & 153.62 & 124.41 & 100.36 & 82.58 & 67.48 & 55.29 & 46.38 & 39.74 & 35.14 & 32.42 \\
\hline 159 & 150.22 & 121.82 & 98.44 & 81.15 & 66.47 & 54.62 & 45.95 & 39.50 & 35.03 & 32.39 \\
\hline 163 & 146.76 & 119.18 & 96.48 & 79.70 & 65.44 & 53.93 & 45.52 & 39.25 & 34.91 & 32.35 \\
\hline 166 & 143.11 & 116.41 & 94.43 & 78.18 & 64.37 & 53.23 & 45.08 & 39.02 & 34.81 & 32.33 \\
\hline 169 & 139.46 & 113.63 & 92.37 & 76.65 & 63.30 & 52.53 & 44.65 & 38.78 & 34.71 & 32.31 \\
\hline 172 & 135.99 & 111.00 & 90.44 & 75.23 & 62.31 & 51.89 & 44.26 & 38.59 & 34.65 & 32.33 \\
\hline 175 & 132.27 & 108.19 & 88.36 & 73.70 & 61.26 & 51.21 & 43.86 & 38.38 & 34.59 & 32.35 \\
\hline 179 & 128.86 & 105.61 & 86.47 & 72.32 & 60.31 & 50.60 & 43.51 & 38.23 & 34.57 & 32.41 \\
\hline 182 & 125.50 & 103.08 & 84.63 & 70.99 & 59.41 & 50.05 & 43.21 & 38.12 & 34.59 & 32.51 \\
\hline 185 & 122.36 & 100.73 & 82.92 & 69.75 & 58.57 & 49.54 & 42.94 & 38.03 & 34.62 & 32.61 \\
\hline 188 & 119.25 & 98.40 & 81.24 & 68.55 & 57.77 & 49.07 & 42.70 & 37.97 & 34.68 & 32.74 \\
\hline 191 & 116.33 & 96.22 & 79.67 & 67.44 & 57.04 & 48.65 & 42.52 & 37.95 & 34.79 & 32.92 \\
\hline 195 & 113.63 & 94.21 & 78.24 & 66.42 & 56.39 & 48.29 & 42.36 & 37.95 & 34.90 & 33.09 \\
\hline 198 & 112.96 & 93.72 & 77.89 & 66.18 & 56.24 & 48.21 & 42.34 & 37.97 & 34.94 & 33.15 \\
\hline
\end{tabular}

TABLE A.8

TEMPERATURE DATA FROM FINELY MESHED $100 \mu \mathrm{m}$ UNRELEASED MICROHOTPLATE SIMULATION

\begin{tabular}{|r|l|l|l|l|l|l|l|l|l|l|l|}
\hline & \multicolumn{10}{|c|}{ Temperature $\left({ }^{\circ} \mathrm{C}\right)$ observed at: } \\
\hline $\begin{array}{l}\text { Pos. } \\
(\mu \mathrm{m})\end{array}$ & $\begin{array}{l}5038 \\
\mathrm{~mW}\end{array}$ & $\begin{array}{l}3880 \\
\mathrm{~mW}\end{array}$ & $\begin{array}{l}2997 \\
\mathrm{~mW}\end{array}$ & $\begin{array}{l}2320 \\
\mathrm{~mW}\end{array}$ & $\begin{array}{l}1708 \\
\mathrm{~mW}\end{array}$ & $\begin{array}{l}1218 \\
\mathrm{~mW}\end{array}$ & $\begin{array}{l}820 \\
\mathrm{~mW}\end{array}$ & $\begin{array}{l}512 \\
\mathrm{~mW}\end{array}$ & $\begin{array}{l}281 \\
\mathrm{~mW}\end{array}$ & $\begin{array}{l}123 \\
\mathrm{~mW}\end{array}$ & $\begin{array}{l}30.4 \\
\mathrm{~mW}\end{array}$ \\
\hline 0 & 430.14 & 345.64 & 280.81 & 230.56 & 185.52 & 149.49 & 120.10 & 97.50 & 80.54 & 68.90 & 62.08 \\
\hline 2 & 444.35 & 356.60 & 289.29 & 237.11 & 190.34 & 152.93 & 122.41 & 98.95 & 81.33 & 69.25 & 62.17 \\
\hline 4 & 478.11 & 382.66 & 309.44 & 252.67 & 201.80 & 161.11 & 127.91 & 102.38 & 83.22 & 70.08 & 62.37 \\
\hline 6 & 523.61 & 417.77 & 336.59 & 273.65 & 217.24 & 172.12 & 135.31 & 107.01 & 85.76 & 71.19 & 62.65 \\
\hline 8 & 550.22 & 438.32 & 352.47 & 285.92 & 226.27 & 178.57 & 139.64 & 109.71 & 87.25 & 71.84 & 62.81 \\
\hline 10 & 517.89 & 413.36 & 333.18 & 271.01 & 215.30 & 170.74 & 134.38 & 106.42 & 85.44 & 71.05 & 62.61 \\
\hline 12 & 483.11 & 386.52 & 312.42 & 254.98 & 203.50 & 162.32 & 128.72 & 102.89 & 83.50 & 70.20 & 62.40 \\
\hline 14 & 519.58 & 414.67 & 334.19 & 271.79 & 215.88 & 171.15 & 134.66 & 106.60 & 85.54 & 71.09 & 62.62 \\
\hline 16 & 561.00 & 446.63 & 358.90 & 290.89 & 229.93 & 181.18 & 141.40 & 110.81 & 87.85 & 72.10 & 62.87 \\
\hline 18 & 566.53 & 450.91 & 362.21 & 293.44 & 231.81 & 182.52 & 142.30 & 111.37 & 88.16 & 72.24 & 62.91 \\
\hline 20 & 519.39 & 414.52 & 334.07 & 271.70 & 215.81 & 171.10 & 134.62 & 106.58 & 85.53 & 71.09 & 62.62 \\
\hline
\end{tabular}




\begin{tabular}{|c|c|c|c|c|c|c|c|c|c|c|c|}
\hline 22 & 482.35 & 385.93 & 311.97 & 254.63 & 203.24 & 162.14 & 128.60 & 102.81 & 83.46 & 70.18 & 62.40 \\
\hline 24 & 512.82 & 409.45 & 330.15 & 268.68 & 213.58 & 169.51 & 133.56 & 105.91 & 85.16 & 70.93 & 62.58 \\
\hline 26 & 554.25 & 441.43 & 354.88 & 287.78 & 227.64 & 179.54 & 140.30 & 110.12 & 87.48 & 71.94 & 62.83 \\
\hline 28 & 564.68 & 449.47 & 361.10 & 292.58 & 231.18 & 182.07 & 141.99 & 111.18 & 88.06 & 72.19 & 62.90 \\
\hline 30 & 525.18 & 418.99 & 337.53 & 274.37 & 217.77 & 172.50 & 135.57 & 107.17 & 85.85 & 71.23 & 62.66 \\
\hline 32 & 476.66 & 381.54 & 308.57 & 252.00 & 201.31 & 160.76 & 127.67 & 102.23 & 83.14 & 70.04 & 62.36 \\
\hline 34 & 521.72 & 416.32 & 335.46 & 272.78 & 216.60 & 171.67 & 135.00 & 106.81 & 85.66 & 71.14 & 62.64 \\
\hline 36 & 575.71 & 457.99 & 367.68 & 297.67 & 234.93 & 184.74 & 143.79 & 112.31 & 88.67 & 72.46 & 62.96 \\
\hline 38 & 579.13 & 460.63 & 369.72 & 299.25 & 236.09 & 185.57 & 144.35 & 112.65 & 88.87 & 72.55 & 62.98 \\
\hline 40 & 521.96 & 416.50 & 335.60 & 272.89 & 216.68 & 171.72 & 135.04 & 106.84 & 85.67 & 71.15 & 62.64 \\
\hline 42 & 474.54 & 379.90 & 307.31 & 251.03 & 200.59 & 160.24 & 127.33 & 102.02 & 83.02 & 69.99 & 62.35 \\
\hline 44 & 529.54 & 422.35 & 340.13 & 276.38 & 219.25 & 173.56 & 136.28 & 107.61 & 86.09 & 71.33 & 62.68 \\
\hline 46 & 590.47 & 469.38 & 376.49 & 304.47 & 239.93 & 188.31 & 146.19 & 113.81 & 89.50 & 72.82 & 63.05 \\
\hline 49 & 588.00 & 467.47 & 375.02 & 303.33 & 239.10 & 187.71 & 145.79 & 113.55 & 89.36 & 72.76 & 63.04 \\
\hline 51 & 525.54 & 419.27 & 337.75 & 274.54 & 217.90 & 172.59 & 135.63 & 107.20 & 85.87 & 71.24 & 62.66 \\
\hline 53 & 478.28 & 382.79 & 309.54 & 252.75 & 201.86 & 161.15 & 127.93 & 102.40 & 83.23 & 70.08 & 62.37 \\
\hline 55 & 531.28 & 423.70 & 341.17 & 277.19 & 219.85 & 173.98 & 136.56 & 107.79 & 86.19 & 71.38 & 62.69 \\
\hline 57 & 560.49 & 446.24 & 358.60 & 290.65 & 229.76 & 181.05 & 141.31 & 110.76 & 87.82 & 72.09 & 62.87 \\
\hline 59 & 553.91 & 441.16 & 354.67 & 287.62 & 227.52 & 179.46 & 140.24 & 110.09 & 87.46 & 71.93 & 62.83 \\
\hline 61 & 518.92 & 414.16 & 333.79 & 271.49 & 215.65 & 170.99 & 134.55 & 106.53 & 85.50 & 71.07 & 62.62 \\
\hline 63 & 481.08 & 384.96 & 311.21 & 254.04 & 202.81 & 161.83 & 128.39 & 102.68 & 83.39 & 70.15 & 62.39 \\
\hline 65 & 519.32 & 414.46 & 334.03 & 271.67 & 215.78 & 171.08 & 134.61 & 106.57 & 85.52 & 71.08 & 62.62 \\
\hline 67 & 560.17 & 446.00 & 358.41 & 290.51 & 229.65 & 180.98 & 141.26 & 110.72 & 87.81 & 72.08 & 62.87 \\
\hline 69 & 550.42 & 438.47 & 352.59 & 286.01 & 226.34 & 178.62 & 139.67 & 109.73 & 87.26 & 71.84 & 62.81 \\
\hline 71 & 509.45 & 406.85 & 328.14 & 267.12 & 212.44 & 168.70 & 133.01 & 105.57 & 84.97 & 70.84 & 62.56 \\
\hline 73 & 481.40 & 385.20 & 311.40 & 254.19 & 202.92 & 161.91 & 128.44 & 102.71 & 83.40 & 70.16 & 62.39 \\
\hline 75 & 516.47 & 412.27 & 332.33 & 270.36 & 214.82 & 170.40 & 134.15 & 106.28 & 85.36 & 71.01 & 62.60 \\
\hline 77 & 534.51 & 426.19 & 343.09 & 278.67 & 220.94 & 174.76 & 137.08 & 108.11 & 86.37 & 71.46 & 62.71 \\
\hline 79 & 522.97 & 417.28 & 336.21 & 273.35 & 217.02 & 171.97 & 135.21 & 106.94 & 85.73 & 71.17 & 62.64 \\
\hline 81 & 500.19 & 399.70 & 322.62 & 262.85 & 209.29 & 166.45 & 131.50 & 104.62 & 84.45 & 70.62 & 62.51 \\
\hline 83 & 491.56 & 393.04 & 317.47 & 258.87 & 206.36 & 164.37 & 130.10 & 103.75 & 83.97 & 70.40 & 62.45 \\
\hline 85 & 525.72 & 419.41 & 337.85 & 274.62 & 217.96 & 172.64 & 135.66 & 107.22 & 85.88 & 71.24 & 62.66 \\
\hline 87 & 549.73 & 437.94 & 352.18 & 285.69 & 226.11 & 178.45 & 139.56 & 109.66 & 87.22 & 71.83 & 62.81 \\
\hline 89 & 536.09 & 427.41 & 344.04 & 279.40 & 221.48 & 175.15 & 137.34 & 108.28 & 86.46 & 71.49 & 62.72 \\
\hline 91 & 503.84 & 402.52 & 324.79 & 264.53 & 210.53 & 167.34 & 132.09 & 105.00 & 84.66 & 70.71 & 62.53 \\
\hline 93 & 482.22 & 385.83 & 311.89 & 254.57 & 203.19 & 162.10 & 128.58 & 102.80 & 83.45 & 70.18 & 62.40 \\
\hline 95 & 508.37 & 406.01 & 327.50 & 266.62 & 212.07 & 168.43 & 132.83 & 105.46 & 84.91 & 70.82 & 62.56 \\
\hline Avg & 521.52 & 416.16 & 335.34 & 272.68 & 216.53 & 171.62 & 134.97 & 106.79 & 85.65 & 71.14 & 62.64 \\
\hline
\end{tabular}

TABLE A.9

\section{TEMPERATURE DATA FROM FINELY MESHED $200 \mu \mathrm{m}$ UNRELEASED MICROHOTPLATE SIMULATION}

\begin{tabular}{|r|l|l|l|l|l|l|l|l|l|l|}
\hline & \multicolumn{10}{|c|}{ Temperature $\left({ }^{\circ} \mathrm{C}\right)$ observed at: } \\
\hline $\begin{array}{l}\text { Pos. } \\
(\mu \mathrm{m})\end{array}$ & $\begin{array}{l}5610 \\
\mathrm{~mW}\end{array}$ & $\begin{array}{l}4203 \\
\mathrm{~mW}\end{array}$ & $\begin{array}{l}3200 \\
\mathrm{~mW}\end{array}$ & $\begin{array}{l}2359 \\
\mathrm{~mW}\end{array}$ & $\begin{array}{l}1674 \\
\mathrm{~mW}\end{array}$ & $\begin{array}{l}1120 \\
\mathrm{~mW}\end{array}$ & $\begin{array}{l}692 \\
\mathrm{~mW}\end{array}$ & $\begin{array}{l}378 \\
\mathrm{~mW}\end{array}$ & $\begin{array}{l}165 \\
\mathrm{~mW}\end{array}$ & $\begin{array}{l}40.8 \\
\mathrm{~mW}\end{array}$ \\
\hline 0 & 392.95 & 309.68 & 250.19 & 200.02 & 159.41 & 126.29 & 100.91 & 82.33 & 69.67 & 62.27 \\
\hline 2 & 365.41 & 289.02 & 234.45 & 188.43 & 151.18 & 120.79 & 97.52 & 80.47 & 68.86 & 62.07 \\
\hline
\end{tabular}




\begin{tabular}{|c|c|c|c|c|c|c|c|c|c|c|}
\hline 4 & 386.20 & 304.61 & 246.33 & 197.18 & 157.39 & 124.94 & 100.08 & 81.87 & 69.47 & 62.22 \\
\hline 6 & 424.47 & 333.32 & 268.20 & 213.28 & 168.83 & 132.58 & 104.80 & 84.46 & 70.60 & 62.50 \\
\hline 8 & 46.57 & 349.89 & 280.83 & 222.58 & 175.43 & 136.98 & 107.52 & 85.95 & 71.25 & 62.66 \\
\hline 10 & 05.86 & 19.36 & 257.57 & 205.45 & 163.27 & 128.86 & 02.50 & 3.20 & 70.05 & 62.36 \\
\hline 12 & 367.58 & 290.65 & 235.69 & 189.34 & 151.82 & 121.23 & 97.78 & 80.62 & 68.92 & 62.08 \\
\hline 14 & 382.90 & 302.14 & 244.45 & 195.79 & 156.40 & 124.28 & 99.67 & 81.65 & 69.38 & 62.20 \\
\hline 16 & 422.73 & 332.01 & 267.21 & 212.55 & 168.31 & 132.23 & 104.58 & 84.34 & 70.55 & 62.49 \\
\hline 18 & 449.97 & 352.44 & 282.77 & 224.01 & 176.45 & 137.66 & 107.94 & 86.18 & 71.36 & 62.68 \\
\hline 20 & 411.80 & 323.81 & 260.96 & 207.95 & 165.04 & 130.05 & 103.24 & 83.60 & 70.23 & 62.41 \\
\hline 22 & 371.25 & 293.40 & 237.79 & 190.88 & 152.92 & 121.96 & 98.24 & 80.86 & 69.03 & 62.11 \\
\hline 24 & 378.69 & 298.98 & 242.04 & 194.02 & 155.15 & 123.44 & 99.15 & 81.37 & 69.25 & 62.16 \\
\hline 26 & 410.26 & 322.66 & 260.08 & 207.30 & 164.58 & 129.74 & 103.05 & 83.50 & 70.18 & 62.39 \\
\hline 28 & 428.36 & 336.23 & 270.43 & 214.92 & 169.99 & 133.35 & 105.28 & 84.72 & 70.72 & 62.53 \\
\hline 30 & 401.16 & 315.83 & 254.88 & 203.47 & 161.86 & 127.92 & 101.92 & 82.88 & 69.91 & 62.33 \\
\hline 32 & 367.30 & 290.43 & 235.53 & 189.22 & 151.74 & 121.17 & 97.75 & 80.60 & 68.92 & 62.08 \\
\hline 34 & 373.76 & 295.28 & 239.23 & 191.94 & 153.67 & 122.46 & 98.55 & 81.03 & 69.11 & 62.13 \\
\hline 36 & 411.44 & 323.54 & 260.76 & 207.80 & 164.93 & 129.98 & 103.19 & 3.58 & 70.22 & 62.40 \\
\hline 38 & 43 & 9.03 & 280.18 & 10 & 09 & .75 & .38 & 5.87 & 71.22 & 2.65 \\
\hline 40 & 44 & 5.04 & .90 & .64 & 5.53 & 37 & .44 & 3.71 & 70.28 & 62.42 \\
\hline 42 & 375.54 & 296.62 & 240.24 & 192.69 & 154.20 & 122.81 & 98.76 & 81.15 & 69.16 & 62.14 \\
\hline 44 & 375.67 & 296.71 & 240.31 & 192.74 & 154.24 & 122.84 & 98.78 & 81.16 & 69.16 & 62.14 \\
\hline 45 & 412.09 & 324.03 & 261.13 & 208.07 & 165.13 & 130.11 & 103.27 & 83.62 & 70.24 & 62.41 \\
\hline 47 & 444.49 & 348.33 & 279.64 & 221.70 & 174.81 & 136.57 & 107.27 & 85.81 & 71.19 & 62.64 \\
\hline 49 & 415.18 & 326.35 & 262.89 & 209.37 & 166.05 & 130.72 & 103.65 & 83.83 & 70.33 & 62.43 \\
\hline 51 & 377.72 & 8.25 & 241.49 & 193.61 & 154.86 & 123.25 & 9.03 & 1.30 & 69.22 & 62.16 \\
\hline 53 & 371.92 & .90 & 17 & 17 & 12 & .09 & 3.32 & .91 & 9.05 & 2.12 \\
\hline 55 & 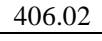 & & & & & & .52 & .21 & 06 & .36 \\
\hline 57 & 436.96 & 2.68 & 34 & 53 & 56 & .07 & .34 & .30 & 0.97 & 2.59 \\
\hline 59 & 405.33 & 318.96 & 257.26 & 205.22 & 163.11 & 128.76 & 102.44 & 83.16 & 70.04 & 62.36 \\
\hline 61 & 375.30 & 296.44 & 240.11 & 192.59 & 154.13 & 122.77 & 98.74 & 81.14 & 69.15 & 62.14 \\
\hline 63 & 373.44 & 295.04 & 239.04 & 191.81 & 153.58 & 122.40 & 98.51 & 81.01 & 69.10 & 62.13 \\
\hline 65 & 408.01 & 320.97 & 258.79 & 206.35 & 163.91 & 129.29 & 102.77 & 83.34 & 70.12 & 62.38 \\
\hline 67 & 438.94 & 344.16 & 276.47 & 219.37 & 173.15 & 135.46 & 106.58 & 85.43 & 71.03 & 62.60 \\
\hline 69 & 412.93 & 324.66 & 261.61 & 208.42 & 165.38 & 130.27 & 103.37 & 3.68 & 70.26 & 62.41 \\
\hline 71 & 9.06 & .26 & 26 & 17 & .26 & 52 & .20 & 39 & 69.26 & .17 \\
\hline 73 & 369.07 & 1.77 & 55 & .97 & 2.27 & 32 & .J & 72 & 68.97 & 62.09 \\
\hline 75 & 403.50 & 17.59 & 566.22 & 04.45 & 162.56 & 8.39 & 2.21 & 3.04 & 59.98 & 2.35 \\
\hline 77 & 435.72 & 341.75 & 274.63 & 218.01 & 172.19 & 134.82 & 106.18 & 85.21 & 70.93 & 62.58 \\
\hline 79 & 415.73 & 326.76 & 263.21 & 209.60 & 166.22 & 130.83 & 103.72 & 83.87 & 70.34 & 62.43 \\
\hline 81 & 381.99 & 301.45 & 243.93 & 195.40 & 156.13 & 124.10 & 99.56 & 81.59 & 69.35 & 62.19 \\
\hline 83 & 366.97 & 290.19 & 235.34 & 189.08 & 151.64 & 121.10 & 97.71 & 80.57 & 68.91 & 62.08 \\
\hline 85 & 401.82 & 316.32 & 255.26 & 203.75 & 162.06 & 128.06 & 102.00 & 82.93 & 69.93 & 62.33 \\
\hline 87 & 431.87 & 338.86 & 272.43 & 216.39 & 171.04 & 134.05 & 105.71 & 84.96 & 70.82 & 62.55 \\
\hline 89 & 414.09 & 325.53 & 262.27 & 208.91 & 165.73 & 130.50 & 103.52 & 83.76 & 70.30 & 62.42 \\
\hline 91 & 379.87 & 299.86 & 242.72 & 194.51 & 155.50 & 123.68 & 99.30 & 81.45 & 69.29 & 62.17 \\
\hline 93 & 360.48 & 285.32 & 231.64 & 186.35 & 149.70 & 119.81 & 96.91 & 80.14 & 68.71 & 62.03 \\
\hline 95 & 394.19 & 310.61 & 250.90 & 200.54 & 159.78 & 126.54 & 101.06 & 82.41 & 69.71 & 62.28 \\
\hline 97 & 414.42 & 325.77 & 262.46 & 209.05 & 165.82 & 130.57 & 103.56 & 83.78 & 70.31 & 62.43 \\
\hline 99 & 409.99 & 322.45 & 259.93 & 207.18 & 164.50 & 129.69 & 103.01 & 83.48 & 70.18 & 2.39 \\
\hline 101 & 386.40 & 304.76 & 246.44 & 197.26 & 157.45 & 98 & 100.10 & 81.89 & 69.48 & 2.22 \\
\hline 103 & 364.58 & 288.39 & 233.98 & 188.08 & 150.93 & 120.63 & 97.41 & 80.41 & 68.84 & 62.06 \\
\hline
\end{tabular}




\begin{tabular}{|c|c|c|c|c|c|c|c|c|c|c|}
\hline 105 & 404.58 & 318.40 & 256.84 & 204.91 & 162.88 & 128.61 & 102.34 & 83.11 & 70.02 & 62.35 \\
\hline 107 & 425.13 & 333.80 & 268.58 & 213.55 & 169.02 & 132.71 & 104.88 & 84.50 & 70.62 & 62.50 \\
\hline 109 & 415.92 & 326.90 & 263.32 & 209.68 & 166.27 & 130.87 & 103.74 & 83.88 & 70.35 & 62.44 \\
\hline 111 & 386.96 & 305.18 & 246.77 & 197.49 & 157.62 & 125.09 & 100.17 & 81.92 & 69.50 & 62.23 \\
\hline 113 & 359.95 & 284.92 & 231.33 & 186.13 & 149.54 & 119.70 & 6.84 & 80.10 & 68.70 & 62.03 \\
\hline 115 & 399.55 & 314.62 & 253.96 & 202.79 & 161.38 & 127.60 & 101.72 & 82.77 & 69.87 & 62.32 \\
\hline 117 & 435.47 & 341.56 & 274.49 & 217.91 & 172.12 & 134.77 & 106.15 & 85.20 & 70.93 & 62.58 \\
\hline 119 & 428.02 & 335.97 & 270.23 & 214 & 89 & 133.28 & 23 & 69 & 0.71 & 62.52 \\
\hline 121 & 391.26 & 308.41 & 249.23 & 199.30 & 158.90 & 5.95 & .70 & 21 & 69.62 & 62.26 \\
\hline 123 & 358.65 & 283.95 & 230.59 & 18 & 149.15 & .45 & 5.68 & 80.01 & 3.66 & 62.02 \\
\hline 125 & 396.58 & 312.40 & 252.26 & 20 & 16 & 7.01 & 1.36 & 82.57 & 69.7 & 62.30 \\
\hline 127 & 430.26 & 337.66 & 271.51 & 215.72 & 56 & 133.73 & 105.51 & 84.85 & 70.77 & 62.54 \\
\hline 129 & 427.03 & 335.23 & 269.66 & 35 & 59 & .08 & 105.11 & 84.63 & 70.68 & 2.52 \\
\hline 131 & 392.56 & 38 & 97 & 5 & 29 & .21 & .86 & 30 & 9.66 & 62.27 \\
\hline 133 & 356.93 & 282.66 & 229.61 & 184.86 & 148.64 & 119.10 & 6.47 & 79.90 & 68.61 & 62.01 \\
\hline 135 & 390.01 & 307.47 & 248.51 & 198.78 & 158.53 & 125.70 & 100.55 & 82.13 & 69.59 & 62.25 \\
\hline 136 & 415.16 & 326.33 & 262.88 & 209.36 & 166.04 & 130.72 & 103.65 & 83.83 & 70.33 & 62.43 \\
\hline 138 & 414.80 & 326.06 & 262.68 & 209.21 & 165.94 & 130.65 & 103.61 & 83.80 & 70.32 & 62.43 \\
\hline 140 & 389.16 & 306.83 & 248.02 & 198.42 & 158.27 & 125.53 & 100.44 & 82.07 & 69.56 & 62.24 \\
\hline 142 & 358.80 & 284.06 & 230.67 & 185.64 & 149.20 & 9.48 & 5.70 & 80.02 & 68.66 & 62.02 \\
\hline 144 & 393.62 & 310.18 & 250.57 & 200.30 & 159.61 & 6.42 & 100.99 & 02.37 & 69.69 & 2.27 \\
\hline 146 & & 9 & 7 & & & 48 & 8 & 85.10 & 70.88 & .57 \\
\hline 14 & & & & & & tor & 7 & & 71.00 & 60 \\
\hline 150 & 393.99 & 3 & 79 & & & .50 & .04 & & .70 & 62.28 \\
\hline 152 & 358.66 & 283.95 & 230.59 & 185.58 & 14 & 119.45 & 5.68 & 01 & 68.66 & 62.02 \\
\hline 154 & 389.54 & 307.11 & 248.24 & 198.58 & 158.39 & 125.61 & 100.49 & 10 & 69.57 & 62.24 \\
\hline 156 & 419.54 & 329.62 & 265.39 & 211.20 & 167.35 & 131.59 & 104.19 & 84.12 & 70.46 & 62.46 \\
\hline 158 & 424.99 & 333.71 & 268.50 & 213.50 & 168.98 & 132.68 & 104.86 & 84.49 & 70.62 & 62.50 \\
\hline 160 & 396.53 & 312.36 & 252.24 & 201.52 & 160.48 & 127.00 & 101.35 & 82.57 & 69.78 & 62.29 \\
\hline 162 & 362.94 & 287.16 & 233.04 & 187.39 & 150.44 & 0.30 & 7.21 & 80.30 & 68.79 & 62.05 \\
\hline 164 & 390.21 & 307.62 & 248.62 & 198.86 & 158.59 & 5.74 & 100.57 & 82.14 & 69.59 & 62.25 \\
\hline 166 & 425.37 & 333.99 & 268.72 & 213.66 & 109.10 & 32.75 & 104.91 & 84.52 & 70.63 & 2.50 \\
\hline 168 & 437.13 & 342.81 & 275.43 & 218.61 & 172.61 & 35.10 & 106.36 & 85.31 & 70.98 & 62.59 \\
\hline 170 & 403.19 & 317.36 & 256.04 & 204.33 & 162.47 & 128.33 & 102.17 & 83.02 & 69.97 & 62.34 \\
\hline 172 & 363.60 & 287.66 & 233.42 & 187.67 & 100.04 & 120.43 & 97.29 & 80.35 & 68.81 & 62.06 \\
\hline 174 & 386.58 & 304.90 & 246.55 & 19 & 157.50 & 02 & 100.13 & 0 & 69.48 & 2.22 \\
\hline 176 & 42 & 8 & .26 & 9 & 34 & 132.25 & 1.59 & 34 & 0.55 & 62.49 \\
\hline 178 & 17 & 343.59 & 276.03 & 219.04 & 172.92 & 135.31 & 106.49 & 85.38 & 71.01 & 62.60 \\
\hline 180 & 403.37 & 49 & 256.15 & 204.40 & 52 & 128.37 & 102.20 & 83.03 & 69.98 & 62.34 \\
\hline Avg & 400.61 & 315.42 & 254.57 & 203.24 & 161.70 & 127.81 & 101.86 & 82.84 & 69.90 & 62.32 \\
\hline
\end{tabular}


TABLE A.10

\section{TEMPERATURE DATA FROM FINELY MESHED $100 \mu \mathrm{m}$ THERMALLY ISOLATED MICROHOTPLATE SIMULATION WITH CONVECTION}

\begin{tabular}{|c|c|c|c|c|c|c|c|c|c|c|}
\hline \multirow[b]{2}{*}{$\begin{array}{l}\text { Pos. } \\
(\mu \mathrm{m})\end{array}$} & \multicolumn{10}{|c|}{ Temperature $\left({ }^{\circ} \mathrm{C}\right)$ observed at: } \\
\hline & $\begin{array}{l}35.5 \\
\mathrm{~mW}\end{array}$ & $\begin{array}{l}27.0 \\
\mathrm{~mW}\end{array}$ & $\begin{array}{l}20.0 \\
\mathrm{~mW}\end{array}$ & $\begin{array}{l}14.8 \\
\mathrm{~mW}\end{array}$ & $\begin{array}{l}10.4 \\
\mathrm{~mW}\end{array}$ & $\begin{array}{l}6.90 \\
\mathrm{~mW}\end{array}$ & $\begin{array}{l}4.32 \\
\mathrm{~mW}\end{array}$ & $\begin{array}{l}2.38 \\
\mathrm{~mW}\end{array}$ & $\begin{array}{l}1.05 \\
\mathrm{~mW}\end{array}$ & $\begin{array}{l}0.261 \\
\mathrm{~mW}\end{array}$ \\
\hline 0 & 1036.29 & 795.28 & 597.62 & 451.59 & 326.42 & 229.86 & 155.18 & 98.80 & 59.97 & 37.03 \\
\hline 3 & 1072.42 & 822.73 & 617.95 & 466.66 & 336.98 & 233.13 & 157.20 & 99.89 & 60.42 & 37.10 \\
\hline 6 & 1082.94 & 830.73 & 623.87 & 471.05 & 340.06 & 234.26 & 157.90 & 100.25 & 60.56 & 37.11 \\
\hline 10 & 1077.78 & 826.79 & 620.94 & 468.85 & 338.50 & 230.55 & 155.54 & 98.91 & 59.92 & 36.88 \\
\hline 13 & 1043.57 & 800.74 & 601.59 & 454.45 & 328.33 & 223.48 & 151.06 & 96.40 & 58.76 & 36.51 \\
\hline 16 & 995.24 & 763.95 & 574.26 & 434.12 & 314.00 & 212.83 & 144.34 & 92.63 & 57.03 & 35.99 \\
\hline 19 & 934.55 & 717.76 & 539.97 & 408.61 & 296.02 & 200.35 & 136.47 & 88.25 & 55.04 & 35.42 \\
\hline 22 & 864.33 & 664.33 & 500.30 & 379.12 & 275.25 & 185.45 & 127.09 & 83.04 & 52.71 & 34.78 \\
\hline 25 & 779.23 & 599.59 & 452.26 & 343.42 & 250.12 & 166.92 & 115.46 & 76.61 & 49.85 & 34.05 \\
\hline 29 & 672.02 & 518.04 & 391.76 & 298.46 & 218.50 & 143.20 & 100.58 & 68.41 & 46.25 & 33.16 \\
\hline 32 & 590.35 & 455.93 & 345.69 & 264.24 & 194.43 & 136.96 & 96.67 & 66.25 & 45.31 & 32.93 \\
\hline 35 & 576.84 & 445.66 & 338.07 & 258.58 & 190.45 & 134.85 & 95.35 & 65.53 & 44.99 & 32.86 \\
\hline 38 & 565.85 & 437.30 & 331.87 & 253.98 & 187.21 & 132.65 & 93.97 & 64.77 & 44.67 & 32.79 \\
\hline 41 & 554.97 & 429.03 & 325.73 & 249.42 & 184.01 & 130.38 & 92.55 & 63.99 & 44.33 & 32.71 \\
\hline 45 & 544.72 & 421.23 & 319.95 & 245.13 & 181.00 & 128.41 & 91.32 & 63.32 & 44.04 & 32.65 \\
\hline 48 & 536.37 & 414.88 & 315.25 & 241.63 & 178.54 & 126.75 & 90.28 & 62.75 & 43.79 & 32.59 \\
\hline 51 & 529.47 & 409.64 & 311.35 & 238.74 & 176.51 & 125.33 & 89.39 & 62.26 & 43.57 & 32.53 \\
\hline 54 & 513.00 & 397.11 & 302.06 & 231.83 & 171.64 & 122.49 & 87.60 & 61.27 & 43.14 & 32.42 \\
\hline 57 & 481.47 & 373.12 & 284.26 & 218.61 & 162.34 & 116.33 & 83.74 & 59.13 & 42.19 & 32.18 \\
\hline 60 & 444.79 & 345.22 & 263.56 & 203.23 & 151.52 & 109.28 & 79.32 & 56.70 & 41.13 & 31.92 \\
\hline 64 & 403.06 & 313.49 & 240.04 & 185.76 & 139.25 & 101.69 & 74.57 & 54.10 & 40.00 & 31.67 \\
\hline 67 & 367.41 & 286.39 & 219.94 & 170.85 & 128.77 & 95.36 & 70.62 & 51.94 & 39.08 & 31.48 \\
\hline 70 & 354.78 & 276.79 & 212.83 & 165.57 & 125.07 & 91.82 & 68.41 & 50.74 & 38.57 & 31.38 \\
\hline 73 & 350.25 & 273.35 & 210.28 & 163.68 & 123.74 & 90.89 & 67.83 & 50.43 & 38.44 & 31.36 \\
\hline 76 & 346.00 & 270.12 & 207.89 & 161.91 & 122.50 & 90.03 & 67.30 & 50.14 & 38.33 & 31.35 \\
\hline 80 & 341.90 & 267.01 & 205.58 & 160.20 & 121.30 & 89.22 & 66.80 & 49.88 & 38.22 & 31.33 \\
\hline 83 & 337.85 & 263.93 & 203.30 & 158.51 & 120.12 & 88.41 & 66.30 & 49.61 & 38.11 & 31.32 \\
\hline 86 & 327.74 & 256.24 & 197.60 & 154.27 & 117.14 & 86.97 & 65.40 & 49.12 & 37.91 & 31.28 \\
\hline 89 & 315.84 & 247.19 & 190.89 & 149.29 & 113.63 & 84.65 & 63.94 & 48.31 & 37.55 & 31.19 \\
\hline 92 & 303.93 & 238.14 & 184.17 & 144.30 & 110.13 & 82.06 & 62.31 & 47.41 & 37.14 & 31.08 \\
\hline 96 & 292.52 & 229.46 & 177.74 & 139.52 & 106.77 & 79.79 & 60.89 & 46.63 & 36.80 & 31.00 \\
\hline 99 & 283.22 & 222.39 & 172.49 & 135.63 & 104.04 & 77.85 & 59.68 & 45.96 & 36.51 & 30.93 \\
\hline 102 & 277.87 & 218.32 & 169.47 & 133.39 & 102.46 & 76.41 & 58.78 & 45.46 & 36.29 & 30.87 \\
\hline 105 & 273.04 & 214.64 & 166.74 & 131.36 & 101.03 & 75.53 & 58.22 & 45.15 & 36.15 & 30.84 \\
\hline 108 & 272.23 & 214.03 & 166.29 & 131.02 & 100.79 & 74.68 & 57.68 & 44.85 & 36.02 & 30.80 \\
\hline 112 & 275.66 & 216.64 & 168.23 & 132.46 & 101.81 & 73.84 & 57.16 & 44.56 & 35.89 & 30.77 \\
\hline 115 & 258.55 & 203.62 & 158.56 & 125.27 & 96.74 & 73.03 & 56.65 & 44.28 & 35.77 & 30.73 \\
\hline 118 & 243.42 & 192.10 & 150.01 & 118.92 & 92.27 & 71.19 & 55.49 & 43.64 & 35.48 & 30.65 \\
\hline 121 & 228.65 & 180.87 & 141.68 & 112.72 & 87.91 & 68.38 & 53.72 & 42.65 & 35.03 & 30.53 \\
\hline 124 & 215.90 & 171.18 & 134.49 & 107.39 & 84.16 & 65.79 & 52.10 & 41.76 & 34.64 & 30.43 \\
\hline 128 & 205.10 & 162.97 & 128.41 & 102.88 & 81.00 & 63.57 & 50.71 & 41.01 & 34.32 & 30.37 \\
\hline 131 & 197.48 & 157.18 & 124.12 & 99.70 & 78.77 & 61.85 & 49.65 & 40.44 & 34.09 & 30.34 \\
\hline 134 & 194.73 & 155.09 & 122.57 & 98.55 & 77.96 & 60.82 & 49.01 & 40.09 & 33.95 & 30.32 \\
\hline
\end{tabular}




\begin{tabular}{|l|r|r|r|r|r|r|r|r|r|r|}
\hline 137 & 192.28 & 153.22 & 121.19 & 97.52 & 77.24 & 60.33 & 48.70 & 39.92 & 33.88 & 30.31 \\
\hline 140 & 189.85 & 151.38 & 119.82 & 96.51 & 76.53 & 59.88 & 48.42 & 39.77 & 33.82 & 30.30 \\
\hline 144 & 187.44 & 149.54 & 118.46 & 95.50 & 75.82 & 59.44 & 48.15 & 39.63 & 33.76 & 30.29 \\
\hline 147 & 183.89 & 146.85 & 116.46 & 94.01 & 74.77 & 58.99 & 47.87 & 39.48 & 33.70 & 30.28 \\
\hline 150 & 177.84 & 142.24 & 113.04 & 91.47 & 72.98 & 58.10 & 47.31 & 39.16 & 33.55 & 30.24 \\
\hline 153 & 172.25 & 137.99 & 109.89 & 89.13 & 71.34 & 56.86 & 46.52 & 38.71 & 33.34 & 30.16 \\
\hline 156 & 167.45 & 134.33 & 107.18 & 87.11 & 69.91 & 55.69 & 45.78 & 38.29 & 33.14 & 30.09 \\
\hline 159 & 162.72 & 130.73 & 104.49 & 85.11 & 68.49 & 54.71 & 45.15 & 37.94 & 32.97 & 30.04 \\
\hline 163 & 158.23 & 127.30 & 101.94 & 83.20 & 67.14 & 53.94 & 44.66 & 37.66 & 32.84 & 30.00 \\
\hline 166 & 154.17 & 124.21 & 99.64 & 81.49 & 65.93 & 53.46 & 44.36 & 37.49 & 32.76 & 29.96 \\
\hline 169 & 151.15 & 121.91 & 97.93 & 80.21 & 65.02 & 53.02 & 44.08 & 37.32 & 32.67 & 29.93 \\
\hline 172 & 149.32 & 120.51 & 96.89 & 79.43 & 64.47 & 52.59 & 43.80 & 37.16 & 32.59 & 29.89 \\
\hline 175 & 147.53 & 119.15 & 95.87 & 78.67 & 63.94 & 52.17 & 43.53 & 37.01 & 32.51 & 29.86 \\
\hline 179 & 145.78 & 117.81 & 94.88 & 77.93 & 63.41 & 51.50 & 43.10 & 36.76 & 32.40 & 29.82 \\
\hline 182 & 143.81 & 116.32 & 93.77 & 77.11 & 62.83 & 49.45 & 41.80 & 36.03 & 32.06 & 29.71 \\
\hline 185 & 135.17 & 109.74 & 88.88 & 73.47 & 60.26 & 47.24 & 40.41 & 35.26 & 31.72 & 29.62 \\
\hline 188 & 119.39 & 97.73 & 79.97 & 66.85 & 55.60 & 45.44 & 39.30 & 34.66 & 31.47 & 29.59 \\
\hline 191 & 109.27 & 90.05 & 74.28 & 62.63 & 52.65 & 43.96 & 38.39 & 34.19 & 31.30 & 29.59 \\
\hline 195 & 102.09 & 84.60 & 70.26 & 59.67 & 50.59 & 42.86 & 37.74 & 33.88 & 31.22 & 29.65 \\
\hline 198 & 96.74 & 80.56 & 67.29 & 57.49 & 49.09 & 41.97 & 37.23 & 33.66 & 31.20 & 29.75 \\
\hline
\end{tabular}

TABLE A.11

\section{CURRENT MAGNITUDE QUERIES AT SIMULATION INLET AND OUTLET BOUNDARIES}

\begin{tabular}{|c|c|c|c|c|c|}
\hline $\begin{array}{l}\text { Microhotplate } \\
\text { Simulation }\end{array}$ & $\begin{array}{l}\text { Current } \\
\text { Specified } \\
\text { (mA) }\end{array}$ & $\begin{array}{l}\text { Inlet } \\
\text { Current } \\
\text { (pA) }\end{array}$ & $\begin{array}{l}\text { Outlet } \\
\text { Current } \\
\text { (pA) }\end{array}$ & $\begin{array}{l}\text { Difference } \\
\text { (pA) }\end{array}$ & $\begin{array}{l}\text { Percent } \\
\text { Difference } \\
\text { (\%) }\end{array}$ \\
\hline \multirow{11}{*}{$\begin{array}{l}\text { Unreleased } \\
100 \mu \mathrm{m} \\
\text { Coarse mesh }\end{array}$} & 10 & $-1.47 \mathrm{E}+11$ & $3.59 \mathrm{E}+09$ & $-1.43 \mathrm{E}+11$ & 97.6 \\
\hline & 20 & $-2.93 E+11$ & $7.18 \mathrm{E}+09$ & $-2.86 \mathrm{E}+11$ & 97.5 \\
\hline & 30 & $-4.40 \mathrm{E}+11$ & $1.08 \mathrm{E}+10$ & $-4.29 \mathrm{E}+11$ & 97.5 \\
\hline & 40 & $-5.87 \mathrm{E}+11$ & $1.44 \mathrm{E}+10$ & $-5.73 \mathrm{E}+11$ & 97.5 \\
\hline & 50 & $-7.34 \mathrm{E}+11$ & $1.79 \mathrm{E}+10$ & $-7.16 \mathrm{E}+11$ & 97.6 \\
\hline & 60 & $-8.80 \mathrm{E}+11$ & $2.15 \mathrm{E}+10$ & $-8.59 \mathrm{E}+11$ & 97.6 \\
\hline & 70 & $-1.03 E+12$ & $2.51 \mathrm{E}+10$ & $-1.00 \mathrm{E}+12$ & 97.6 \\
\hline & 80 & $-1.17 \mathrm{E}+12$ & $2.87 \mathrm{E}+10$ & $-1.14 \mathrm{E}+12$ & 97.5 \\
\hline & 90 & $-1.32 \mathrm{E}+12$ & $3.23 \mathrm{E}+10$ & $-1.29 \mathrm{E}+12$ & 97.6 \\
\hline & 100 & $-1.47 \mathrm{E}+12$ & $3.59 \mathrm{E}+10$ & $-1.43 \mathrm{E}+12$ & 97.6 \\
\hline & 110 & $-1.61 \mathrm{E}+12$ & $3.95 \mathrm{E}+10$ & $-1.57 \mathrm{E}+12$ & 97.5 \\
\hline \multirow{10}{*}{$\begin{array}{l}\text { Unreleased } \\
200 \mu \mathrm{m} \\
\text { Coarse mesh }\end{array}$} & 10 & $-8.30 \mathrm{E}+10$ & $9.43 \mathrm{E}+09$ & $-7.36 \mathrm{E}+10$ & 88.6 \\
\hline & 20 & $-1.66 \mathrm{E}+11$ & $1.88 \mathrm{E}+10$ & $-1.47 \mathrm{E}+11$ & 88.7 \\
\hline & 30 & $-2.49 \mathrm{E}+11$ & $2.83 \mathrm{E}+10$ & $-2.21 \mathrm{E}+11$ & 88.6 \\
\hline & 40 & $-3.32 \mathrm{E}+11$ & $3.77 \mathrm{E}+10$ & $-2.94 \mathrm{E}+11$ & 88.6 \\
\hline & 50 & $-4.15 \mathrm{E}+11$ & $4.71 \mathrm{E}+10$ & $-3.68 \mathrm{E}+11$ & 88.7 \\
\hline & 60 & $-4.98 \mathrm{E}+11$ & $5.66 \mathrm{E}+10$ & $-4.41 \mathrm{E}+11$ & 88.6 \\
\hline & 70 & $-5.81 \mathrm{E}+11$ & $6.60 \mathrm{E}+10$ & $-5.15 \mathrm{E}+11$ & 88.6 \\
\hline & 80 & $-6.64 \mathrm{E}+11$ & $7.54 \mathrm{E}+10$ & $-5.89 \mathrm{E}+11$ & 88.6 \\
\hline & 90 & $-7.47 \mathrm{E}+11$ & $8.48 \mathrm{E}+10$ & $-6.62 E+11$ & 88.6 \\
\hline & 100 & $-8.30 \mathrm{E}+11$ & $9.43 \mathrm{E}+10$ & $-7.36 \mathrm{E}+11$ & 88.6 \\
\hline Isolated & 1 & $-6.64 \mathrm{E}+09$ & $8.85 E+08$ & $-5.76 \mathrm{E}+09$ & 86.7 \\
\hline
\end{tabular}




\begin{tabular}{|c|c|c|c|c|c|}
\hline \multirow{9}{*}{$\begin{array}{l}100 \mu \mathrm{m} \\
\text { Coarse mesh }\end{array}$} & 2 & $-1.33 E+10$ & $1.77 \mathrm{E}+09$ & $-1.15 E+10$ & 86.7 \\
\hline & 3 & $-2.00 \mathrm{E}+10$ & $2.65 E+09$ & $-1.74 \mathrm{E}+10$ & 86.8 \\
\hline & 4 & $-2.66 \mathrm{E}+10$ & $3.54 \mathrm{E}+09$ & $-2.31 \mathrm{E}+10$ & 86.7 \\
\hline & 5 & $-3.33 E+10$ & $4.42 \mathrm{E}+09$ & $-2.89 \mathrm{E}+10$ & 86.7 \\
\hline & 6 & $-4.00 \mathrm{E}+10$ & $5.31 \mathrm{E}+09$ & $-3.47 \mathrm{E}+10$ & 86.7 \\
\hline & 7 & $-4.66 \mathrm{E}+10$ & $6.19 \mathrm{E}+09$ & $-4.04 \mathrm{E}+10$ & 86.7 \\
\hline & 8 & $-5.33 E+10$ & $7.08 \mathrm{E}+09$ & $-4.62 \mathrm{E}+10$ & 86.7 \\
\hline & 9 & $-6.00 \mathrm{E}+10$ & $7.96 \mathrm{E}+09$ & $-5.20 \mathrm{E}+10$ & 86.7 \\
\hline & 10 & $-6.66 \mathrm{E}+10$ & $8.85 \mathrm{E}+09$ & $-5.78 \mathrm{E}+10$ & 86.7 \\
\hline \multirow{11}{*}{$\begin{array}{l}\text { Unreleased } \\
100 \mu \mathrm{m} \\
\text { Fine mesh }\end{array}$} & 10 & $-8.96 \mathrm{E}+09$ & $8.82 \mathrm{E}+09$ & $-1.40 \mathrm{E}+08$ & 1.56 \\
\hline & 20 & $-1.79 \mathrm{E}+10$ & $1.76 \mathrm{E}+10$ & $-3.00 \mathrm{E}+08$ & 1.68 \\
\hline & 30 & $-2.69 \mathrm{E}+10$ & $2.65 E+10$ & $-4.00 \mathrm{E}+08$ & 1.49 \\
\hline & 40 & $-3.58 \mathrm{E}+10$ & $3.53 \mathrm{E}+10$ & $-5.00 \mathrm{E}+08$ & 1.40 \\
\hline & 50 & $-4.48 \mathrm{E}+10$ & $4.41 \mathrm{E}+10$ & $-7.00 \mathrm{E}+08$ & 1.56 \\
\hline & 60 & $-5.38 E+10$ & $5.29 \mathrm{E}+10$ & $-9.00 \mathrm{E}+08$ & 1.67 \\
\hline & 70 & $-6.27 \mathrm{E}+10$ & $6.17 \mathrm{E}+10$ & $-1.00 \mathrm{E}+09$ & 1.59 \\
\hline & 80 & $-7.17 \mathrm{E}+10$ & $7.06 \mathrm{E}+10$ & $-1.10 \mathrm{E}+09$ & 1.53 \\
\hline & 90 & $-8.06 \mathrm{E}+10$ & $7.94 \mathrm{E}+10$ & $-1.20 \mathrm{E}+09$ & 1.49 \\
\hline & 100 & $-8.96 \mathrm{E}+10$ & $8.82 \mathrm{E}+10$ & $-1.40 \mathrm{E}+09$ & 1.56 \\
\hline & 110 & $-9.85 E+10$ & $9.70 \mathrm{E}+10$ & $-1.50 \mathrm{E}+09$ & 1.52 \\
\hline \multirow{10}{*}{$\begin{array}{l}\text { Unreleased } \\
200 \mu \mathrm{m} \\
\text { Fine mesh }\end{array}$} & 10 & $-8.82 \mathrm{E}+09$ & $8.82 \mathrm{E}+09$ & $0.00 \mathrm{E}+00$ & 0.00 \\
\hline & 20 & $-1.76 \mathrm{E}+10$ & $1.76 \mathrm{E}+10$ & $0.00 \mathrm{E}+00$ & 0.00 \\
\hline & 30 & $-2.64 \mathrm{E}+10$ & $2.64 \mathrm{E}+10$ & $0.00 \mathrm{E}+00$ & 0.00 \\
\hline & 40 & $-3.53 E+10$ & $3.52 \mathrm{E}+10$ & $-1.00 \mathrm{E}+08$ & 0.28 \\
\hline & 50 & $-4.41 \mathrm{E}+10$ & $4.41 \mathrm{E}+10$ & $0.00 \mathrm{E}+00$ & 0.00 \\
\hline & 60 & $-5.29 \mathrm{E}+10$ & $5.29 \mathrm{E}+10$ & $0.00 \mathrm{E}+00$ & 0.00 \\
\hline & 70 & $-6.17 \mathrm{E}+10$ & $6.17 \mathrm{E}+10$ & $0.00 \mathrm{E}+00$ & 0.00 \\
\hline & 80 & $-7.06 \mathrm{E}+10$ & $7.06 \mathrm{E}+10$ & $0.00 \mathrm{E}+00$ & 0.00 \\
\hline & 90 & $-7.94 \mathrm{E}+10$ & $7.93 \mathrm{E}+10$ & $-1.00 \mathrm{E}+08$ & 0.13 \\
\hline & 100 & $-8.82 \mathrm{E}+10$ & $8.81 \mathrm{E}+10$ & $-1.00 \mathrm{E}+08$ & 0.11 \\
\hline \multirow{10}{*}{$\begin{array}{l}\text { Isolated } \\
100 \mu \mathrm{m} \\
\text { Fine mesh }\end{array}$} & 1 & $-8.94 \mathrm{E}+08$ & $8.82 \mathrm{E}+08$ & $-1.20 \mathrm{E}+07$ & 1.34 \\
\hline & 2 & $-1.79 \mathrm{E}+09$ & $1.76 \mathrm{E}+09$ & $-3.00 \mathrm{E}+07$ & 1.68 \\
\hline & 3 & $-2.68 \mathrm{E}+09$ & $2.65 \mathrm{E}+09$ & $-3.00 \mathrm{E}+07$ & 1.12 \\
\hline & 4 & $-3.58 \mathrm{E}+09$ & $3.53 \mathrm{E}+09$ & $-5.00 \mathrm{E}+07$ & 1.40 \\
\hline & 5 & $-4.47 \mathrm{E}+09$ & $4.41 \mathrm{E}+09$ & $-6.00 \mathrm{E}+07$ & 1.34 \\
\hline & 6 & $-5.37 \mathrm{E}+09$ & $5.29 \mathrm{E}+09$ & $-8.00 \mathrm{E}+07$ & 1.49 \\
\hline & 7 & $-6.26 \mathrm{E}+09$ & $6.17 \mathrm{E}+09$ & $-9.00 \mathrm{E}+07$ & 1.44 \\
\hline & 8 & $-7.16 \mathrm{E}+09$ & $7.06 \mathrm{E}+09$ & $-1.00 \mathrm{E}+08$ & 1.40 \\
\hline & 9 & $-8.05 E+09$ & $7.94 \mathrm{E}+09$ & $-1.10 \mathrm{E}+08$ & 1.37 \\
\hline & 10 & $-8.95 E+09$ & $8.82 E+09$ & $-1.30 \mathrm{E}+08$ & 1.45 \\
\hline
\end{tabular}




\section{REFERENCES}

[1] Semancik, S., Cavicchi, R. E., Wheeler, M. C., Tiffany, J. E., Poirier, G. E., Walton, R. M., Suehle, J. S., Panchapakesan, and B., DeVoe, D. L. 2001. Microhotplate platforms for chemical sensor research. Sensors and Actuators B 77:579-591.

[2] Raman, B., Meier, D. C., Evju, J. K., and Semancik, S. 2009. Designing and optimizing microsensor arrays for recognizing chemical hazards in complex environments. Sensors and Actuators B 137:617-629.

[3] Triantafyllopoulou, R. and Tsamis, C. 2008. Detection of CO and NO using low power metal oxide sensors. Physica Status Solidi A 205 11:2643-2646.

[4] Ahn, J., Kim, Y., and Wang, G. 2009. Electrochemical properties of $\mathrm{SnO}_{2}$ nanowires prepared by a simple heat treatment of Sn-Ag alloys. Journal of Alloys and Compounds 483:422-424.

[5] Xu, J., Wang, D., Qin, L., Yu, W., and Pan, Q. 2009. $\mathrm{SnO}_{2}$ nanorods and hollow spheres: Controlled synthesis and gas sensing properties. Sensors and Actuators B 137:490-495.

[6] Köck, A., Tischner, A., Maier, T., Kast, M., Edtmaier, C., Gspan, C., and Kothleitner, G. 2009. Atmospheric pressure fabrication of $\mathrm{SnO}_{2}$-nanowires for highly sensitive $\mathrm{CO}$ and $\mathrm{CH}_{4}$ detection. Sensors and Actuators B 138:160-167.

[7] Sberveglieri, G., Baratto, C., Comini, E., Faglia, G., Ferroni, M., Pardo, M., Ponzoni, A., and Vomiero, A. 2009. Semiconducting tin oxide nanowires and thin films for Chemical Warfare Agents detection. Thin Solid Films 517:6156-6160.

[8] Tischner, A., Köck, A., Maier, T., Edtmaier, C., Gspan, C., and Kothleitner, G. 2009. Tin oxide nanocrystalline films and nanowires for gas sensing applications. Microelectronic Engineering 86:1258-1261.

[9] Kumar, V., Sen, S., Muth, K. P., Gaur, N. K., Gupta, S. K., and Yakhmi, J. V. 2009. Copper doped $\mathrm{SnO}_{2}$ nanowires as highly sensitive $\mathrm{H}_{2} \mathrm{~S}$ gas sensor. Sensors and Actuators B 138:587-590. 
[10] Feng, H. T., Zhuo, R. F., Chen, J. T., Yan, D., Feng, J. J., Li, H. J., Cheng, S., and Yan, P. X. 2009. Axial periodical nanostructures of Sb-doped $\mathrm{SnO}_{2}$ grown by chemical vapor deposition. Physica E 41:1640-1644.

[11] Cao, Y., Pan, W., Zong, Y., and Jia, D. 2009. Preparation and gas-sensing properties of pure and $\mathrm{Nd}$-doped $\mathrm{ZnO}$ nanorods by low-heating solid-state chemical reaction. Sensors and Actuators B 138:480-484.

[12] Fan, Z. and Lu, J. G. 2006. Chemical Sensing With ZnO Nanowire Field-Effect Transistor. IEEE Transactions on Nanotechnology 5:393-396.

[13] Hari, P., Baumer, M., Tennyson, W. D., and Bumm, L. A. 2008. ZnO nanorod growth by chemical bath method. Journal of Non-Crystalline Solids 354:2843-2848.

[14] Zhang, H., Feng, J., Wang, J., and Zhang, M. 2007. Preparation of ZnO nanorods through wet chemical method. Materials Letters 61:5202-5205.

[15] Cheng, C., Liu, B., Yang, H., Zhou, W., Sun, L., Chen, R., Yu, S. F., Zhang, J., Gong, H., Sun, H., and Fan, H. J. 2009. Hierarchical Assembly of ZnO Nanostructures on $\mathrm{SnO}_{2}$ Backbone Nanowires: Low-Temperature Hydrothermal Preparation and Optical Properties. American Chemical Society Nano 3:3069-3076.

[16] Choi, S., Park, J. Y., and Kim, S. S. 2009. Synthesis of $\mathrm{SnO}_{2}-\mathrm{ZnO}$ core-shell nanofibers via a novel two-step process and their gas sensing properties. Nanotechnology 20:465603.

[17] Kim, H. W., Kebede, M. A., and Kim, H. S. 2009. ZnO sputter coating on $\mathrm{SnO}_{2}$ nanowires: Effects of thin coating and subsequent thermal annealing. Optical Materials 31:1853-1856.

[18] Song, X. and Liu, L. 2009. Characterization of electrospun $\mathrm{ZnO}^{-\mathrm{SnO}_{2}}$ nanofibers for ethanol sensor. Sensors and Actuators A 154:175-179.

[19] Xiang, Q., Meng, G., Zhang, Y., Xu, J., Xu, P., Pan, Q., and Yu, W. 2010. Ag nanoparticle embedded-Zno nanorods synthesized via a photochemical method and its gas-sensing properties. Sensors and Actuators B 143:635-640.

[20] Zong, Y., Cao, Y., Jia, D., Bao, S., and Lu, Y. 2010. Facile synthesis of Ag/ZnO nanorods using $\mathrm{Ag} / \mathrm{C}$ cables as templates and their gas-sensing properties. Materials Letters 64:243-245.

[21] Liao, L., Zhang, Z., Yan, B., Zheng, Z., Bao, Q. L., Wu, T., Li, C. M., Shen, Z. X., Zhang, J. X., Gong, H., Li, J. C., and Yu, T. 2009. Multifunctional CuO nanowire devices: p-type field effect transistors and CO gas sensors. Nanotechnology 20:085203. 
[22] Mu, Y., Yang, J., Han, S., Hou, H., and Fan, Y. 2010. Syntheses and gas-sensing properties of $\mathrm{CuO}$ nanostructures by using $\left[\mathrm{Cu}(\mathrm{pbbt}) \mathrm{Cl}_{2}\right]_{2} \cdot \mathrm{CH}_{3} \mathrm{OH}$ as a precursor. Materials Letters 64:1287-1290.

[23] Hoa, N. D., An, S. Y., Dung, N. Q., Quy, N. V., and Kim, D. 2010. Synthesis of p-type semiconducting cupric oxide thin films and their application to hydrogen detection. Sensors and Actuators B 146:239-244.

[24] Righettoni, M., Tricoli, A., and Pratsinis, S. E. 2010. Thermally Stable, SilicaDoped $\varepsilon-\mathrm{WO}_{3}$ for Sensing of Acetone in the Human Breath. Chemistry of Materials 22:3152-3157.

[25] Heidari, E. K., Zamani, C., Marzbanrad, E., Raissi, B., and Nazarpour, S. 2010. $\mathrm{WO}_{3}$-based $\mathrm{NO}_{2}$ sensors fabricated through low frequency AC electrophoretic deposition. Sensors and Actuators B 146:165-170.

[26] Tamaki, J., Zhang, Z., Fujimori, K., Akiyama, M., Harada, T., Miura, N., and Yamazoe, N. 1994. Grain-Size Effects in Tungsten Oxide-Based Sensor for Nitrogen Oxides. Journal of the Electrochemical Society 141:2207-2210.

[27] Fine, G. F., Cavanagh, L. M., Afonja, A., and Binions, R. 2010. Metal Oxide Semi-Conductor Gas Sensors in Environmental Monitoring. Sensors 10:5469-5502.

[28] Chaudhari, G. N., Jagtap, S. V., Gedam, N. N., Pawar, M. J., and Sangawar, V. S. 2009. Sol-gel synthesized semiconducting $\mathrm{LaCo}_{0.8} \mathrm{Fe}_{0.2} \mathrm{O}_{3}$-based powder for thick film $\mathrm{NH}_{3}$ gas sensor. Talanta 78:1136-1140.

[29] Kahng, Y. H., Lu, W., Tobin, R. G., Loloee, R., and Ghosh, R. N. 2009. The role of oxygen in hydrogen sensing by a platinum-gate silicon carbide gas sensor: An ultrahigh vacuum study. Journal of Applied Physics 105:064511.

[30] Wiche, G., Berns, A., Steffes, H., and Obermeier, E. 2005. Thermal analysis of silicon carbide based micro hotplates for metal oxide gas sensors. Sensors and Actuators A 123-124:12-17.

[31] Fung, S. K. H., Tang, Z., Chan, P. C. H., Sin, J. K. O., and Cheung, P. W. 1996. Thermal analysis and design of a micro-hotplate for integrated gas-sensor applications. Sensors and Actuators A 54:482-487.

[32] Hunter, G. W., Neudeck, P. G., Liu, C. C., Ward, B., Wu, Q. H., Dutta, P., Frank, M., Trimbol, J., Fulkerson, M., Patton, B., Makel, D., and Thomas, V. 2002. Development of Chemical Sensor Arrays for Harsh Environments and Aerospace Applications. Proceedings of the IEEE International Conference on Sensors (Orlando, FL), 24:1126-1133. 
[33] Benn, G. 2001. Design of a Silicon Carbide Micro-Hotplate Geometry for High Temperature Chemical Sensing. Master of Science thesis, Massachusetts Institute of Technology.

[34] Chen, L. 2008. Silicon Carbide Pressure Sensors and Infra-red Emitters. Doctor of Philosophy dissertation, Case Western Reserve University.

[35] Hunter, G. W., Neudeck, P. G., Okojie, R. S., Beheim, G. M., Thomas, V., Chen, L., Lukco, D., Liu, C. C., Ward, B., and Makel, D. 2002. Development of SiC Gas Sensor Systems. Proceedings of the $201^{\text {st }}$ Meeting of the Electrochemical Society (Philadelphia, PA).

[36] Graf, M., Jurischka, R., Barrettino, D., and Hierlemann, A. 2005. 3D nonlinear modeling of microhotplates in CMOS technology for use as metal-oxide-based gas sensors. Journal of Micromechanics and Microengineering 15:190-200.

[37] Khanna, V. K., Prasad, M., Dwivedi, V. K., Shekhar, C., Pankaj, A. C., and Basu, J. 2007. Design and electro-thermal simulation of a polysilicon microheater on a suspended membrane for use in gas sensing. Indian Journal of Pure \& Applied Physics 45:332-335.

[38] Messina, M., Franzè, F., Speciale, N., Cozzani, E., and Roncaglia, A. 2009. Thermofluid Analysis of Ultra Low Power Hotplates for a MOX Gas Sensing Device. IEEE Sensors Journal 9:504-511.

[39] Williams, K. R. and Muller, R. S. 1996. Etch Rates for Micromachining Processing. Journal of Microelectromechanical Systems 5:256-269.

[40] Incropera, Frank P., DeWitt, David P., Bergman, Theodore L., and Lavine, Adrienne S. 2007. Fundamentals of Heat and Mass Transfer, $6^{\text {th }}$ ed. New York: John Wiley \& Sons, Inc.

[41] Bird, R. Byron, Stewart, Warren E., and Lightfoot, Edwin N. 2007. Transport Phenomena, $2^{\text {nd }}$ ed. New York: John Wiley \& Sons, Inc.

[42] Solzbacher, F., Doll, T., and Obermeier, E. 2003. A comprehensive analytical and numerical analysis of transient and static micro hotplate characteristics. Proceedings of the $12^{\text {th }}$ International Conference on Solid State Sensors, Actuators and Microsystems (Boston, MA), Transducers '03, 1856-1859. 
VITA

NAME: $\quad$ Kane Jonathan Miller

ADDRESS: $\quad$ Department of Chemical Engineering

University of Louisville

Louisville, KY 40292

DOB: $\quad$ St. Louis, MO - May 18, 1987

EDUCATION \& TRAINING: $\quad$ B.S., Chemical Engineering University of Louisville 2005-09

M.Eng., Chemical Engineering University of Louisville 2009-10

PROFESSIONAL SOCIETIES: $\quad$ American Institute of Chemical Engineers

NATIONAL MEETING

PRESENTATIONS:

"Thermal Analysis of Silicon Carbide Microhotplates for Gas Sensors"

American Institute of Chemical Engineers 2009 Annual Meeting - November 2009

Nashville, TN 